CIVIL ENGINEERING STUDIES

Illinois Center for Transportation Series No. 18-007

UILU-ENG-2018-2007

ISSN: 0197-9191

\title{
MODIFIED MICRO-DEVAL PROCEDURE FOR POLISHING OF FINE ASPHALT MIX AGGREGATES
}

\author{
Prepared By \\ Zina Eluri
}

EZ Engineering Solutions, LLC

Research Report No. FHWA-ICT-18-006

A report of the findings of

ICT PROJECT R27-SP36

Modified Micro-Deval Procedure for Polishing of Fine Asphalt Mix Aggregates

https://doi.org/10.36501/0197-9191/18-007

Illinois Center for Transportation

May 2018 

TECHNICAL REPORT DOCUMENTATION PAGE

\begin{tabular}{|c|c|c|c|c|c|}
\hline $\begin{array}{l}\text { 1. Report No. } \\
\text { FHWA-ICT-18-006 }\end{array}$ & \multicolumn{2}{|c|}{$\begin{array}{l}\text { 2. Government Accession No. } \\
\text { N/A }\end{array}$} & \multicolumn{3}{|c|}{$\begin{array}{l}\text { 3. Recipient's Catalog No. } \\
\text { N/A }\end{array}$} \\
\hline \multirow{2}{*}{\multicolumn{3}{|c|}{$\begin{array}{l}\text { 4. Title and Subtitle } \\
\text { Modified Micro-Deval Procedure for Polishing of Fine Asphalt Mix Aggregates }\end{array}$}} & \multicolumn{3}{|c|}{$\begin{array}{l}\text { 5. Report Date } \\
\text { May } 2018\end{array}$} \\
\hline & & & \multicolumn{3}{|c|}{$\begin{array}{l}\text { 6. Performing Organization Code } \\
\text { N/A }\end{array}$} \\
\hline \multicolumn{3}{|l|}{$\begin{array}{l}\text { 7. Author(s) } \\
\text { Zina Eluri }\end{array}$} & \multicolumn{3}{|c|}{$\begin{array}{l}\text { 8. Performing Organization Report No. } \\
\text { ICT-18-007 } \\
\text { UILU-ENG-2018-2007 }\end{array}$} \\
\hline \multirow{2}{*}{\multicolumn{3}{|c|}{$\begin{array}{l}\text { 9. Performing Organization Name and Address } \\
\text { Illinois Center for Transportation } \\
\text { Department of Civil and Environmental Engineering } \\
\text { University of Illinois at Urbana-Champaign } \\
205 \text { North Mathews Avenue, MC-250 } \\
\text { Urbana, IL } 61801\end{array}$}} & \multicolumn{3}{|c|}{$\begin{array}{l}\text { 10. Work Unit No. } \\
\text { N/A }\end{array}$} \\
\hline & & & \multicolumn{3}{|c|}{$\begin{array}{l}\text { 11. Contract or Grant No. } \\
\text { R27-SP36 }\end{array}$} \\
\hline \multirow{2}{*}{\multicolumn{3}{|c|}{$\begin{array}{l}\text { 12. Sponsoring Agency Name and Ad } \\
\text { Illinois Department of Transportation } \\
\text { Bureau of Research } \\
126 \text { East Ash Street } \\
\text { Springfield, IL } 62704\end{array}$}} & \multicolumn{3}{|c|}{$\begin{array}{l}\text { 13. Type of Report and Period Covered } \\
\text { Final Report } \\
\text { September 1, } 2017 \text { - May 31, } 2018\end{array}$} \\
\hline & & & \multicolumn{3}{|c|}{$\begin{array}{l}\text { 14. Sponsoring Agency Code } \\
\text { FHWA }\end{array}$} \\
\hline \multicolumn{6}{|c|}{$\begin{array}{l}\text { Conducted in cooperation with the U.S. Department of Tran } \\
\text { https://doi.org/10.36501/0197-9191/18-007 }\end{array}$} \\
\hline \multicolumn{6}{|c|}{$\begin{array}{l}\text { 16. Abstract } \\
\text { A procedure combining Micro-Deval and } 2^{\text {nd }} \text { generation Aggregate Imaging Measurement System (AIMS-II) test procedures was } \\
\text { developed to characterize aggregate polishing characteristics, and in turn, provide a means for qualifying aggregate sources for } \\
\text { friction purposes. This study focused on the minimum number of aggregate particles, aggregate sizes, and the number of } \\
\text { revolutions in the Micro-Deval test. Only two aggregate sources were included in this study. Thus, further analyses are needed } \\
\text { for wider range of aggregate sources/mineralogical properties in order to establish the minimum required aggregate shape } \\
\text { properties for friction. }\end{array}$} \\
\hline \multicolumn{2}{|c|}{$\begin{array}{l}\text { 17. Key Words } \\
\text { Aggregate, AIMS-II, Imaging, Angularity, Texture, Polishing. }\end{array}$} & \multicolumn{4}{|c|}{$\begin{array}{l}\text { 18. Distribution Statement } \\
\text { No restrictions. This document is available through the } \\
\text { National Technical Information Service, Springfield, VA } \\
22161 \text {. }\end{array}$} \\
\hline \multicolumn{2}{|l|}{$\begin{array}{l}\text { 19. Security Classif. (of this report) } \\
\text { Unclassified }\end{array}$} & \multicolumn{2}{|c|}{$\begin{array}{l}\text { 20. Security Classif. (of this page) } \\
\text { Unclassified }\end{array}$} & $\begin{array}{l}\text { 21. No. of Pages } \\
22 \mathrm{pp}+ \\
\text { appendices }\end{array}$ & $\begin{array}{l}\text { 22. Price } \\
\text { N/A }\end{array}$ \\
\hline
\end{tabular}

Form DOT F 1700.7 (8-72)

Reproduction of completed page authorized 



\section{ACKNOWLEDGMENT, DISCLAIMER, MANUFACTURERS' NAMES}

This publication is based on the results of ICT-R27-SP36, Modified Micro-Deval Procedure for Polishing of Fine Asphalt Mix Aggregates. ICT-R27-SP36 was conducted in cooperation with the Illinois Center for Transportation; the Illinois Department of Transportation; and the U.S. Department of Transportation, Federal Highway Administration.

Members of the Technical Review panel were the following:

- John Senger, IDOT - BR, TRP Chair

- Sean Stutler, IDOT - CBM

- $\quad$ Kyle Bodine, IDOT - CBM

- Brian Hill, IDOT - CBM

- Ryan Culton, IDOT - CBM

- Joshua Smith, IDOT - CBM

- Danny McGee, IDOT - CBM

- Garry Millhoff, IDOT - CBM

- LaDonna Rowden, IDOT - BR

The contents of this report reflect the view of the author, who is responsible for the facts and the accuracy of the data presented herein. The contents do not necessarily reflect the official views or policies of the Illinois Center for Transportation, the Illinois Department of Transportation, or the Federal Highway Administration. This report does not constitute a standard, specification, or regulation.

Trademark or manufacturers' names appear in this report only because they are considered essential to the object of this document and do not constitute an endorsement of product by the Federal Highway Administration, the Illinois Department of Transportation, or the Illinois Center for Transportation. 


\section{EXECUTIVE SUMMARY}

The main objectives of this project were to: 1) Develop a modified Micro-Deval procedure that is based on an aggregate size range of $3 / 8 \mathrm{in} .(9.5 \mathrm{~mm})$ to $\# 8(2.36 \mathrm{~mm})$, which can achieve terminal polishing; and 2) Identify the minimum number of aggregate particles needed for testing with the Micro-Deval and characterization of its shape properties using the $2^{\text {nd }}$ generation Aggregate Imaging Measurement System (AIMS-II).

The procedure developed in this study requires two separate samples for each aggregate source. The first sample is for aggregate particles passing the $3 / 8$ in. sieve and retained on the $\# 4$ sieve, while the second sample is of aggregate particles passing the \#4 sieve and retained on the \#8 sieve. Each sample is then scanned in AIMS-II to obtain initial aggregate shape properties, polished in MicroDeval for 13,500 revolutions, and then scanned again in AIMS-II to obtain terminal polishing aggregate shape properties. Polishing of the aggregate requires soaking the aggregate for 60 minutes in $0.75 \mathrm{~L}$ of water, followed by tumbling in the Micro-Deval with 1250 grams of steel balls.

In addition to the modified procedure, an asymptotic analysis of the data collected during this study was conducted to determine the target number of particles for AIMS-II imaging. The analysis revealed that a target of 250 particles should be used to obtain shape properties for the aggregate sizes selected in this study.

The main recommendation of this report is to implement the modified procedure developed in this study, and test aggregate sources covering the state of Illinois and neighboring states. Such sources should also cover a wide variety of aggregate mineralogical properties such as: limestone, dolomite, gravel, etc. 


\section{CONTENTS}

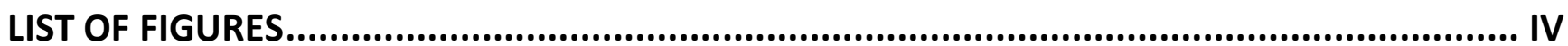

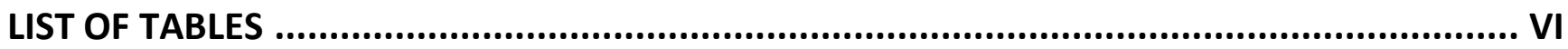

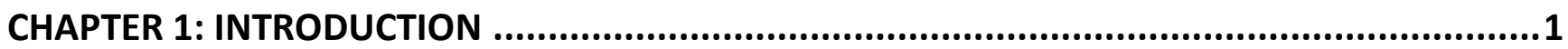

1.1 BACKGROUND

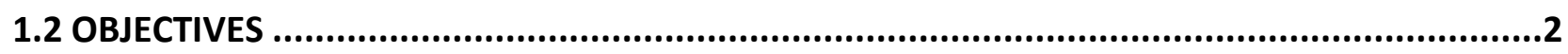

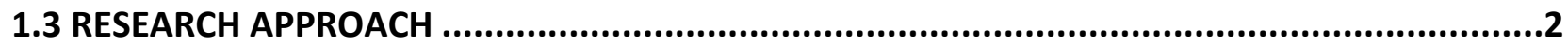

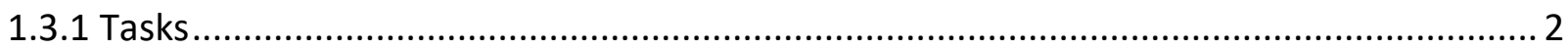

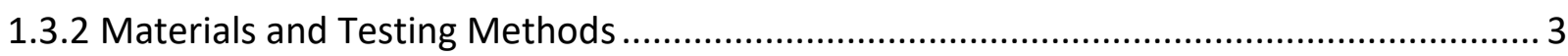

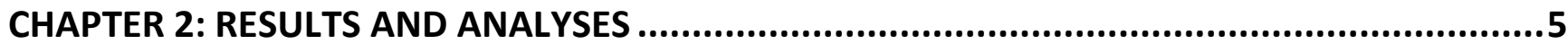

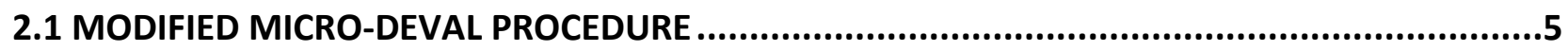

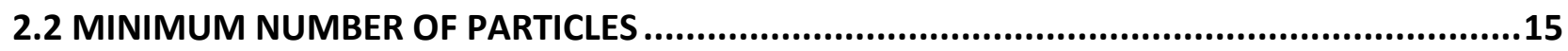

CHAPTER 3: SUMMARY AND IMPLEMENTATION RECOMMENDATIONS.............................20

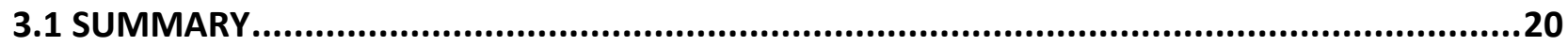

3.2 IMPLEMENTATION RECOMMENDATION .........................................................................21

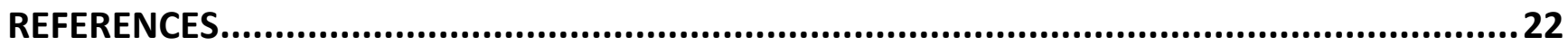

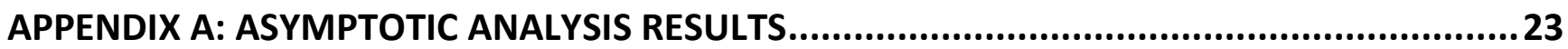

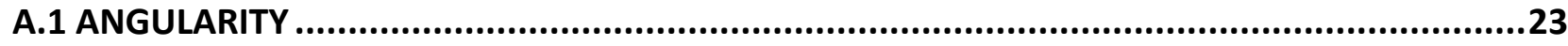

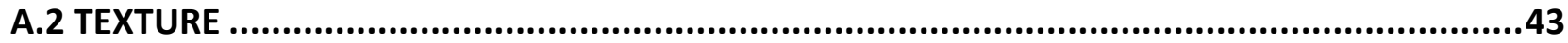




\section{LIST OF FIGURES}

Figure 1.1. Second generation Aggregate Imaging Measurement System (AIMS-II)...........................1

Figure 1.2. R27-SP27 Texture vs. angularity with proposed acceptable zones....................................2

Figure 2.1. Angularity Index as Function of Micro-Deval Revolutions (Source 1 - size \#4)...................6

Figure 2.2. Texture Index as Function of Micro-Deval Revolutions (Source 1 - size \#4)........................6

Figure 2.3. CAAT Index as Function of Micro-Deval Revolutions (Source 1 - size \#4)..........................7

Figure 2.4. Angularity Index as Function of Micro-Deval Revolutions (Source 1 - size \#8).....................7

Figure 2.5. Texture Index as Function of Micro-Deval Revolutions (Source 1 - size \#8)........................8

Figure 2.6. CAAT Index as Function of Micro-Deval Revolutions (Source 1 - size \#8)............................8

Figure 2.7. Angularity Index as Function of Micro-Deval Revolutions (Source 2 - size \#4)....................9

Figure 2.8. Texture Index as Function of Micro-Deval Revolutions (Source 2 - size \#4)........................9

Figure 2.9. CAAT Index as Function of Micro-Deval Revolutions (Source 2 - size \#4)..........................10

Figure 2.10. Angularity Index as Function of Micro-Deval Revolutions (Source 2 - size \#8)................10

Figure 2.11. Texture Index as Function of Micro-Deval Revolutions (Source 2 - size \#8)...................11

Figure 2.12. CAAT Index as Function of Micro-Deval Revolutions (Source 2 - size \#8)........................11

Figure 2.13. Asymptotic Analysis: Source 1 - Size \#4 Angularity after 3,000 Micro-Deval

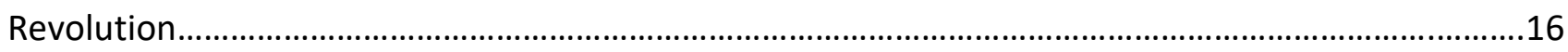

Figure 2.14 Asymptotic Analysis: Source 1 - Size \#4 Angularity after 12,000 Micro-Deval

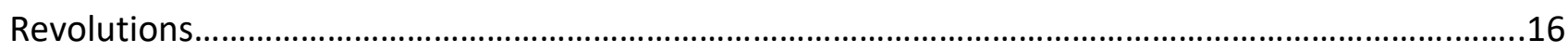

Figure 2.15. Asymptotic Analysis: Source 2 - Size \#4 Angularity Before Polishing in Micro-Deval.....17

Figure 2.16. Asymptotic Analysis: Source 2 - Size \#4 Angularity after 7,500 Micro-Deval

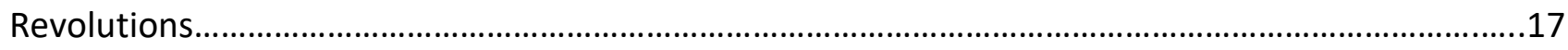

Figure 2.17. Asymptotic Analysis: Source 1 - Size \#4 Texture Before Polishing in Micro-Deval.........18

Figure 2.18. Asymptotic Analysis: Source 1 - Size \#4 Texture after 10,500 Micro-Deval

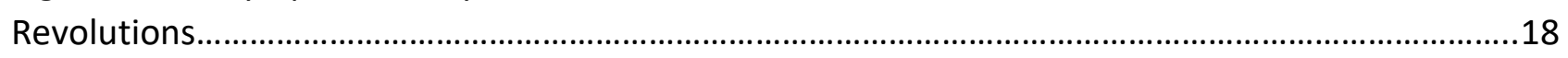

Figure 2.19. Asymptotic Analysis: Source 2 - Size \#8 Texture Before Polishing in Micro-Deval.........19

Figure 2.20. Asymptotic Analysis: Source 2 - Size \#8 Texture after 13,500 Micro-Deval

Revolutions. 


\section{LIST OF TABLES}

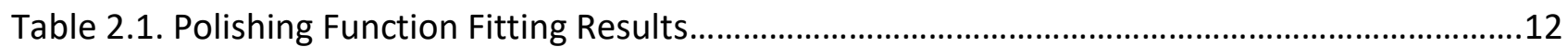

Table 2.2. Statistical Inference on the Angularity Means....................................................................13

Table 2.3. Statistical Inference on the Texture Means....................................................................14

Table 2.4. Statistical Inference on the CAAT Means...........................................................................15 



\section{CHAPTER 1: INTRODUCTION}

\subsection{BACKGROUND}

Recently completed research studies, sponsored by the Illinois Department of Transportation (IDOT) through the Illinois Center for Transportation (ICT), focused on the implementation of the 2nd generation Aggregate Imaging Measurement System (AIMS-II, see Figure 1.1) in measuring aggregate shape properties (Mahmoud and Ortiz, 2014 \& Mahmoud and Perales, 2015). An aggregate polishing procedure, coupling AIMS-II for measuring aggregate shape properties and the Micro-Deval (MD) as a polishing procedure, was developed by Mahmoud and Ortiz (2014). The polishing trends and ranking from that study compared favorably with IDOT's historical friction data. Additionally, a database was generated for all aggregates tested in that study; the database included aggregate shape properties (texture and angularity) measured before and after polishing in the MD. In a follow up study (Mahmoud and Perales, 2015), further analyses were conducted and Variable Speed Test (VST) friction values were included to provide a direct comparison to polishing in the MD. Finally, a system for qualifying aggregates for friction purposes was introduced based on aggregate angularity and surface texture (Figure 1.2).

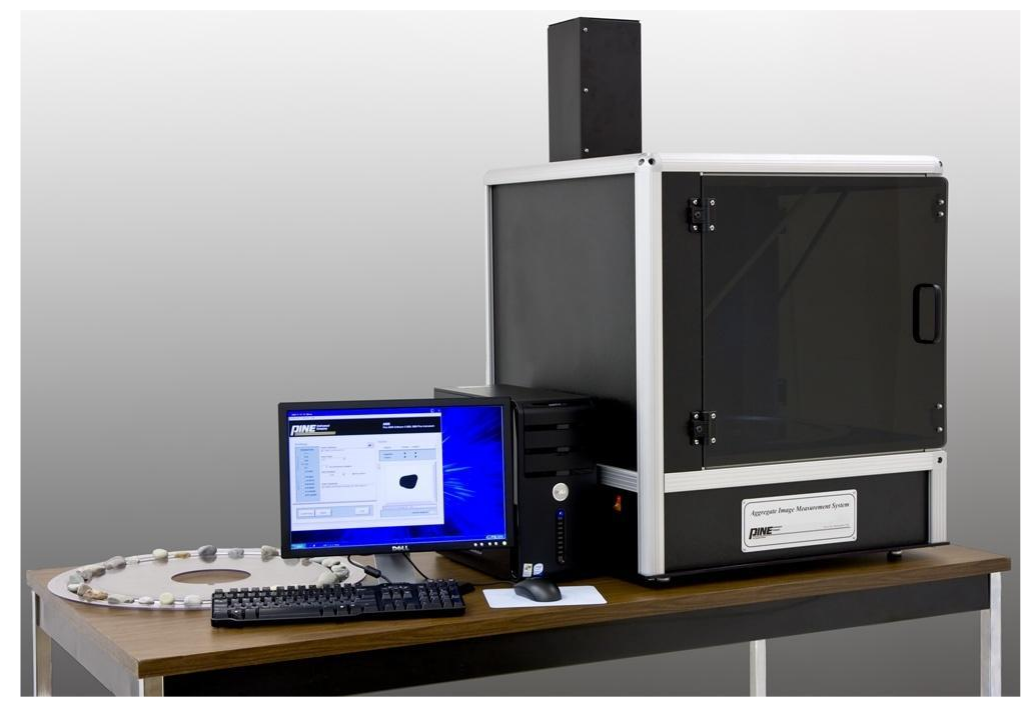

Figure 1.1. Second generation Aggregate Imaging Measurement System (AIMS-II). 


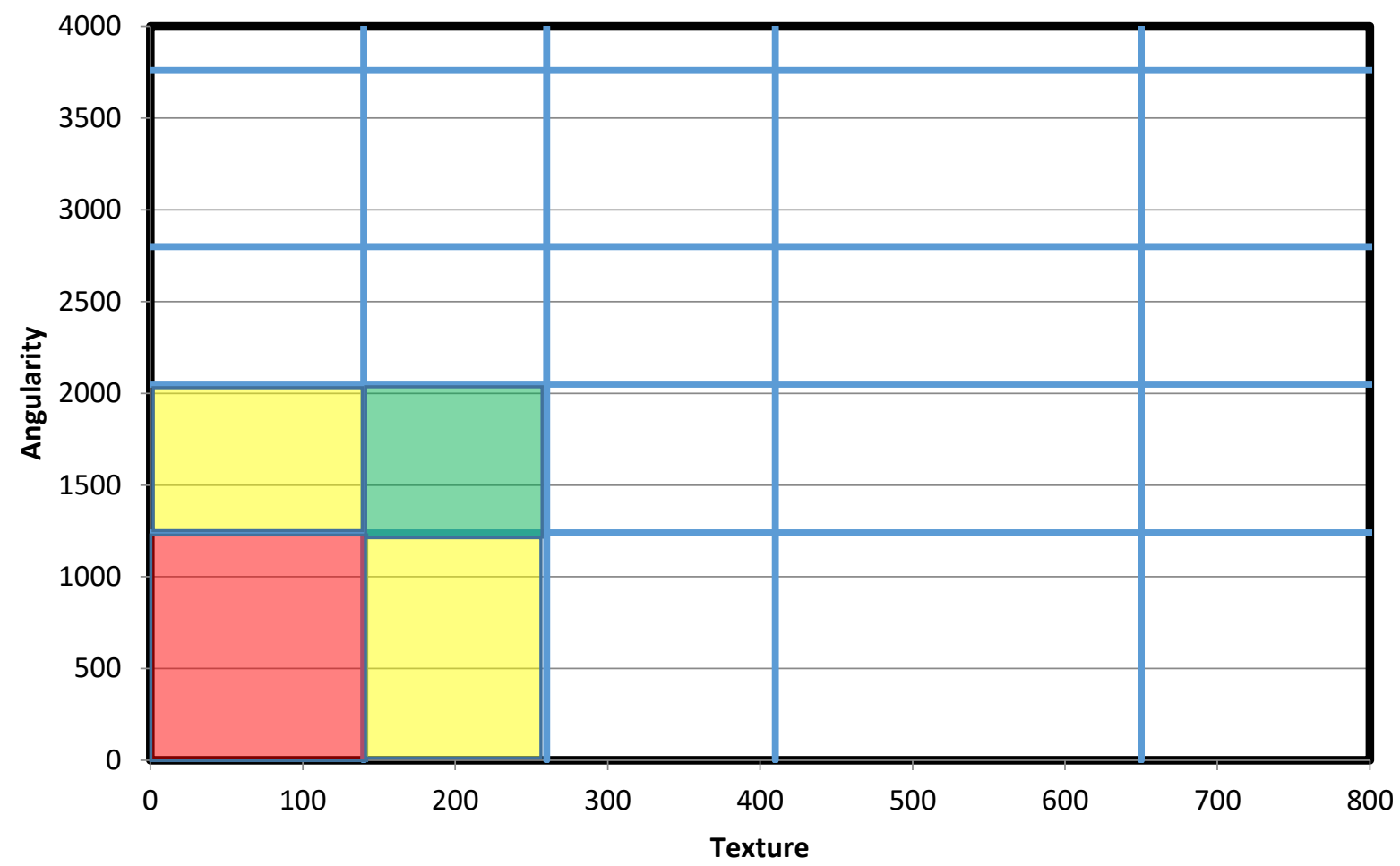

Figure 1.2. R27-SP27 Texture vs. Angularity with Proposed Acceptable Zones.

The previous two projects focused on one aggregate size fraction (passing the $1 / 2 \mathrm{in}$. sieve and retained on the $3 / 8$ in. sieve). However, with IDOT moving toward finer surface mixes, it is important to understand the terminal polishing for finer surface mix aggregates ( $3 / 8$ in to \#8).

\subsection{OBJECTIVES}

The main objectives of this project were to:

1. Develop a modified Micro-Deval procedure that is based on the aggregate size range of $3 / 8 \mathrm{in}$. to \#8 that can achieve terminal polishing.

2. Identify the minimum number of particles that need to be scanned in AIMS-II to effectively capture aggregate shape properties.

\subsection{RESEARCH APPROACH}

\subsubsection{Tasks}

The objectives of this research study were accomplished by performing the following tasks: 


\subsubsection{Task 1 - Kickoff Meeting}

A kickoff meeting was held, the Principal Investigator (PI) discussed the research approach and the details of the tasks in this project. In this meeting, the PI and the Technical Review Panel (TRP) decided on details regarding aggregate sources, the number of samples, and the aggregate sizes for the rest of the tasks.

\subsubsection{Task 2 - Modified Micro-Deval Procedure}

The PI worked with IDOT personnel to develop a modified Micro-Deval procedure to include aggregate sizes passing the $3 / 8$ in. sieve and retained on the \#8 sieve.

\subsubsection{Task 3 - Minimum Number of Aggregate Particles}

The PI analyzed aggregate shape properties obtained from AIMS-II scanning results for both polished and raw aggregates to obtain the minimum number of aggregate particles for the size fractions considered in this study. The analysis focused on the asymptotic approach.

\subsubsection{Task 4 - Preliminary Analysis and Recommendation Presentation to TRP}

The PI met with the TRP and discussed the results of Tasks 2 and 3 . Based on the preliminary analysis and discussions with the TRP, the PI will provide recommendations for future use of AIMS-II data, and a modified aggregate polishing procedure in this final report.

\subsubsection{Task 5 - Prepare and Revise the Final Report}

The final report explains the study methodology, findings, and conclusions.

\subsubsection{Materials and Testing Methods}

Two aggregate sources were selected for this study Midway (source 1 ) and Pana (source 2). For each source, two sizes were investigated. The first size contained aggregate particles passing the $3 / 8 \mathrm{in}$. sieve and retained on the \#4 sieve. The second size contained aggregate particles passing the \#4 sieve and retained on the \#8 sieve. For the sake of simplicity, the first size will be referred to as \#4 size, and the second size will be referred to as \#8 size for the remainder of this report.

AIMS-II was used to measure aggregate shape properties, and Micro-Deval was used as the polishing mechanism. The aggregate shape properties considered for this study included texture, angularity, and Coarse Aggregate Angularity and Texture (CAAT) Index. Details of AIMS-II shape properties and the equipment operations can be found in previous studies (Mahmoud and Ortiz 2014; Mahmoud and Perales 2015)

The following procedure was used to obtain the required aggregate polishing characteristics:

1. Aggregate Samples Preparation: as mentioned earlier in this section, two sizes were investigated for each aggregate source. Several samples were prepared for each of the two 
sizes from the various sources. Multiple samples were prepared to allow for polishing at different intervals in the Micro-Deval as explained in Step-3 of this procedure.

2. Initial Scan: every sample was scanned in AIMS-II prior to polishing to obtain initial aggregate shape properties.

3. Polishing: aggregate samples were then polished in Micro-Deval at increasing numbers of revolutions $(3,000,4,500,6,000, \ldots$ etc.). The samples were soaked in $0.75+/-0.05 \mathrm{~L}$ of water for 60 minutes and placed in the Micro-Deval with $1250+/-5$ grams of steel balls to induce polishing.

4. Post Polishing Scan: following the the Micro-Deval process, every polished sample was then scanned in AIMS-II to obtain final aggregate shape properties. 


\section{CHAPTER 2: RESULTS AND ANALYSES}

\subsection{MODIFIED MICRO-DEVAL PROCEDURE}

The polishing procedure detailed in Chapter 1 was carried out for the aggregate sources and sizes selected for this study. The main objective of this task was to determine the minimum number of revolutions needed in the modified Micro-Deval procedure to achieve terminal polish. An exponential polishing curve (Equation 1) was fitted to the data:

$$
\operatorname{Agg} \operatorname{Prop}(\operatorname{Rev})=a+b e^{-c * \operatorname{Rev}}
$$

where:

AggProp: aggregate shape property such as Angularity, Texture, or CAAT;

Rev: Micro-Deval Revolutions in thousands;

a: regression coefficient representing terminal value;

b: regression coefficient ( $a+b$ : representing initial value); and

c: regression coefficient representing polishing rate.

Several research studies utilized this equation to describe aggregate polishing curves (Mahmoud and Ortiz, 2014; Mahmoud and Perales, 2015; Kassem et. Al, 2014; \& Masad e.al, 2007). Figure 2.1 illustrates the change in angularity as a function of the number of revolutions in the Micro-Deval for Source 1 - Size \#4. The " $x$ " markers on each plot represent the AIMS-II test results. The solid line represents the exponential polishing curve fitted to the data points. The data shows a clear drop in angularity after the first 3,000 cycles. After 3,000 cycles, the angularity value appears to remain approximately constant as the number of the revolutions increase. This trend was noticed for Source 1 - Size \#4 texture and CAAT values, as can be seen in Figures 2.2 and 2.3, respectively. The same evaluation was completed on a second aggregate size from the same source. Figures 2.4 through 2.6 illustrate the changes in angularity, texture, and CAAT, respectively, as a function of the number of revolutions in the Micro-Deval for Source 1 - Size \#8. The trends were very similar to the Size \#4 of the same aggregate source. 


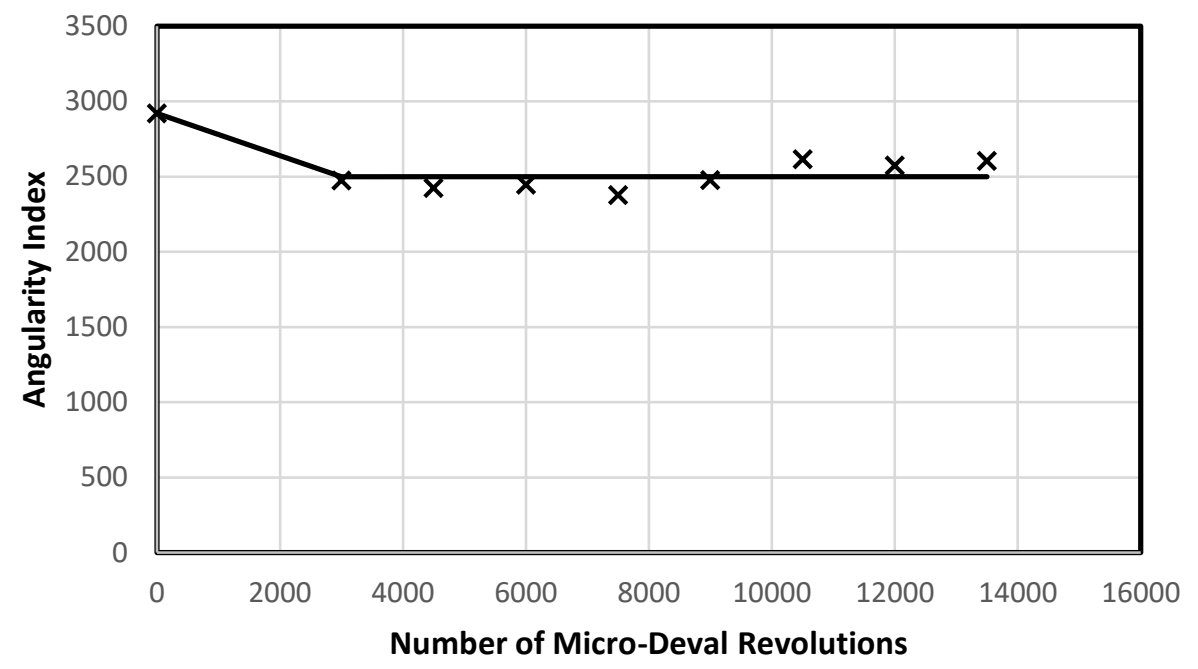

Figure 2.1. Angularity Index as a Function of Micro-Deval Revolutions (Source 1 - Size \#4).

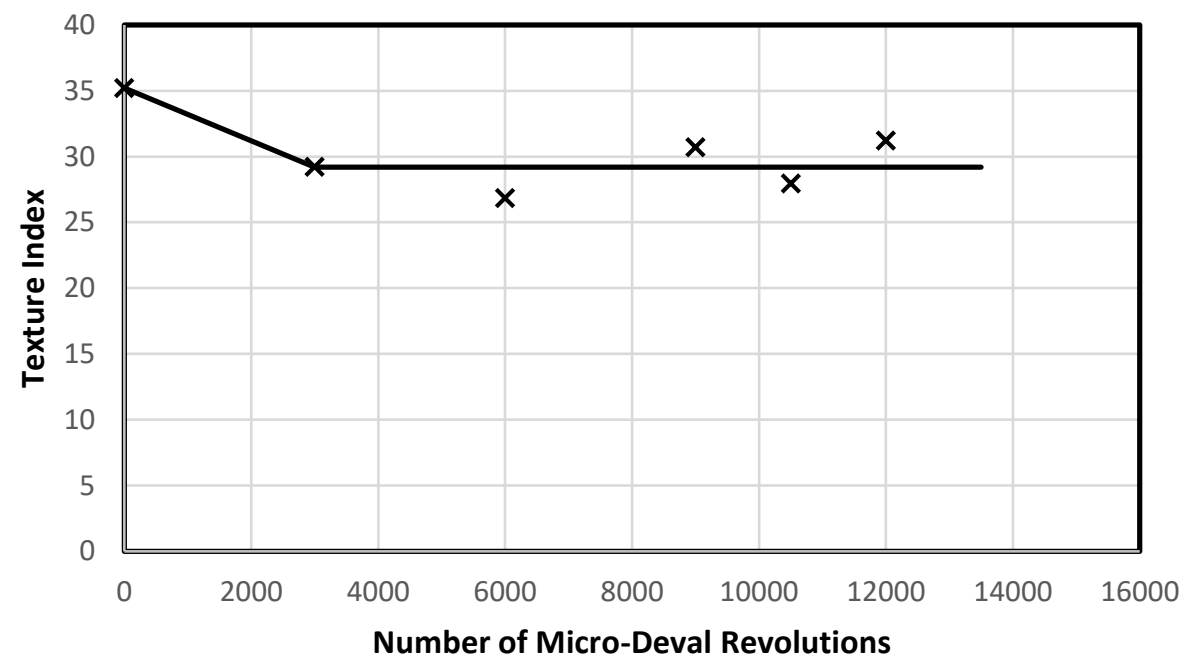

Figure 2.2. Texture Index as a Function of Micro-Deval Revolutions (Source 1 - Size \#4). 


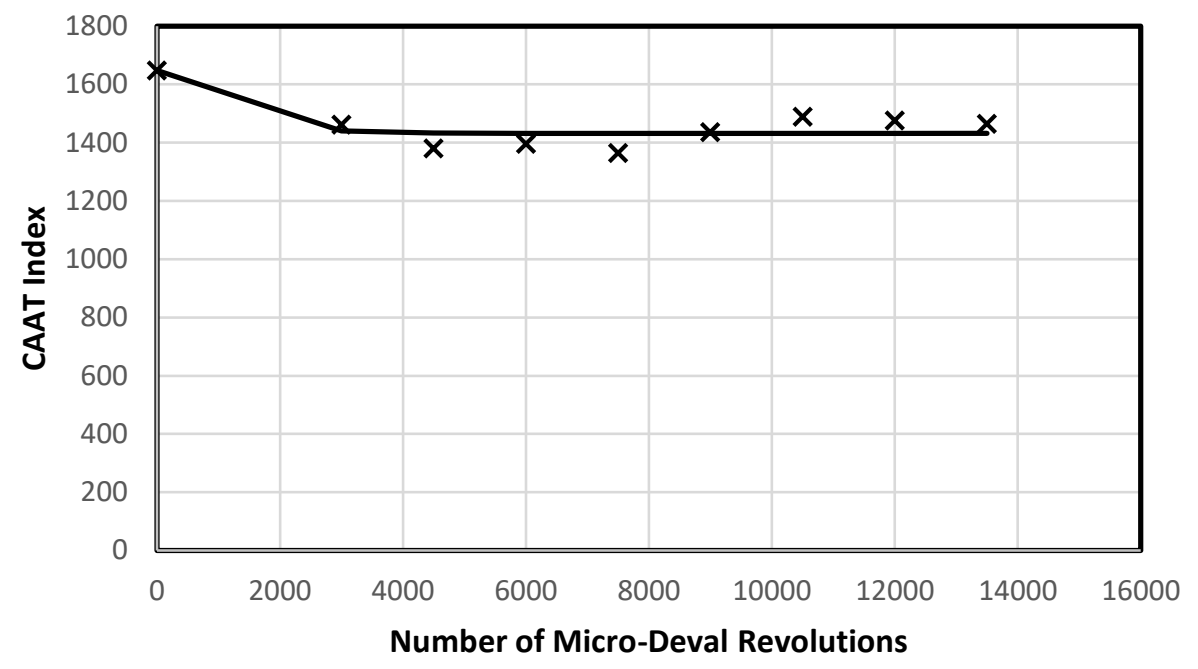

Figure 2.3. CAAT Index as a Function of Micro-Deval Revolutions (Source 1 - Size \#4).

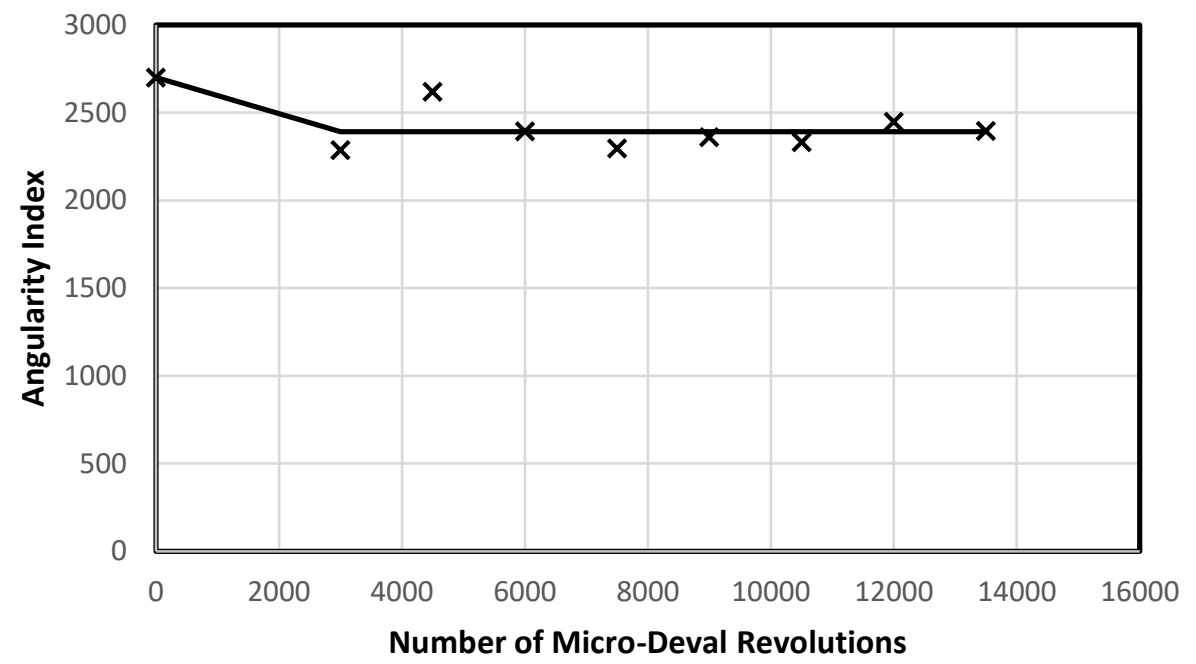

Figure 2.4. Angularity Index as a Function of Micro-Deval Revolutions (Source 1 - Size \#8). 


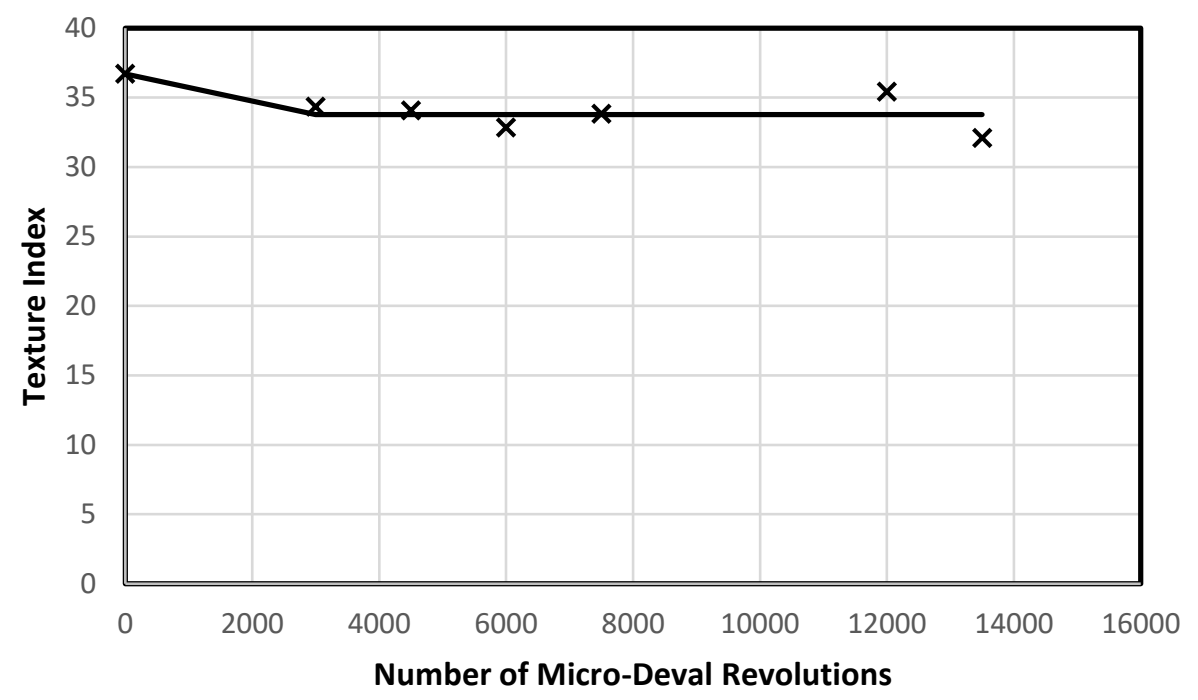

Figure 2.5. Texture Index as a Function of Micro-Deval Revolutions (Source 1 - Size \#8).

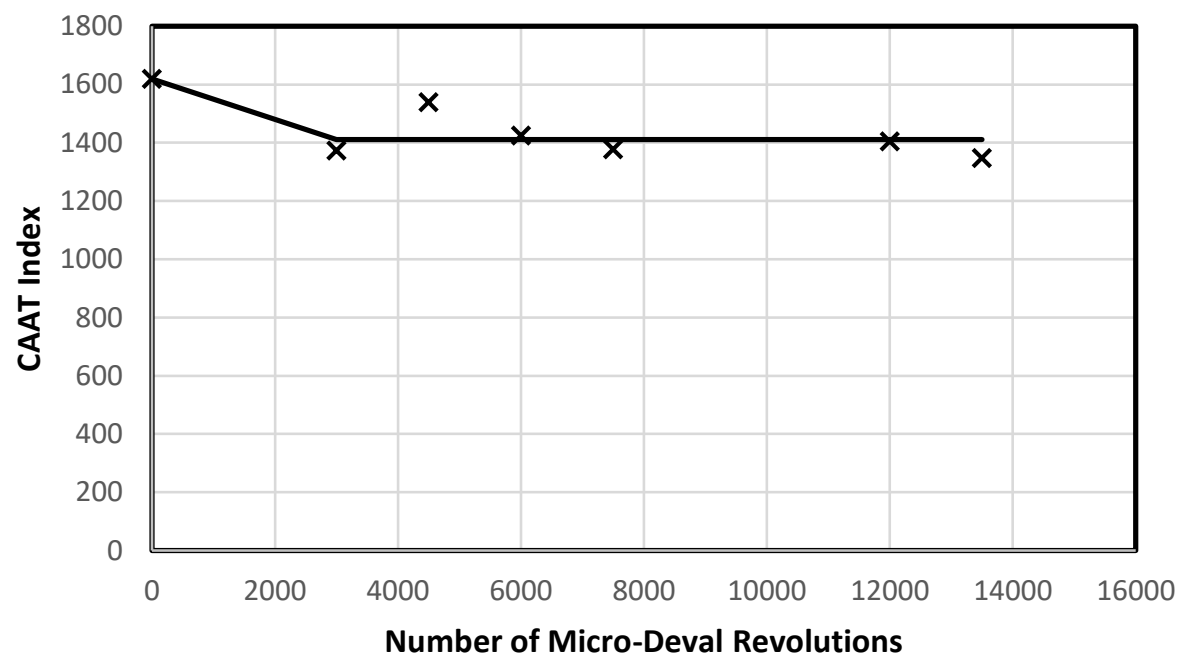

Figure 2.6. CAAT Index as a Function of Micro-Deval Revolutions (Source 1 - Size \#8).

The polishing curves for Source 1 showed an immediate drop in measured aggregate properties and reached terminal polishing with less than 5,000 revolutions in the Micro-Deval. However, Source 2 exhibited more sensitivity to polishing in the Micro-Deval. This can be clearly seen in Figures 2.7 through 2.12. Figure 2.7 illustrates the change in angularity as a function of the number of revolutions in the Micro-Deval for Source 2 - Size \#4. The data shows a continuous drop in angularity with an increasing number of revolutions. However, the angularity reduction rate decreased around 8,000 revolutions and seemed to reach a plateau afterward. A similar trend was noticed for Source $2-$ Size \#4 texture and CAAT values, as can be seen in Figures 2.8 and 2.9, respectively. On the other hand, Figures 2.10 through 2.12 illustrate the change in angularity, texture, and CAAT as a function of the 
number of revolutions in the Micro-Deval for Source 2 - Size \#8. The trends were very similar to Size \#4 of the same aggregate source.

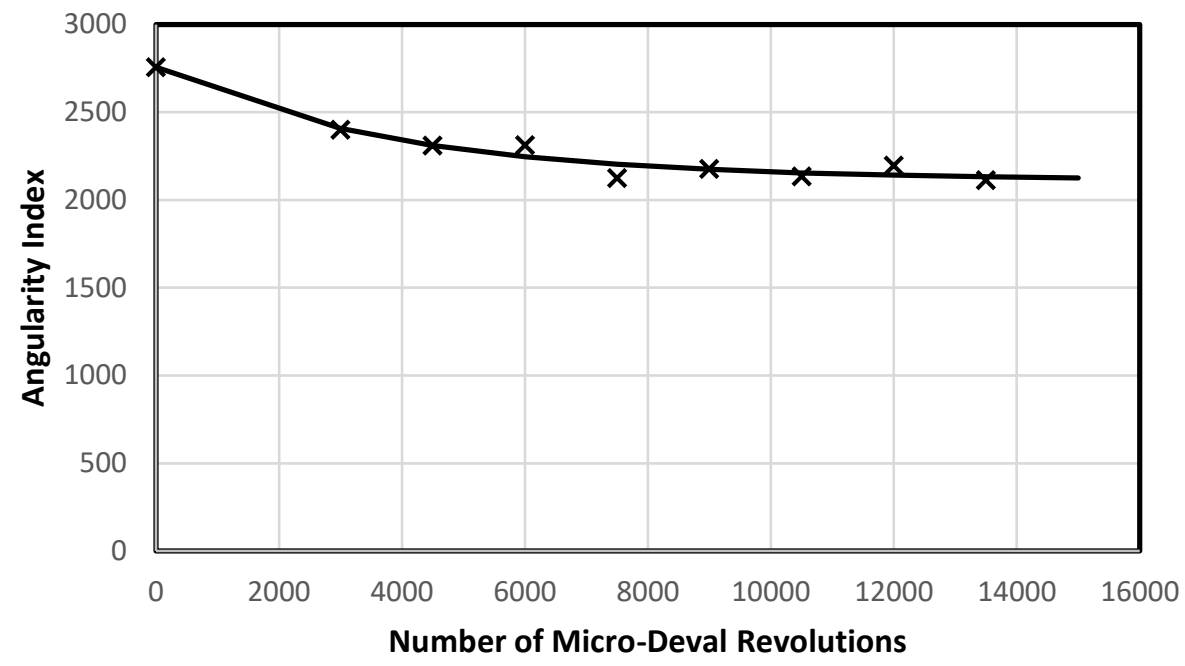

Figure 2.7. Angularity Index as a Function of Micro-Deval Revolutions (Source 2 - Size \#4).

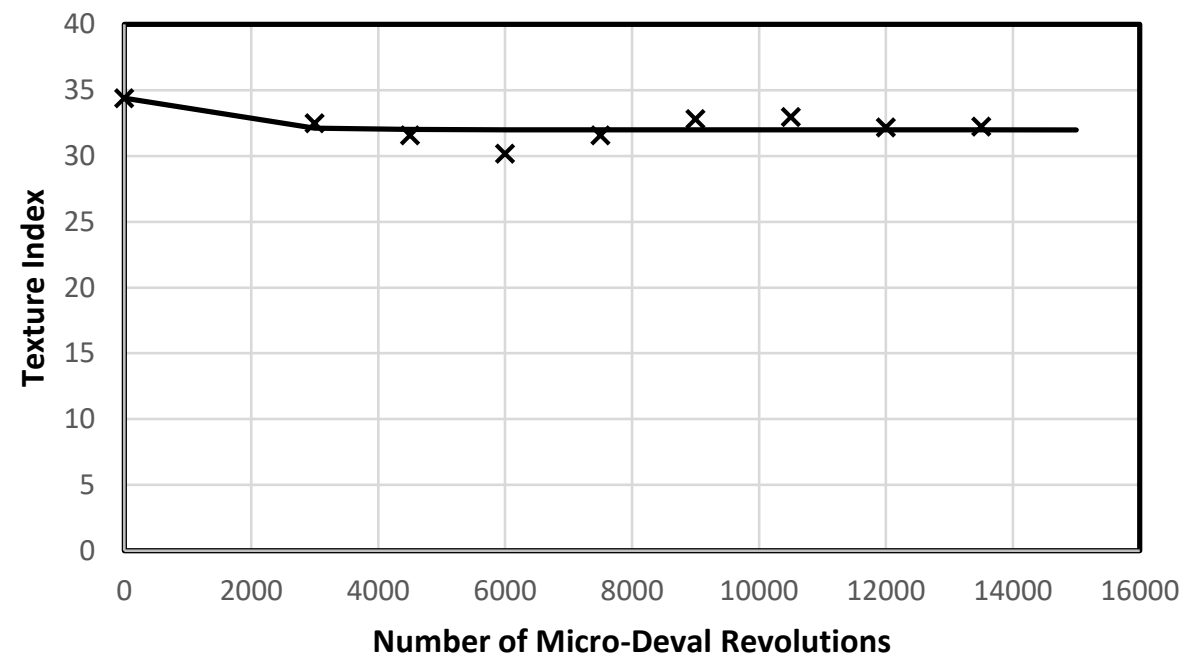

Figure 2.8. Texture Index as a Function of Micro-Deval Revolutions (Source 2 - Size \#4). 


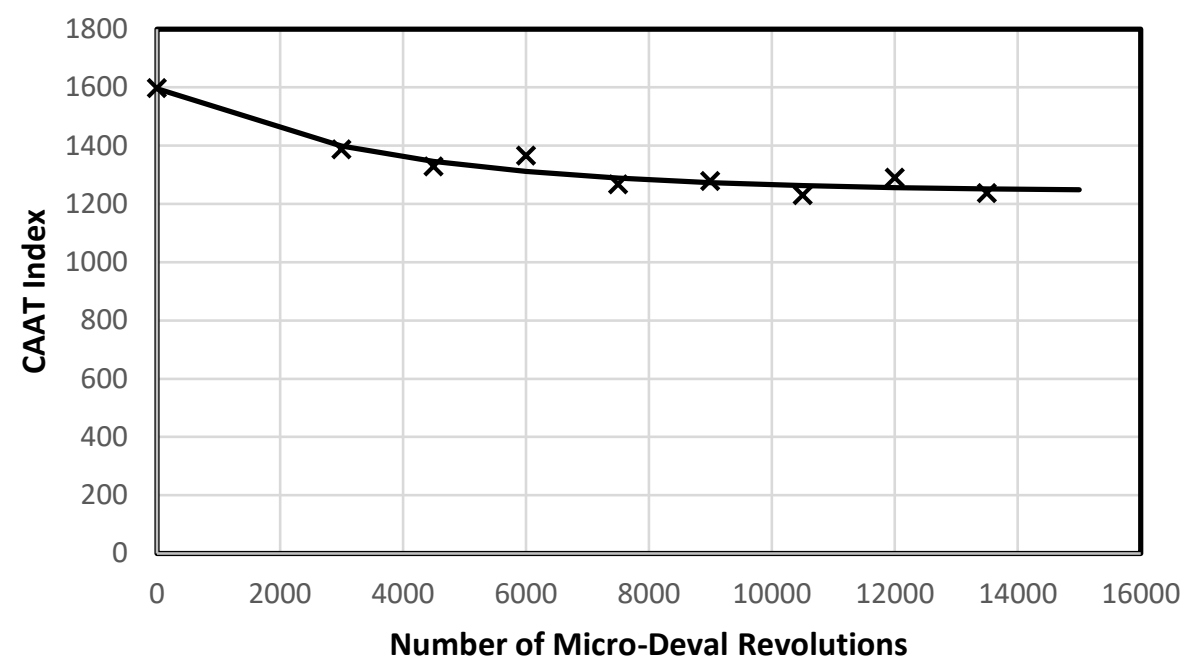

Figure 2.9. CAAT Index as a Function of Micro-Deval Revolutions (Source 2 - Size \#4).

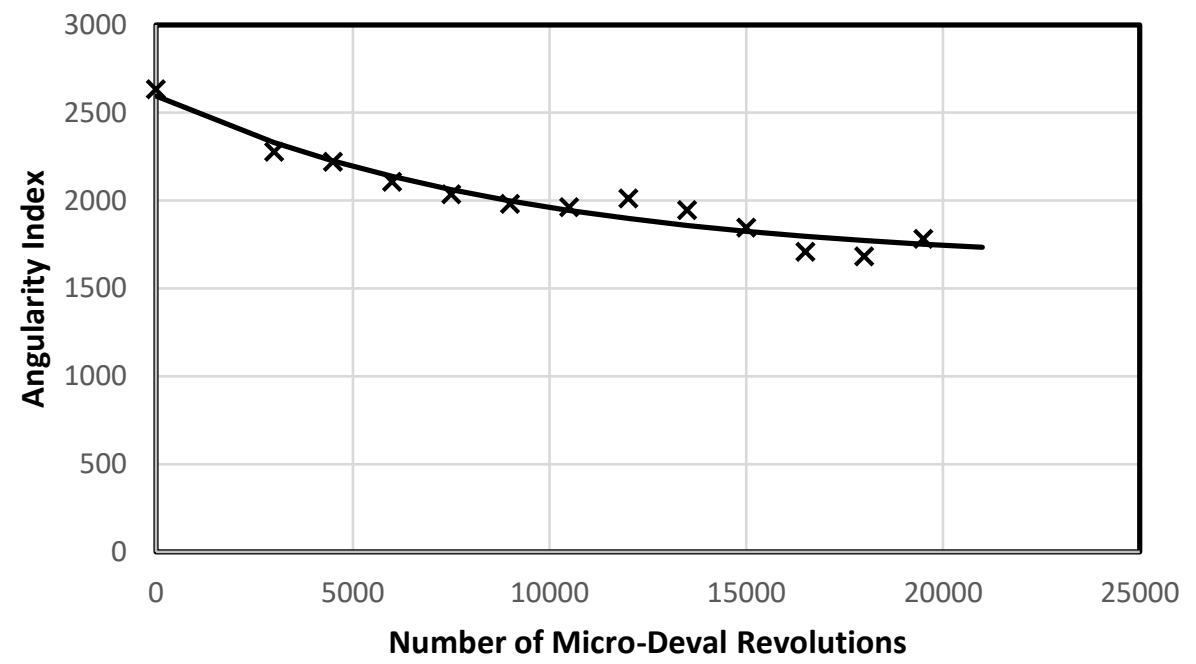

Figure 2.10. Angularity Index as a Function of Micro-Deval Revolutions (Source 2 - Size \#8). 


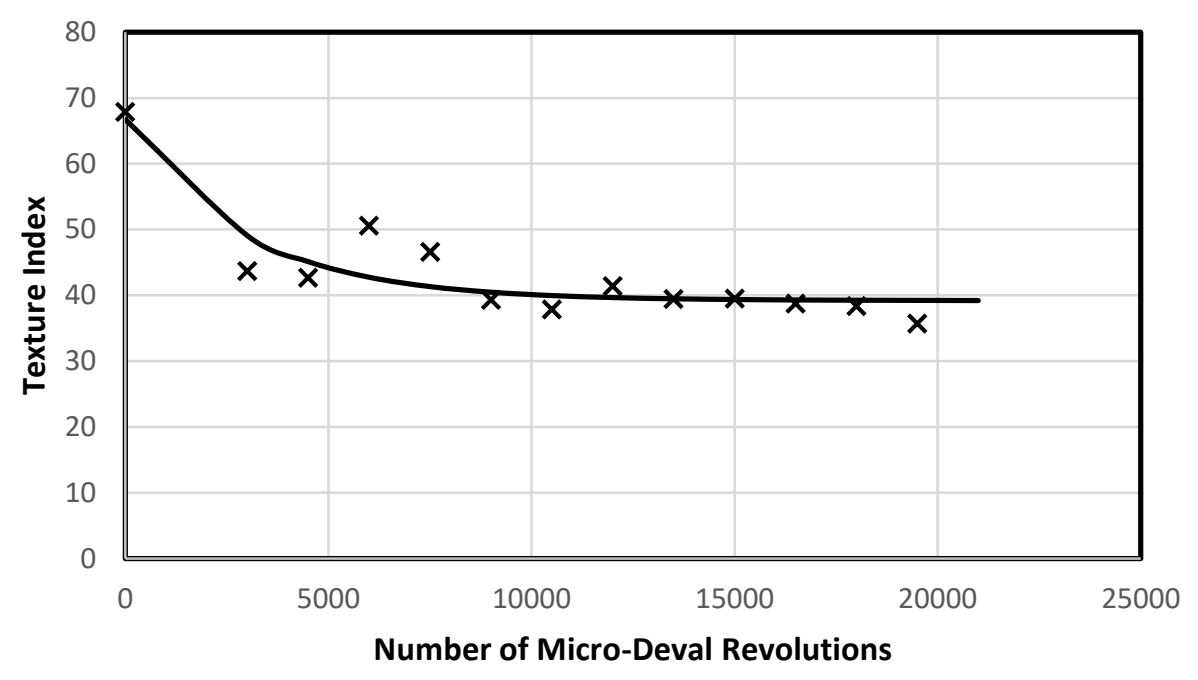

Figure 2.11. Texture Index as a Function of Micro-Deval Revolutions (Source 2 - Size \#8).

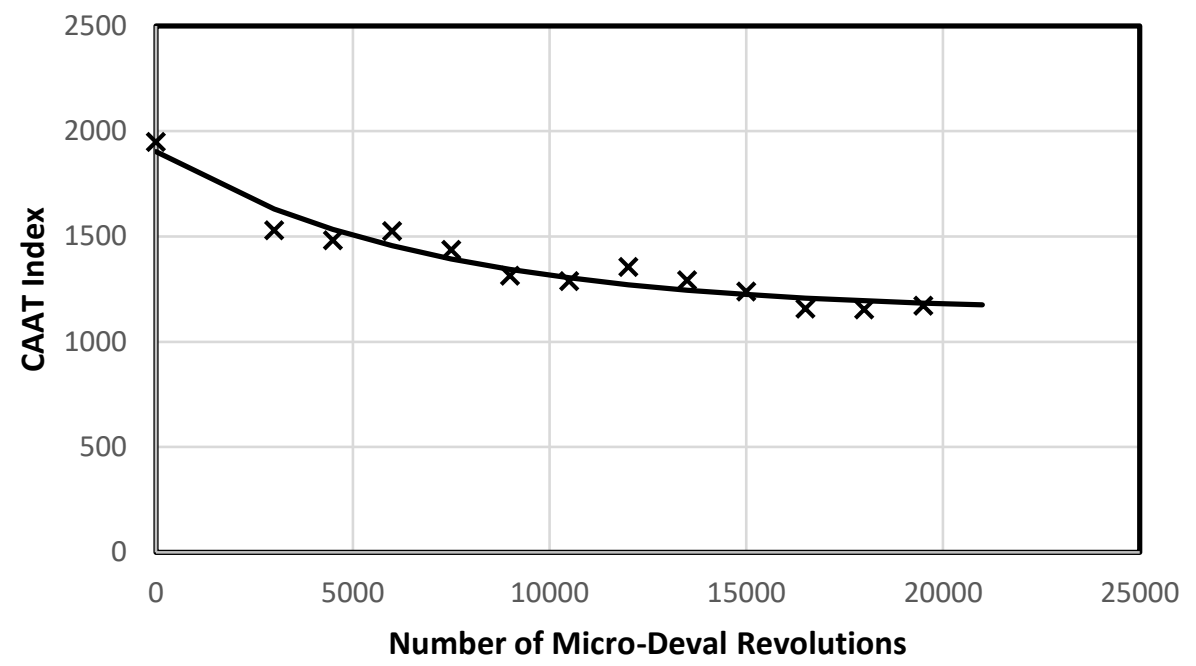

Figure 2.12. CAAT Index as a Function of Micro-Deval Revolutions (Source 2 - Size \#8).

The least squares method was used to obtain parameters $a, b$, and c of Equation 1 that best fit the data points as shown in Figures 2.1 thorough 2.12. The fitting parameters are summarized in Table 2.1 . 
Table 2.1. Polishing Function Fitting Results

\begin{tabular}{|l|c|c|c|c|c|}
\hline & & $\mathbf{a}$ & $\mathbf{b}$ & $\mathbf{C}$ & $\mathbf{R}^{\mathbf{2}}$ \\
\hline \multirow{3}{*}{$\begin{array}{l}\text { Source 1 - } \\
\end{array}$} & Angularity & 2499.25 & 420.77 & 3.58 & 0.74 \\
\cline { 2 - 6 } & Texture & 29.19 & 6.01 & 4.69 & 0.69 \\
\cline { 2 - 6 } & CAAT & 1432.09 & 215.94 & 1.07 & 0.73 \\
\hline \multirow{3}{*}{$\# \mathbf{8}$} & Angularity & 2391.60 & 309.10 & 5.83 & 0.52 \\
\cline { 2 - 6 } & Texture & 33.78 & 2.93 & 4.69 & 0.52 \\
\cline { 2 - 6 } & CAAT & 1410.87 & 208.01 & 4.86 & 0.61 \\
\hline \multirow{2}{*}{ Source 2 - } & Angularity & 2113.10 & 643.85 & 0.26 & 0.96 \\
\cline { 2 - 6 } & Texture & 31.98 & 2.41 & 0.95 & 0.48 \\
\cline { 2 - 6 } & CAAT & 1242.79 & 352.89 & 0.27 & 0.94 \\
\hline \multirow{2}{*}{$\begin{array}{l}\text { Source 2 - } \\
\text { \#8 }\end{array}$} & Angularity & 1634.14 & 961.32 & 0.11 & 0.94 \\
\cline { 2 - 6 } & Texture & 39.21 & 27.53 & 0.34 & 0.83 \\
\cline { 2 - 6 } & CAAT & 1140.69 & 762.43 & 0.15 & 0.93 \\
\hline
\end{tabular}

Based on the visual inspection of Figures 2.1 through 2.12, the research team decided to investigate the efficacy of the current procedure to reach terminal polishing at 13,500 revolutions. A t-test statistical analysis was conducted to compare aggregate shape properties between consecutive Micro-Deval polishing revolution intervals. A 95\% Confidence Interval ( $\mathrm{Cl}$ ) was calculated for the difference in the shape property mean between consecutive Micro-Deval revolutions intervals. The Cls are obtained using the following equation:

$$
Z_{0}=\overline{X_{1}}-\overline{X_{1}}-Z_{\frac{\alpha}{2}} \sqrt{\frac{\sigma_{1}^{2}}{n_{1}}+\frac{\sigma_{2}^{2}}{n_{2}}} \leq \mu_{1}-\mu_{2} \leq Z_{0}=\overline{X_{1}}-\overline{X_{1}}+Z_{\frac{\alpha}{2}} \sqrt{\frac{\sigma_{1}^{2}}{n_{1}}+\frac{\sigma_{2}^{2}}{n_{2}}}
$$

where $Z_{\alpha / 2}$ is the upper $\alpha / 2$ percentage point of the standard normal distribution $(\alpha=0.05$ for this study). Table 2.2 lists the Cls for the angularity results, while Tables 2.3 and 2.4 list the Cls for the texture and CAAT results, respectively. A Cl containing zero shows that the averages are not different, which indicates that terminal polishing is achieved at that number of revolutions. Assessing terminal polishing at 13,500 revolutions, eleven out of twelve Cls contained zero, which reinforced the visual observation from Figures 2.1 through 2.12. 
Table 2.2. Statistical Inference on the Angularity Means

\begin{tabular}{|c|c|c|c|}
\hline Sample & $\begin{array}{l}\text { Micro-Deval } \\
\text { Revolutions }\end{array}$ & CI Lower Limit & CI Upper Limit \\
\hline \multirow{8}{*}{$\begin{array}{l}\text { Source } 1 \text { - } \\
\# 4\end{array}$} & 3000 & -529.926 & -282.786 \\
\hline & 4500 & -175.43 & 79.24999 \\
\hline & 6000 & -101.715 & 146.638 \\
\hline & 7500 & -189.198 & 48.41544 \\
\hline & 9000 & -22.1291 & 222.337 \\
\hline & 10500 & 13.49738 & 262.5005 \\
\hline & 12000 & -167.16 & 86.30898 \\
\hline & 13500 & -96.4208 & 154.9718 \\
\hline \multirow{8}{*}{$\begin{array}{l}\text { Source } 1 \text { - } \\
\# 8\end{array}$} & 3000 & -517.802 & -288.237 \\
\hline & 4500 & 219.8787 & 443.6271 \\
\hline & 6000 & -341.395 & -109.106 \\
\hline & 7500 & -208.343 & 14.91009 \\
\hline & 9000 & -43.8523 & 172.7402 \\
\hline & 10500 & -140.121 & 81.29314 \\
\hline & 12000 & 2.30266 & 229.7573 \\
\hline & 13500 & -170.083 & 67.3848 \\
\hline \multirow{8}{*}{$\begin{array}{l}\text { Source } 2 \text { - } \\
\# 4\end{array}$} & 3000 & -446.07 & -217.584 \\
\hline & 4500 & -208.058 & 25.77346 \\
\hline & 6000 & -116.186 & 121.0331 \\
\hline & 7500 & -303.438 & -72.8657 \\
\hline & 9000 & -57.0216 & 162.2084 \\
\hline & 10500 & -156.516 & 71.84258 \\
\hline & 12000 & -56.8389 & 178.4584 \\
\hline & 13500 & -199.91 & 37.37861 \\
\hline \multirow{8}{*}{$\begin{array}{l}\text { Source } 2 \text { - } \\
\text { \#8 }\end{array}$} & 3000 & -471.18 & -241.657 \\
\hline & 4500 & -168.138 & 57.03934 \\
\hline & 6000 & -232.761 & 3.175882 \\
\hline & 7500 & -184.461 & 42.62262 \\
\hline & 9000 & -167.538 & 59.61746 \\
\hline & 10500 & -132.386 & 94.55281 \\
\hline & 12000 & -58.082 & 157.0507 \\
\hline & 13500 & -175.858 & 45.34275 \\
\hline
\end{tabular}


Table 2.3. Statistical Inference on the Texture Means

\begin{tabular}{|c|c|c|c|}
\hline Sample & $\begin{array}{l}\text { Micro-Deval } \\
\text { Revolutions }\end{array}$ & CI Lower Limit & CI Upper Limit \\
\hline \multirow{8}{*}{$\begin{array}{l}\text { Source } 1 \text { - } \\
\# 4\end{array}$} & 3000 & -10.5216 & 4.29894 \\
\hline & 4500 & -4.27404 & 24.00624 \\
\hline & 6000 & -25.822 & 1.317737 \\
\hline & 7500 & -1.59596 & 28.77702 \\
\hline & 9000 & -25.0165 & 5.555059 \\
\hline & 10500 & -6.34022 & 0.86073 \\
\hline & 12000 & -4.03582 & 10.56826 \\
\hline & 13500 & -4.50531 & 10.41235 \\
\hline \multirow{8}{*}{$\begin{array}{l}\text { Source } 1 \text { - } \\
\# 8\end{array}$} & 3000 & -3.45082 & 2.835481 \\
\hline & 4500 & -4.29025 & 3.782736 \\
\hline & 6000 & -5.04963 & 2.576308 \\
\hline & 7500 & -3.59058 & 5.564673 \\
\hline & 9000 & 30.60549 & 40.83231 \\
\hline & 10500 & -7.34069 & 1.676267 \\
\hline & 12000 & -38.3814 & -24.2263 \\
\hline & 13500 & -13.6129 & 6.972728 \\
\hline \multirow{8}{*}{$\begin{array}{l}\text { Source } 2 \text { - } \\
\# 4\end{array}$} & 3000 & -6.60356 & 2.206815 \\
\hline & 4500 & -5.04169 & 3.174708 \\
\hline & 6000 & -5.19051 & 2.418576 \\
\hline & 7500 & -1.28024 & 4.041655 \\
\hline & 9000 & -1.92551 & 4.446998 \\
\hline & 10500 & -4.06429 & 4.362816 \\
\hline & 12000 & -5.00241 & 3.444038 \\
\hline & 13500 & -3.46303 & 3.562993 \\
\hline \multirow{8}{*}{$\begin{array}{l}\text { Source } 2 \text { - } \\
\text { \#8 }\end{array}$} & 3000 & -1.39814 & 4.852607 \\
\hline & 4500 & -4.30684 & 2.378847 \\
\hline & 6000 & 4.497096 & 11.23837 \\
\hline & 7500 & -7.20714 & -0.71454 \\
\hline & 9000 & -10.5067 & -4.05923 \\
\hline & 10500 & -4.80701 & 1.92761 \\
\hline & 12000 & 0.286307 & 6.739651 \\
\hline & 13500 & -4.75181 & 0.878517 \\
\hline
\end{tabular}


Table 2.4. Statistical Inference on the CAAT Means

\begin{tabular}{|c|c|c|c|}
\hline Sample & $\begin{array}{l}\text { Micro-Deval } \\
\text { Revolutions }\end{array}$ & CI Lower Limit & CI Upper Limit \\
\hline \multirow{8}{*}{$\begin{array}{l}\text { Source } 1 \text { - } \\
\# 4\end{array}$} & 3000 & -259.914 & -38.0107 \\
\hline & 4500 & -201.33 & 39.75259 \\
\hline & 6000 & -84.56 & 114.8455 \\
\hline & 7500 & -135.416 & 74.48222 \\
\hline & 9000 & -39.7728 & 180.5947 \\
\hline & 10500 & -48.7385 & 154.4027 \\
\hline & 12000 & -101.506 & 75.92153 \\
\hline & 13500 & -99.2102 & 78.23386 \\
\hline \multirow{8}{*}{$\begin{array}{l}\text { Source } 1 \text { - } \\
\# 8\end{array}$} & 3000 & -308.06 & -181.766 \\
\hline & 4500 & 103.8944 & 228.1525 \\
\hline & 6000 & -178.77 & -51.1048 \\
\hline & 7500 & -107.628 & 13.47542 \\
\hline & 9000 & 429.4145 & 559.8822 \\
\hline & 10500 & -117.506 & 27.56874 \\
\hline & 12000 & -500.939 & -344.125 \\
\hline & 13500 & -150.178 & 36.45039 \\
\hline \multirow{8}{*}{$\begin{array}{l}\text { Source } 2 \text { - } \\
\# 4\end{array}$} & 3000 & -256.378 & -126.521 \\
\hline & 4500 & -122.068 & 6.295251 \\
\hline & 6000 & -33.7201 & 105.749 \\
\hline & 7500 & -169.353 & -26.7565 \\
\hline & 9000 & -58.082 & 80.14285 \\
\hline & 10500 & -119.803 & 24.38754 \\
\hline & 12000 & -12.9598 & 132.1025 \\
\hline & 13500 & -123.255 & 18.57486 \\
\hline \multirow{8}{*}{$\begin{array}{l}\text { Source } 2 \text { - } \\
\# 8\end{array}$} & 3000 & -227.719 & -95.4568 \\
\hline & 4500 & -115.16 & 17.12503 \\
\hline & 6000 & -23.4244 & 110.5468 \\
\hline & 7500 & -153.247 & -22.1147 \\
\hline & 9000 & -189.343 & -58.4758 \\
\hline & 10500 & -89.0377 & 39.47819 \\
\hline & 12000 & 6.377879 & 129.165 \\
\hline & 13500 & -125.979 & -3.21782 \\
\hline
\end{tabular}

\subsection{MINIMUM NUMBER OF PARTICLES}

To investigate the minimum number of aggregate particles required for scanning with AIMS, an asymptotic analysis was conducted. In this analysis, the changes in shape properties were tracked as functions of the number of particles scanned. Figures 2.13 through 2.20 illustrate examples for angularity and texture analyses (similar plots for all aggregates scanned in this study are listed in Appendix A). It is evident that the average of both angularity and texture reach an approximately 
constant value at around 200 particles for the sources considered in this study. Based on this, it is recommended that 250 particles should be scanned with AIMS-II.

Source 1 - Size \#4 After 3000 Revolutions

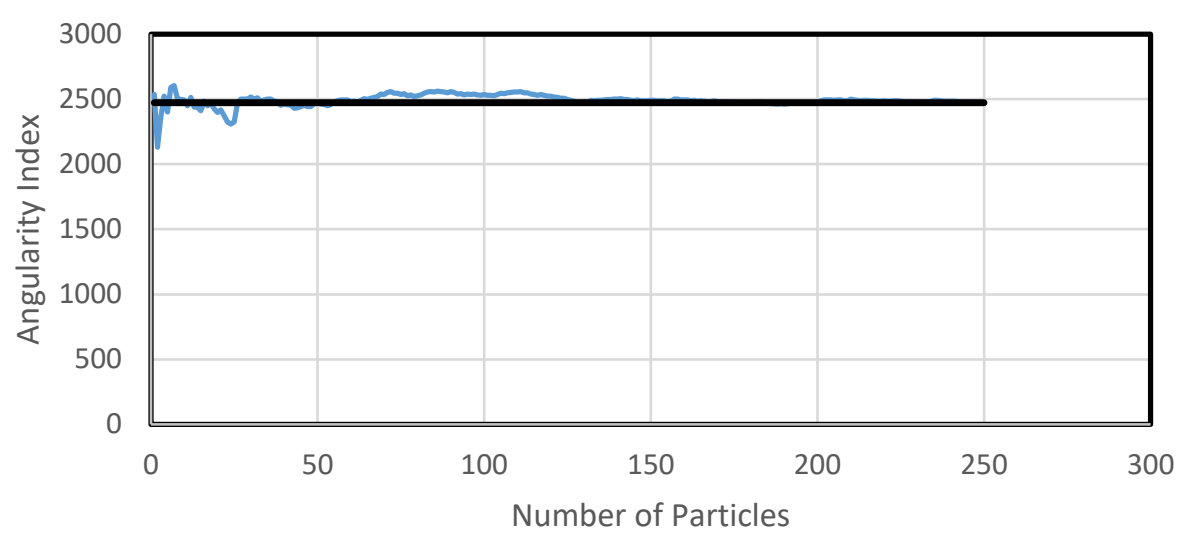

Average Angularity Index

Angularity Index (250 Particles)

Figure 2.13. Asymptotic Analysis: Source 1 - Size \#4 Angularity after 3,000 Micro-Deval Revolutions.

Source 1 - Size \#4 After 12000 Revolutions

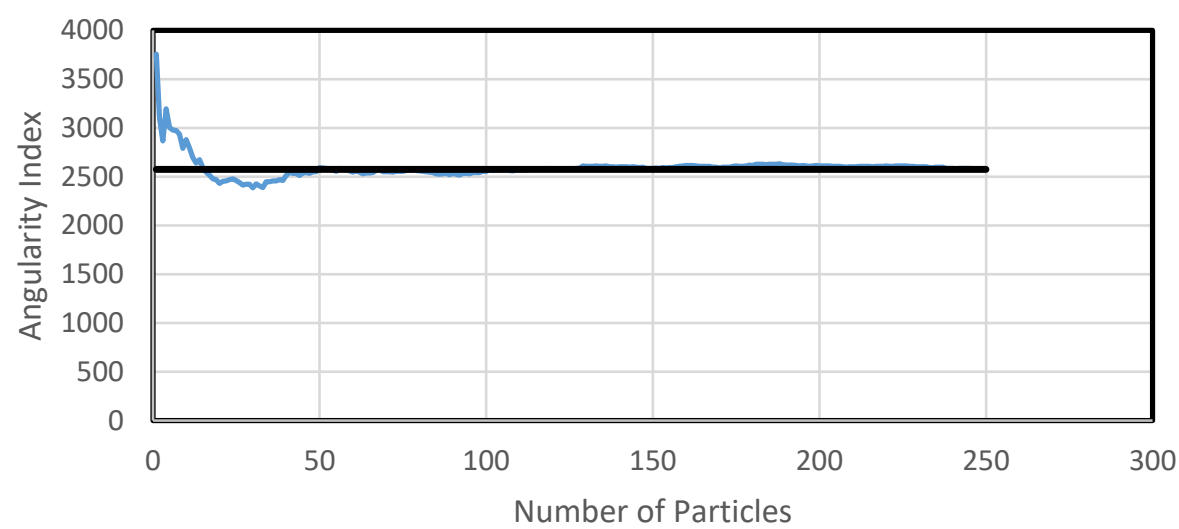

- Average Angularity Index _ Angularity Index (250 Particles)

Figure 2.14 Asymptotic Analysis: Source 1 - Size \#4 Angularity after 12,000 Micro-Deval Revolutions 
Source 2 - Size \#4 Before Polishing

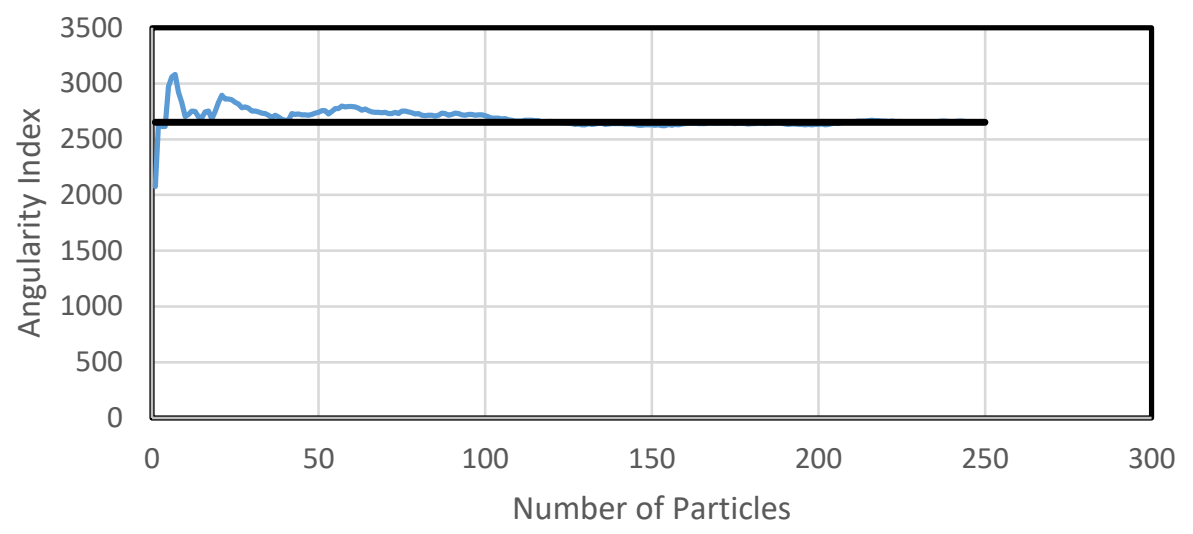

Average Angularity Index $\quad$ Angularity Index (250 Particles)

Figure 2.15. Asymptotic Analysis: Source 2 - Size \#4 Angularity Before Polishing in Micro-Deval.

Source 2 - Size \#4 After 7500 Revolutions

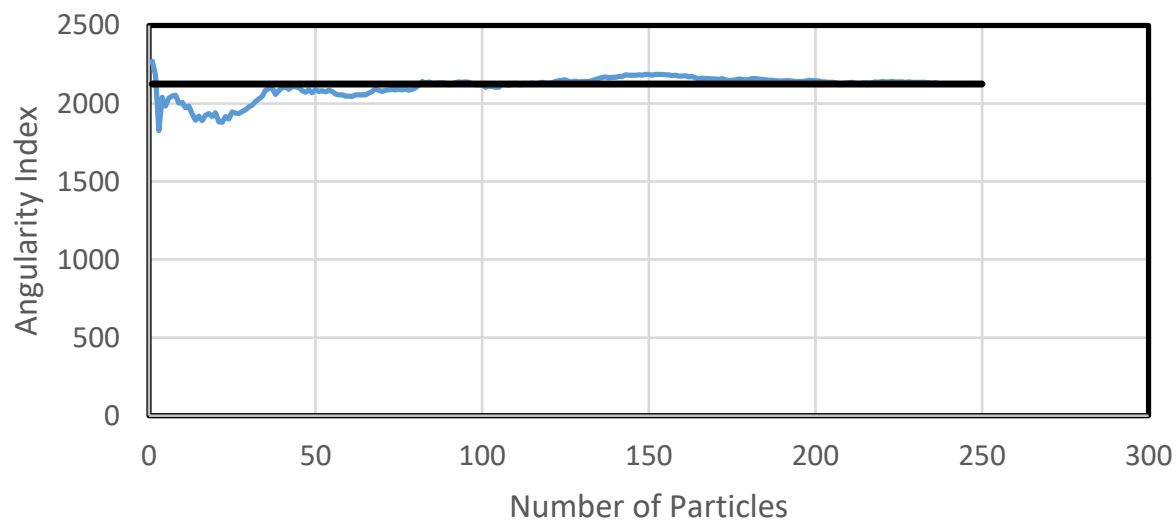

Average Angularity Index

Angularity Index (250 Particles)

Figure 2.16. Asymptotic Analysis: Source 2 - Size \#4 Angularity after 7,500 Micro-Deval Revolutions. 


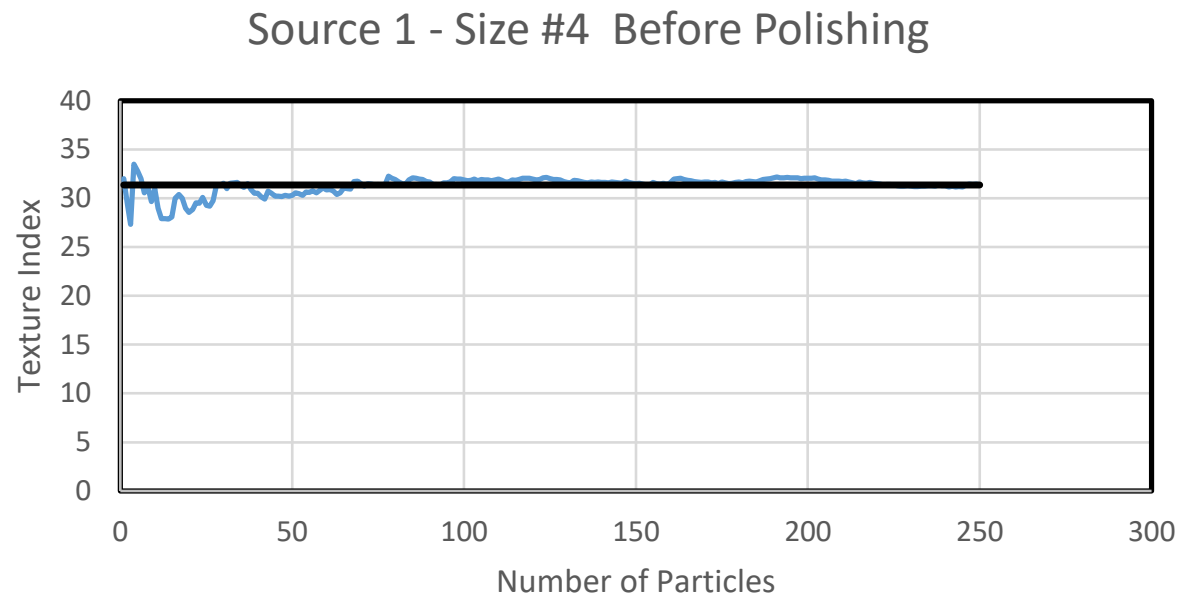

Average Texture Index $\quad$ Texture Index (250 Particles)

Figure 2.17. Asymptotic Analysis: Source 1 - Size \#4 Texture Before Polishing in Micro-Deval.

Source 1 - Size \#4 After 10500 Revolutions

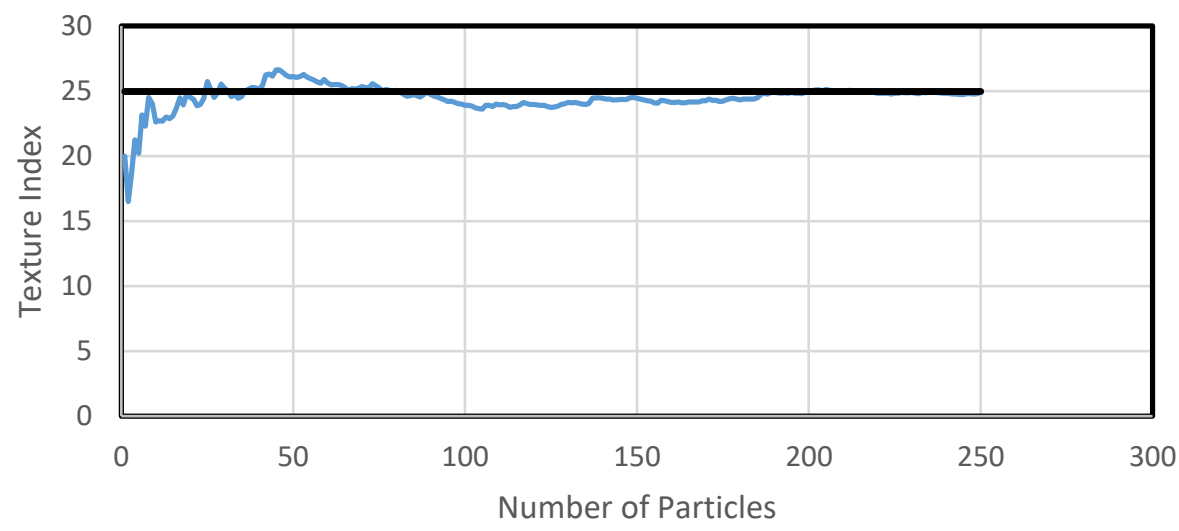

Average Texture Index $\quad \longrightarrow$ Texture Index (250 Particles)

Figure 2.18. Asymptotic Analysis: Source 1 - Size \#4 Texture after 10,500 Micro-Deval Revolutions. 


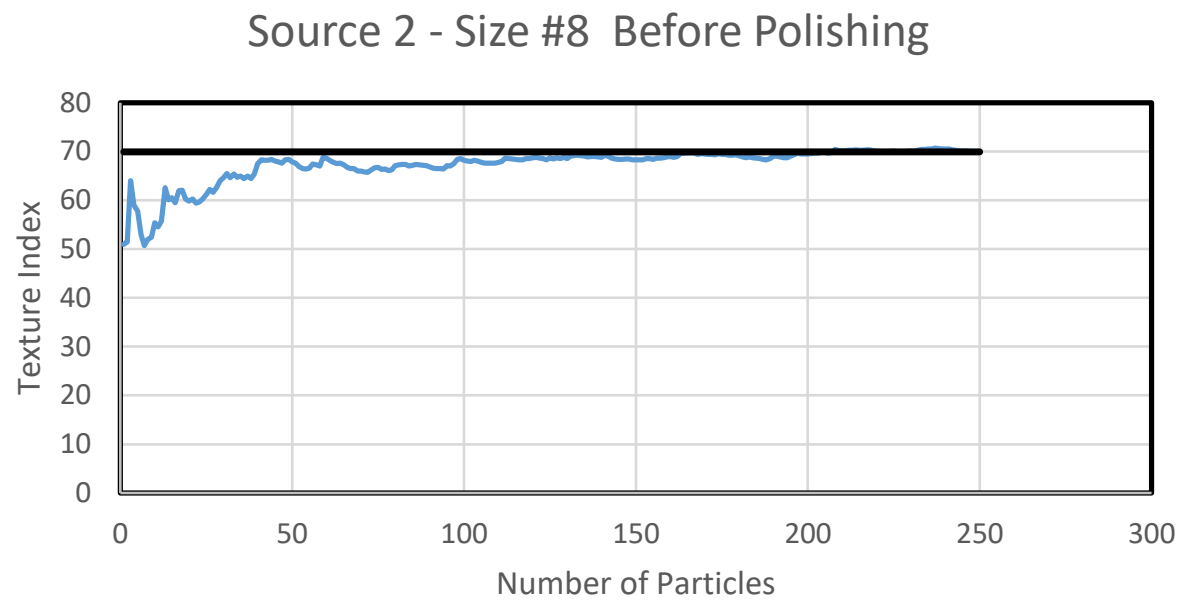

- Average Texture Index — Texture Index (250 Particles)

Figure 2.19. Asymptotic Analysis: Source 2 - Size \#8 Texture Before Polishing in Micro-Deval.

Source 2 - Size \#8 After 13500 Revolutions

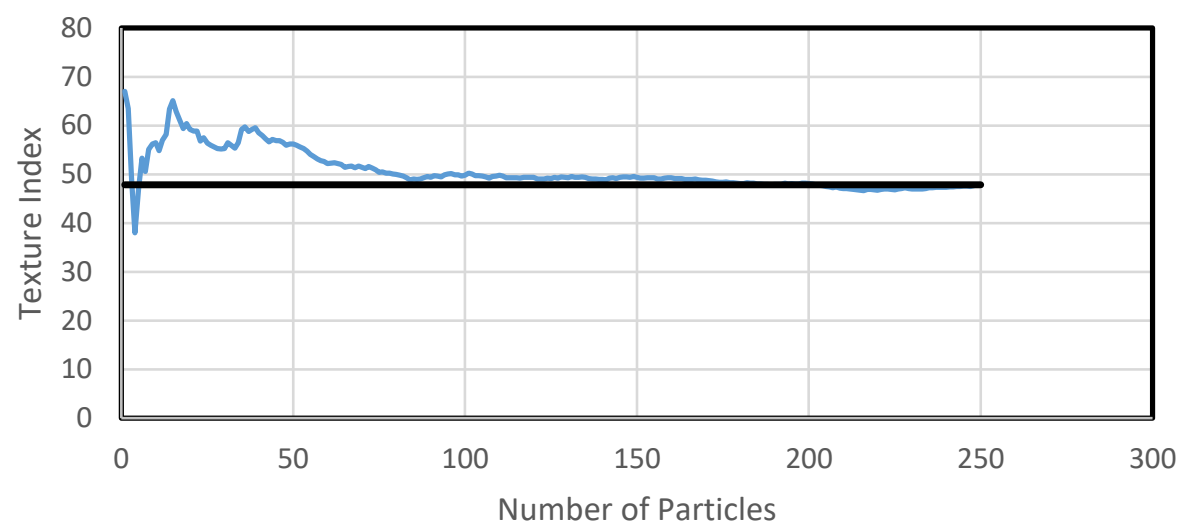

Average Texture Index $\quad \longrightarrow$ Texture Index (250 Particles)

Figure 2.20. Asymptotic Analysis: Source 2 - Size \#8 Texture after 13,500 Micro-Deval Revolutions. 


\section{CHAPTER 3: SUMMARY AND IMPLEMENTATION RECOMMENDATIONS}

\subsection{SUMMARY}

A modified Micro-Deval procedure for the assessment of aggregate polishing was developed. Specifically, the procedure focused on aggregate sizes passing the $3 / 8 \mathrm{in}$. sieve and retained on \#8 sieve. This procedure can be summarized in the following steps:

1. Sample 1:

a. Obtain 250 grams of aggregate particles passing a 3/8 in. sieve and retained on a \#4 sieve.

b. Scan the aggregate sample prior to polishing in the Micro-Deval, to obtain initial Angularity, Texture, and CAAT values.

c. Place the sample into a Micro-Deval container.

d. Add $0.75+/-0.05 \mathrm{~L}$ of water to the sample in the container and soak for 60 minutes.

e. Add 1,250 +/- 5 grams of stainless steel ballsto the aggregate sample and water mix.

f. Place the container into a Micro-Deval apparatus and apply 13,500 revolutions.

g. Wash and sieve the sample over a \#4 sieve.

h. Scan the polished aggregate sample to obtain terminal Angularity, Texture, and CAAT values.

i. [Optional] repeat steps $A$ through $G$ for a second sample and modify the number of revolutions to 5,000 in part $f$.

2. Sample 2:

a. Obtain 250 grams of aggregate particles passing a \#4 sieve and retained on a \#8 sieve.

b. Scan the aggregate sample prior to polishing in the Micro-Deval, to obtain initial Angularity, Texture, and CAAT values.

c. Place the sample into a Micro-Deval container.

d. Add $0.75+/-0.05 \mathrm{~L}$ of water to the sample in the container and soak for 60 minutes.

e. Add 1,250 +/- 5 grams of stainless steel balls to the aggregate sample and water mix. 
f. Place the container into a Micro-Deval apparatus and apply 13,500 revolutions.

g. Wash and sieve the sample over a \#8 sieve.

h. Scan the polished aggregate sample to obtain terminal Angularity, Texture, and CAAT values.

i. [Optional] repeat steps $A$ through $G$ for a second sample and modify the number of revolutions to 5000 in part $\mathrm{f}$.

In addition to the modified procedure, an asymptotic analysis revealed that a target of 250 particles should be used to obtain shape properties in AIMS-II for the aggregate sizes selected in this study.

\subsection{IMPLEMENTATION RECOMMENDATION}

It is important to establish the correct aggregate shape properties requirement for asphalt pavement surface friction. In order to do so, a full factorial study should be initiated to focus on the following:

1. Cover as many sources from around the state and from neighboring states as possible. Sources should cover a wide variety of aggregate mineralogical properties such as: limestone, dolomite, gravel, etc.

2. Similar to this study, two sizes should be considered: passing the $3 / 8 \mathrm{in}$. sieve and retained on the \#4; and passing the \#4 sieve and retained on the \#8.

3. Each aggregate sample should be scanned in AIMS-II prior to polishing, and after 13,500 Micro-Deval polishing revolutions.

4. It's also recommended to obtain aggregate shape properties in AIMS-II after 5,000 MicroDeval polishing revolutions. This intermediate polishing point will help in understanding the polishing rate and aggregate source, rather than just initial and terminal values.

5. Use a cluster analysis and other statistical methods to establish limits for acceptable aggregate shape properties to provide required friction in asphalt surface mixes. A comparison to historical friction data and previous ICT projects will be critical to accomplishing this task. 


\section{REFERENCES}

Kassem, E., Awed, A., Masad, E., and D. Little. 2014. "Development of Predictive Model for Skid Loss of Asphalt Pavements". Journal of Transportation Research Board 2372:83-96.

Mahmoud, E. and E. Ortiz. 2014. Implementation of AIMS in Measuring Aggregate Resistance to Polishing, Abrasion, and Breakage. Report No. FHWA-ICT-14-014. Illinois Center for Transportation, Rantoul, IL: Illinois Department of Transportation. 52 pp.

Mahmoud, E. and G. Perales. 2015. Investigation of Relationships between AIMS Shape Properties and VST Friction Values. Report No. FHWA-ICT-15-006. Illinois Center for Transportation, Rantoul, IL: Illinois Department of Transportation. 37 pp.

Masad, E., Luce. A., Mahmoud, E. and A. Chowdhury. 2007. Relationship of Aggregate Texture to Asphalt Pavement Skid Resistance Using Image Analysis of Aggregate Shape. Final Report for Highway IDEA Project 114.NCHRP. 24 pp. 


\section{APPENDIX A: ASYMPTOTIC ANALYSIS RESULTS}

\section{A.1 ANGULARITY}

Source 1 - Size \#4

Source 1 - Size \#4 Before Polishing

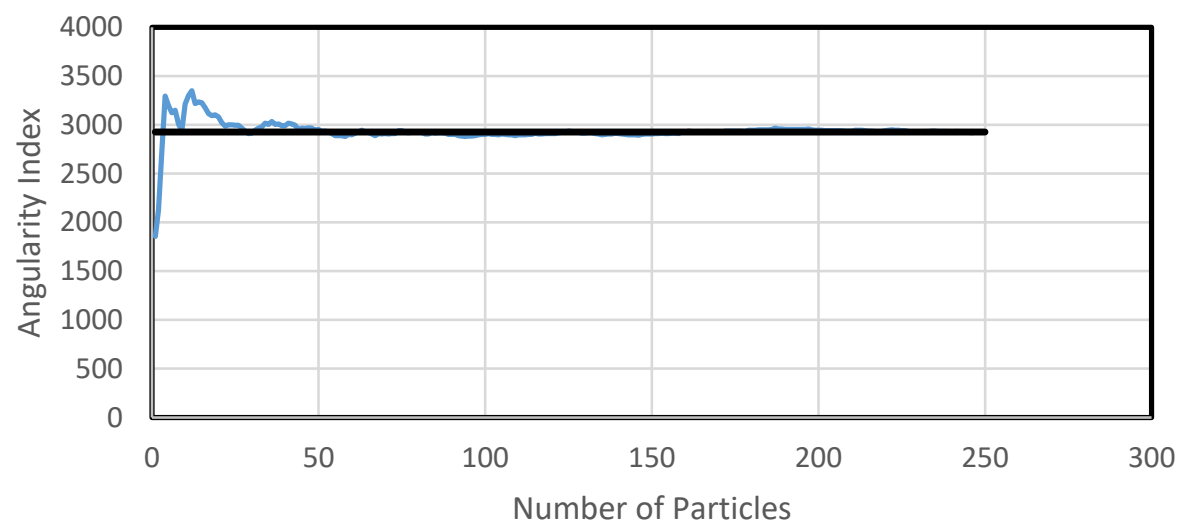

Average Angularity Index _ _ Angularity Index (250 Particles)

Source 1 - Size \#4 After 3000 Revolutions

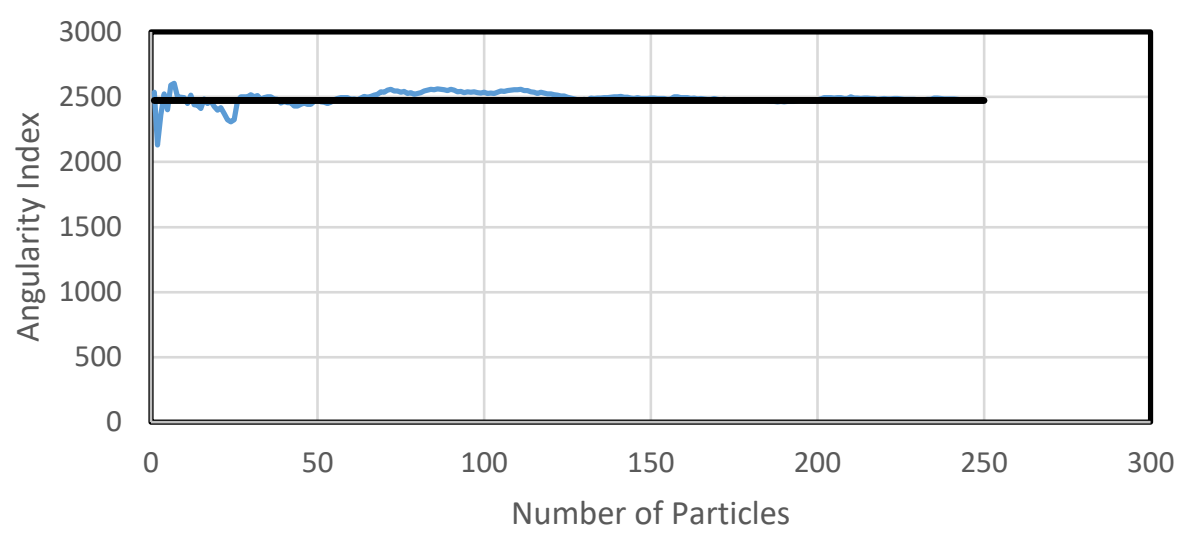

Average Angularity Index

Angularity Index (250 Particles) 
Source 1 - Size \#4 After 4500 Revolutions
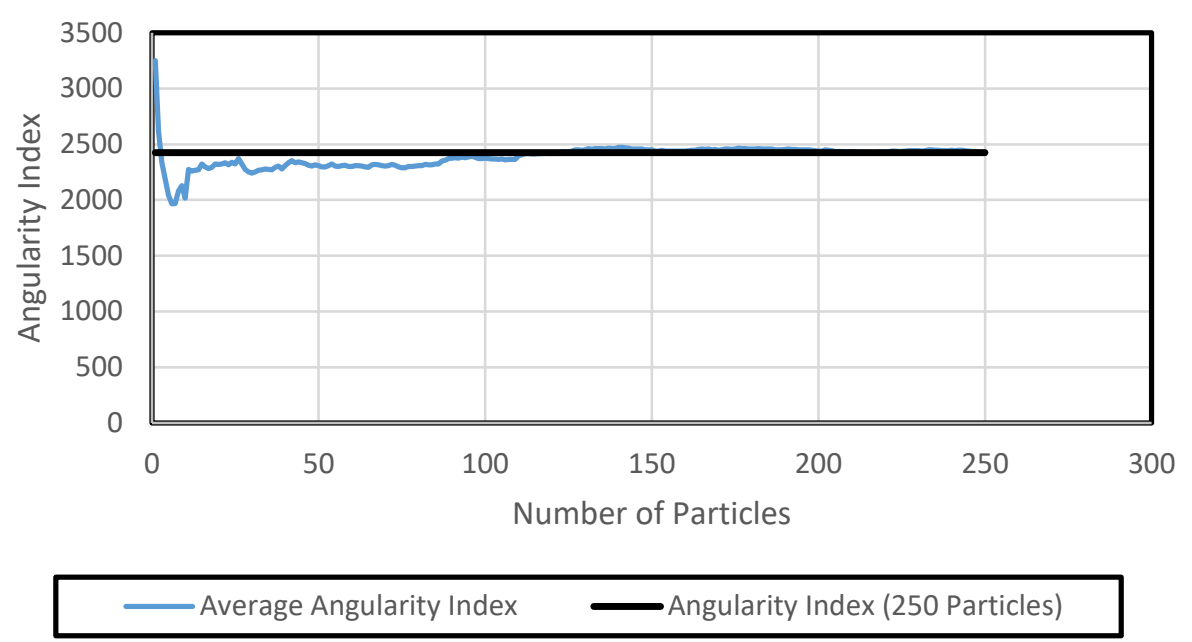

Source 1 - Size \#4 After 6000 Revolutions

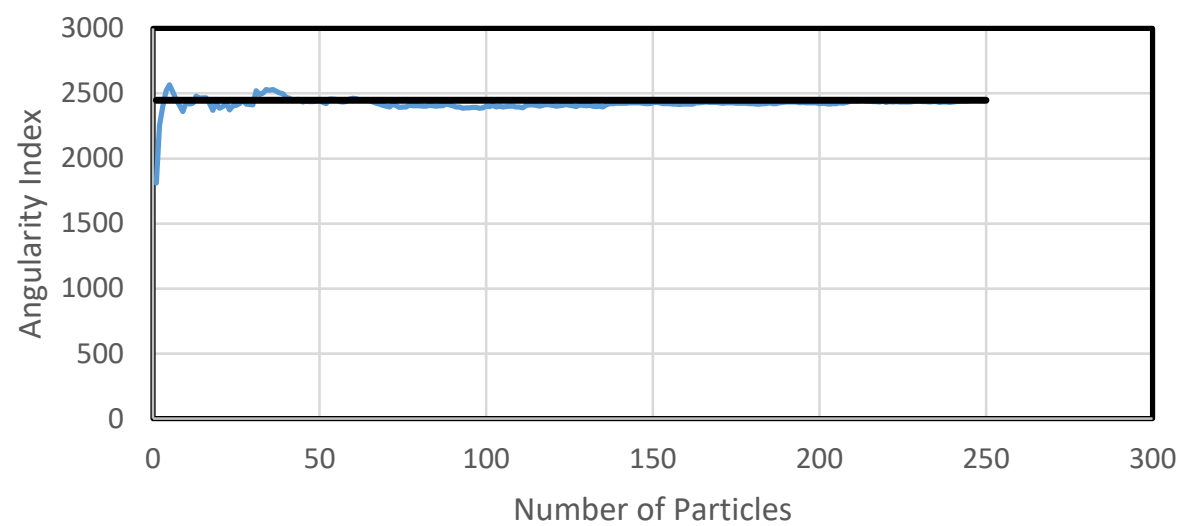

Average Angularity Index _ Angularity Index (250 Particles) 
Source 1 - Size \#4 After 7500 Revolutions
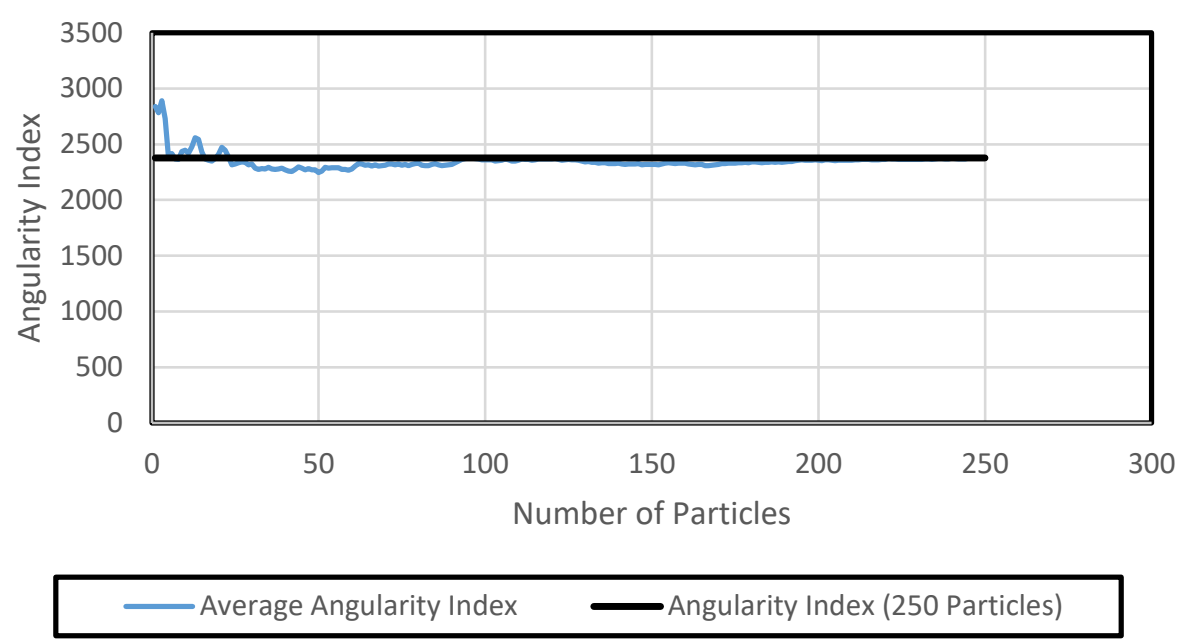

Source 1 - Size \#4 After 9000 Revolutions

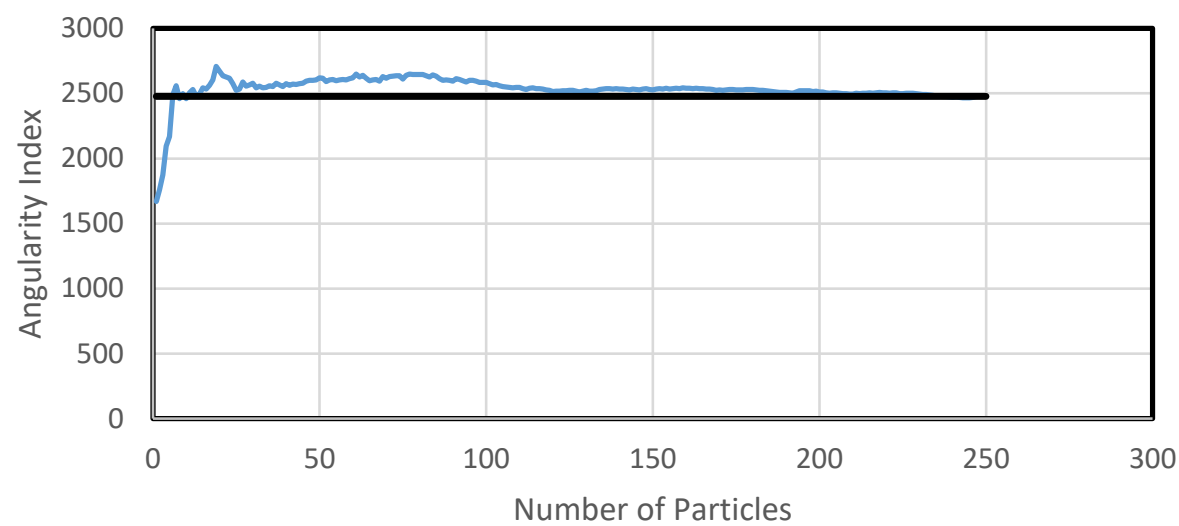

Average Angularity Index _ Angularity Index (250 Particles) 
Source 1 - Size \#4 After 10500 Revolutions
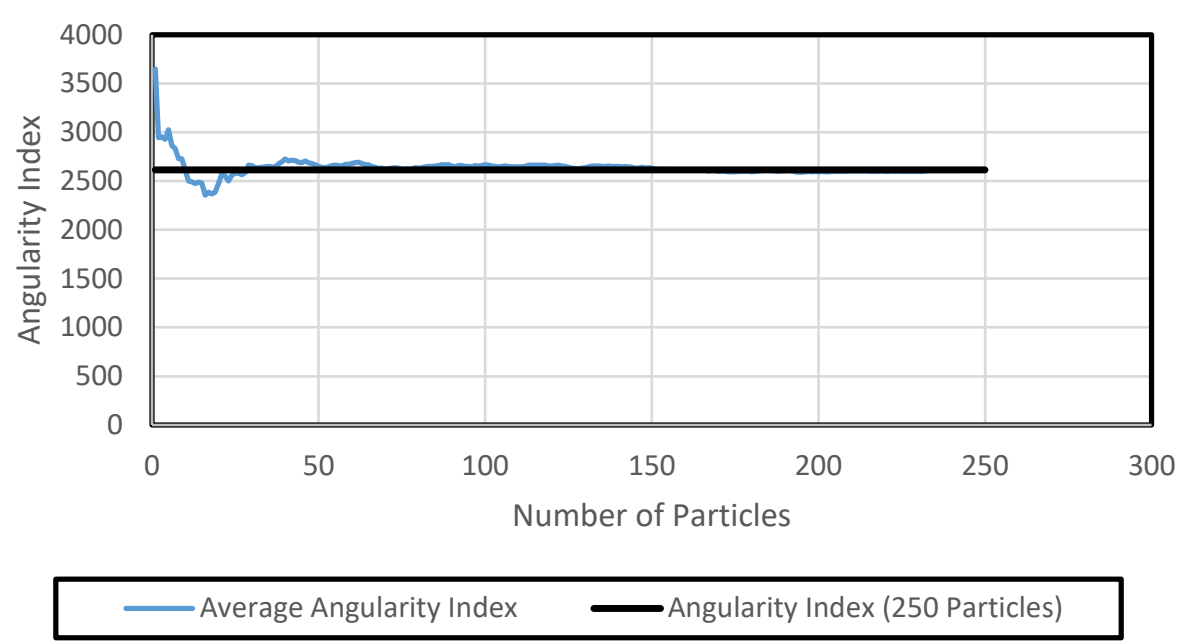

Source 1 - Size \#4 After 12000 Revolutions

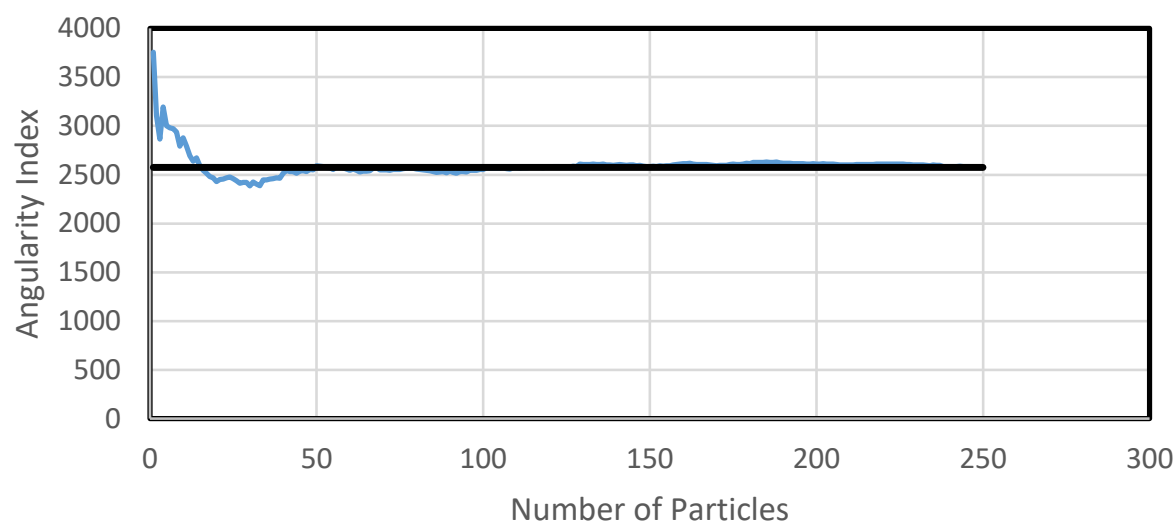




\section{Source 1 - Size \#4 After 13500 Revolutions}

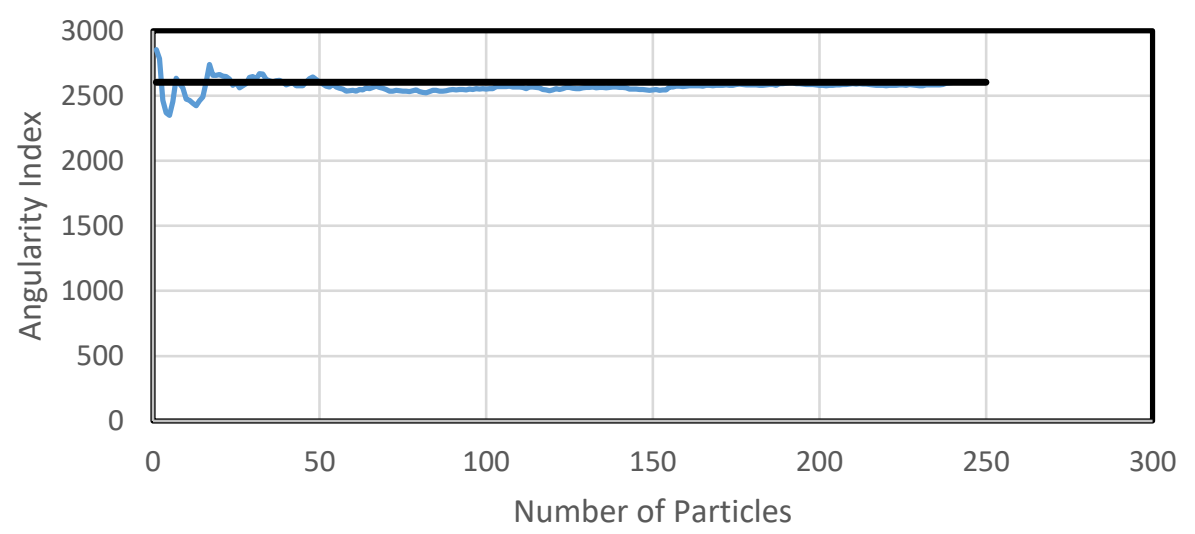

Average Angularity Index _ Angularity Index (250 Particles) 


\section{Source 1 - Size \#8 (Angularity)}
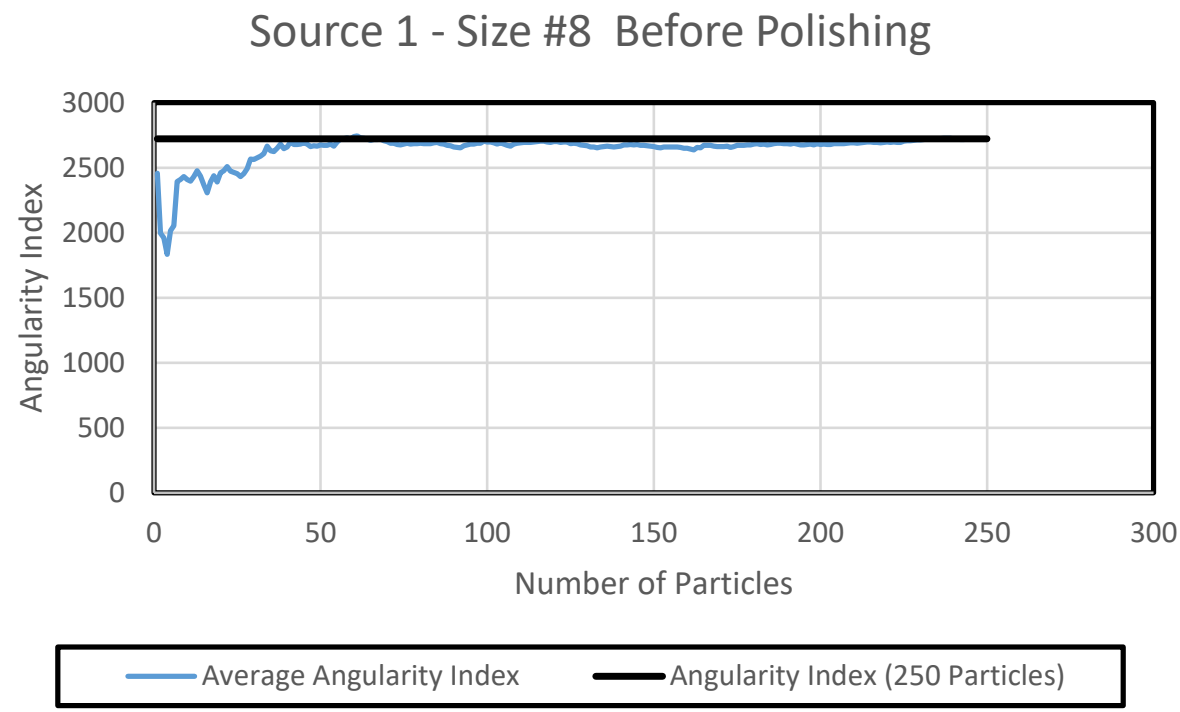

Source 1 - Size \#8 After 3000 Revolutions

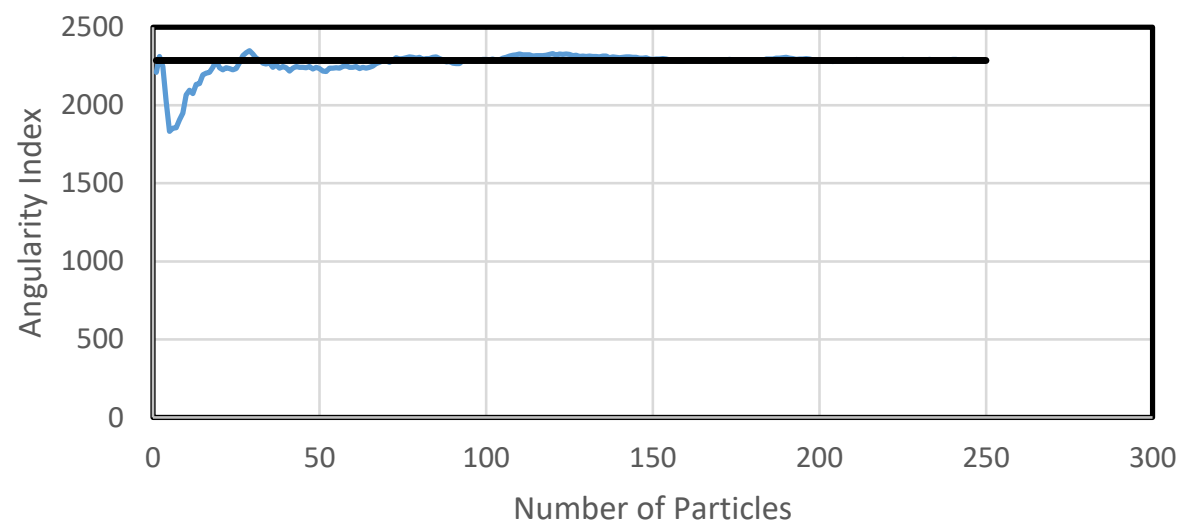

Average Angularity Index

Angularity Index (250 Particles) 


\section{Source 1 - Size \#8 After 4500 Revolutions}
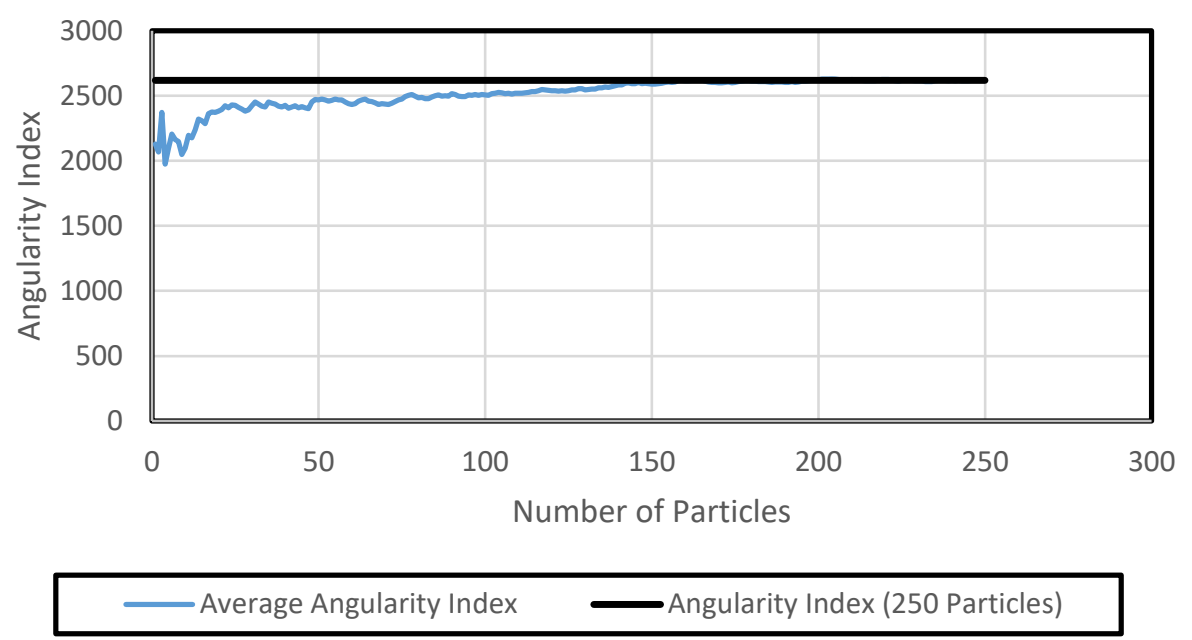

Source 1 - Size \#8 After 6000 Revolutions

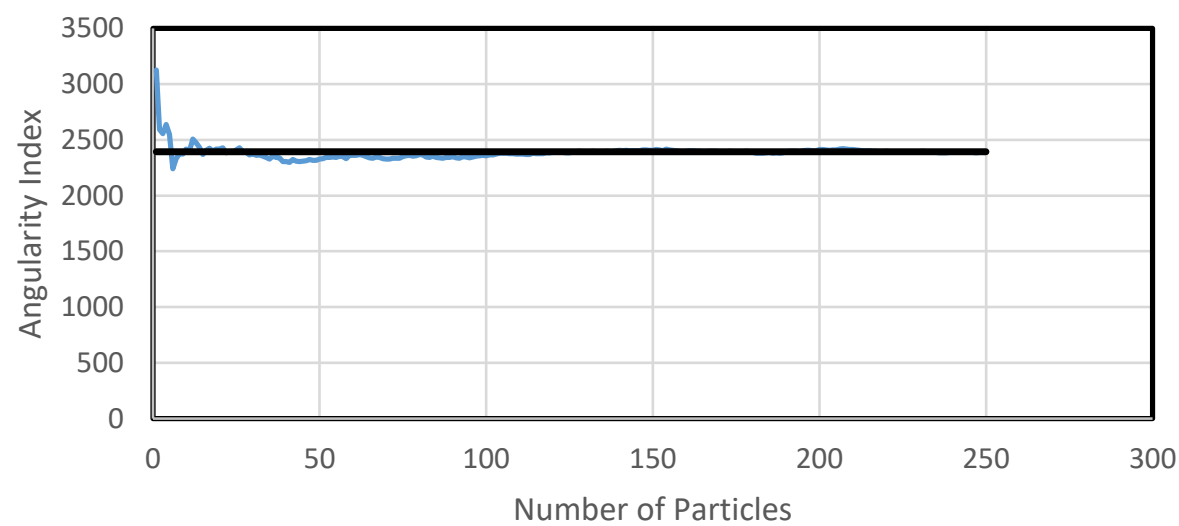


Source 1 - Size \#8 After 7500 Revolutions
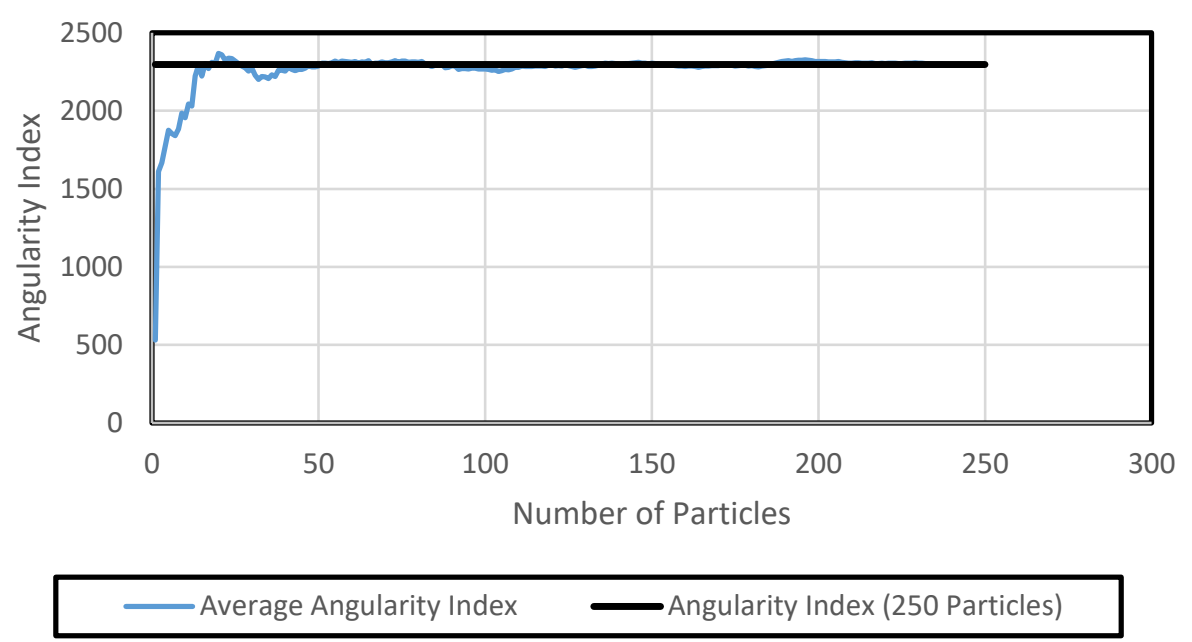

Source 1 - Size \#8 After 9000 Revolutions

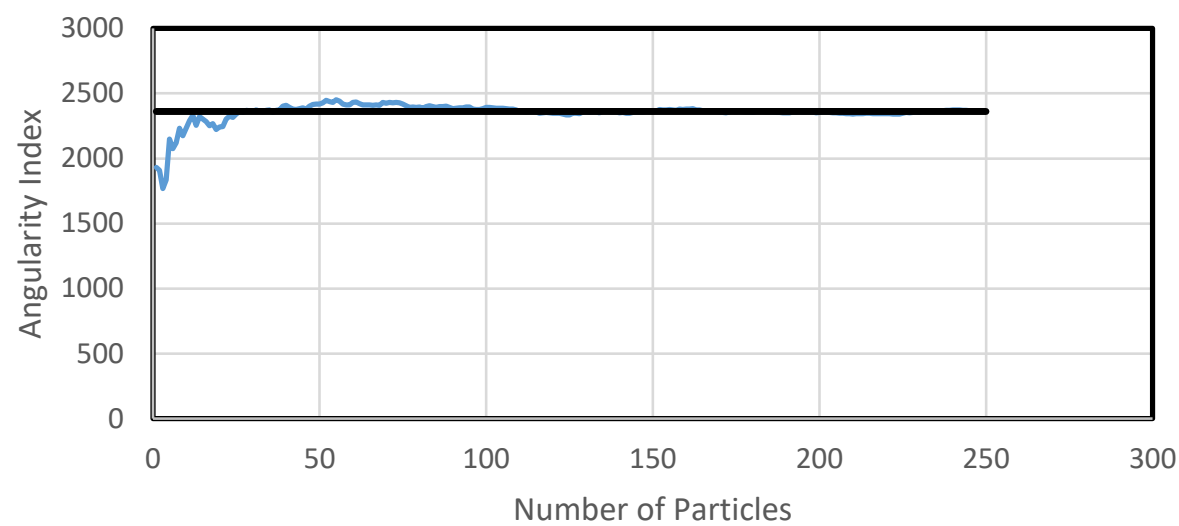


Source 1 - Size \#8 After 10500 Revolutions
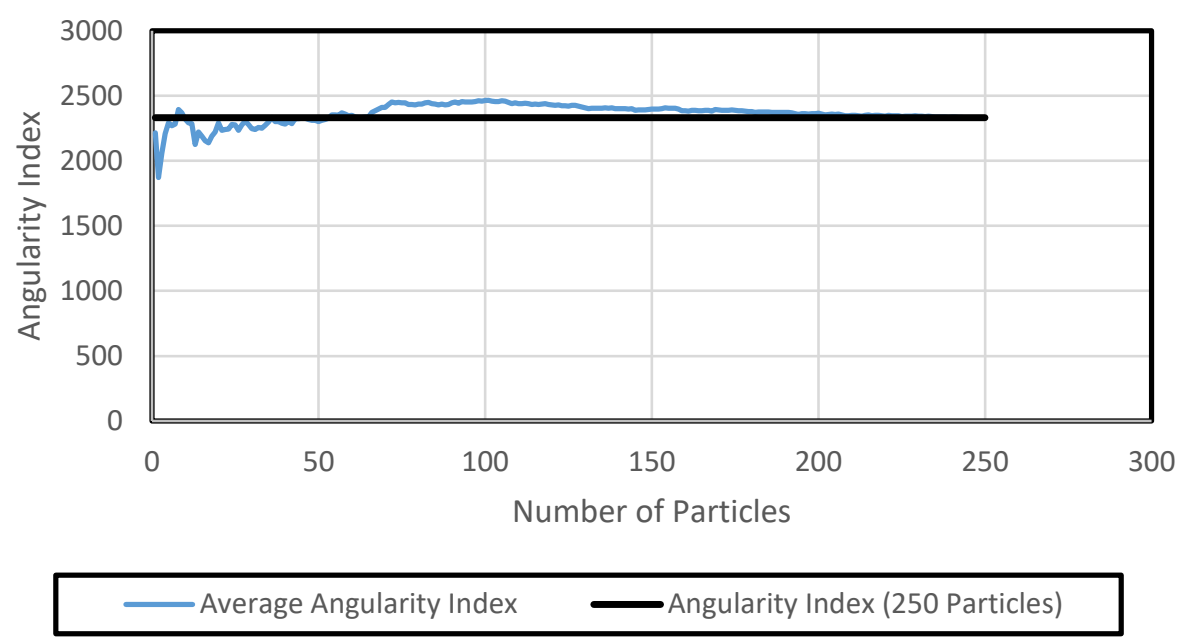

Source 1 - Size \#8 After 12000 Revolutions

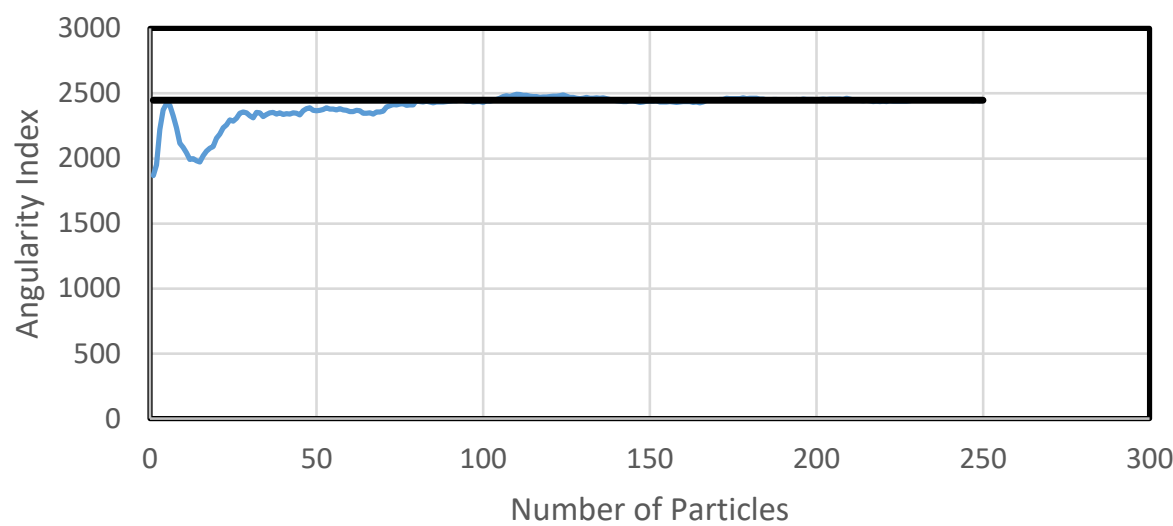


Source 1 - Size \#8 After 13500 Revolutions

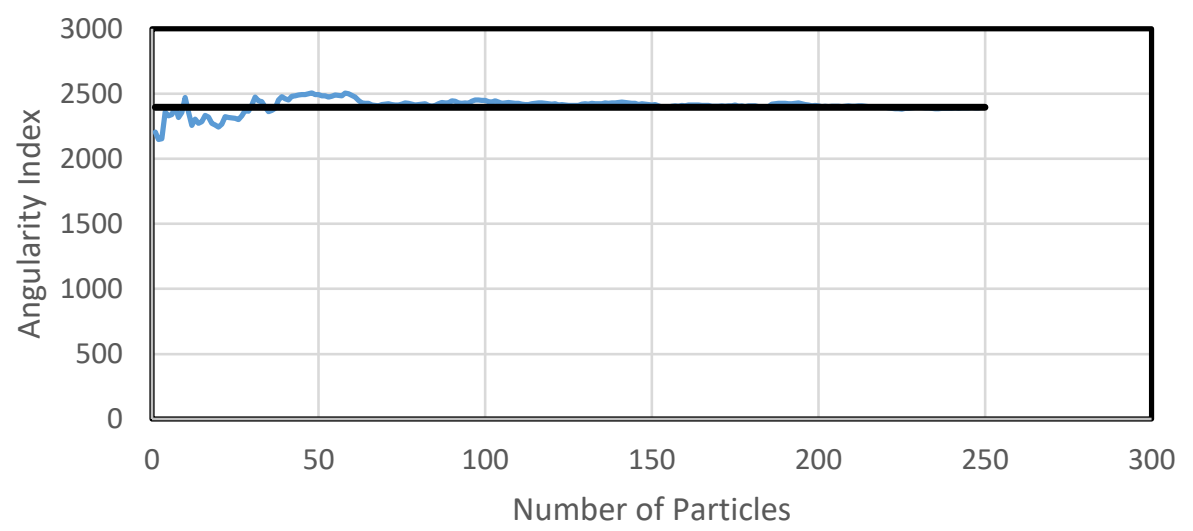

- Average Angularity Index $\quad$ Angularity Index (250 Particles) 


\section{Source 2 - Size \#4 (Angularity)}

Source 2 - Size \#4 Before Polishing
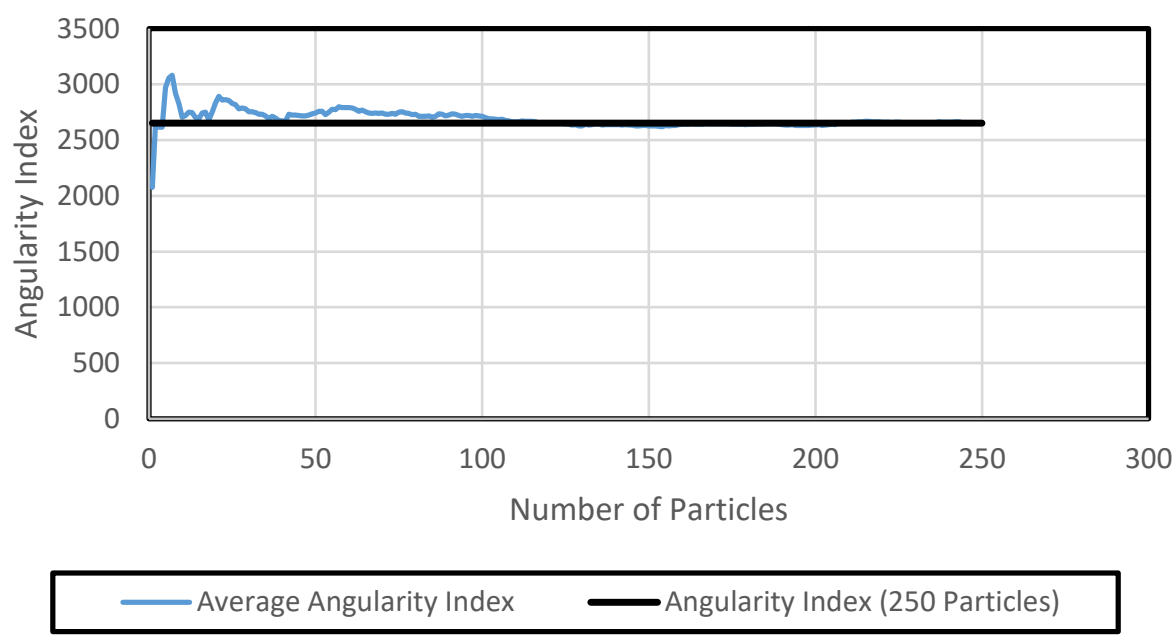

Source 2 - Size \#4 After 3000 Revolutions

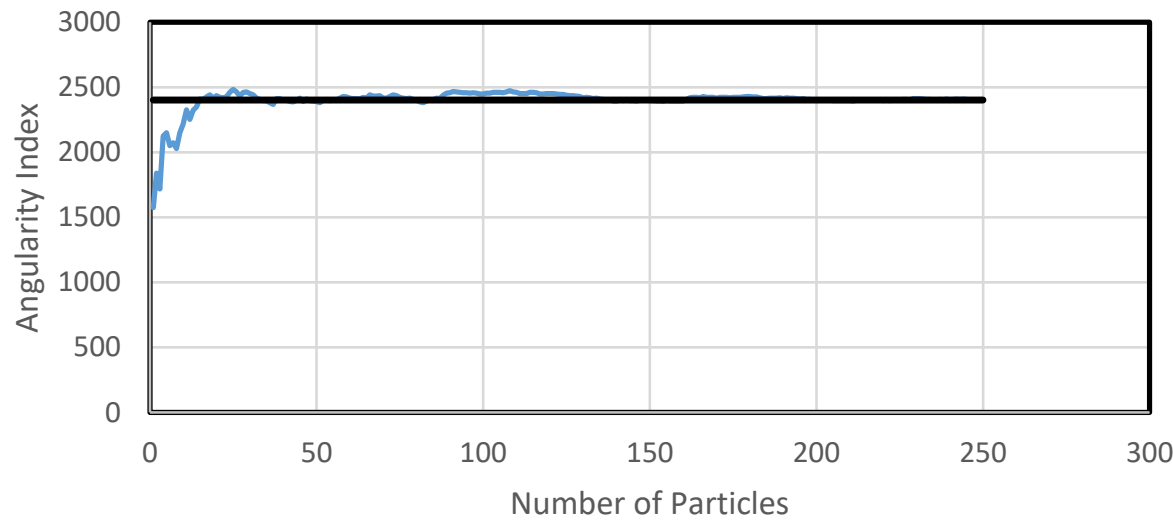


Source 2 - Size \#4 After 4500 Revolutions
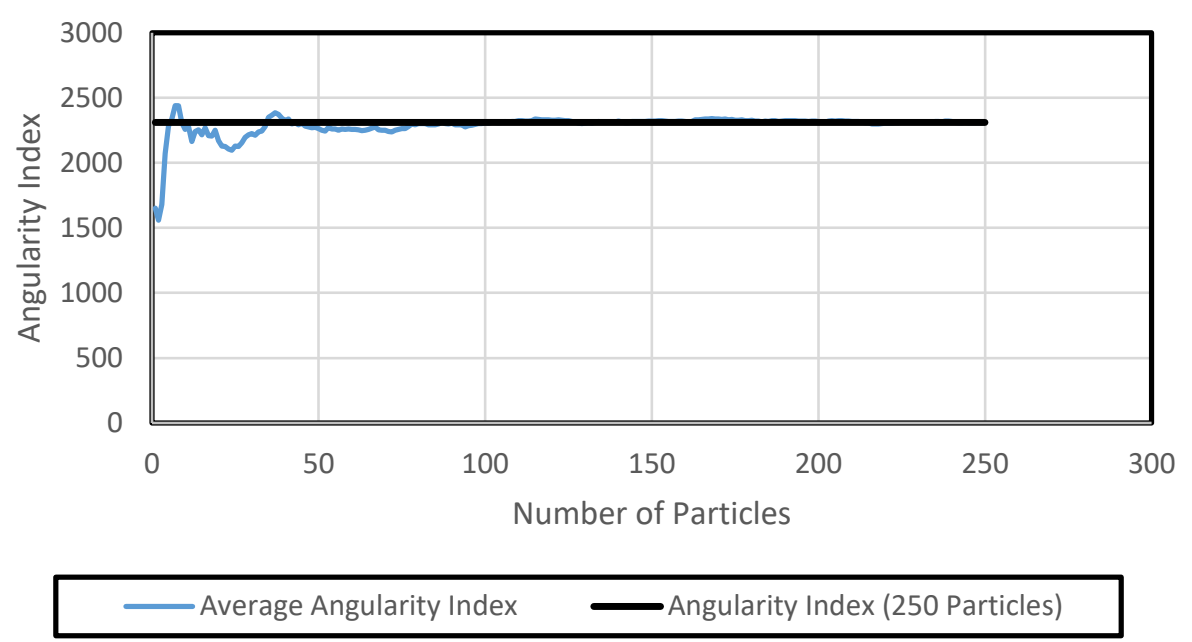

Source 2 - Size \#4 After 6000 Revolutions

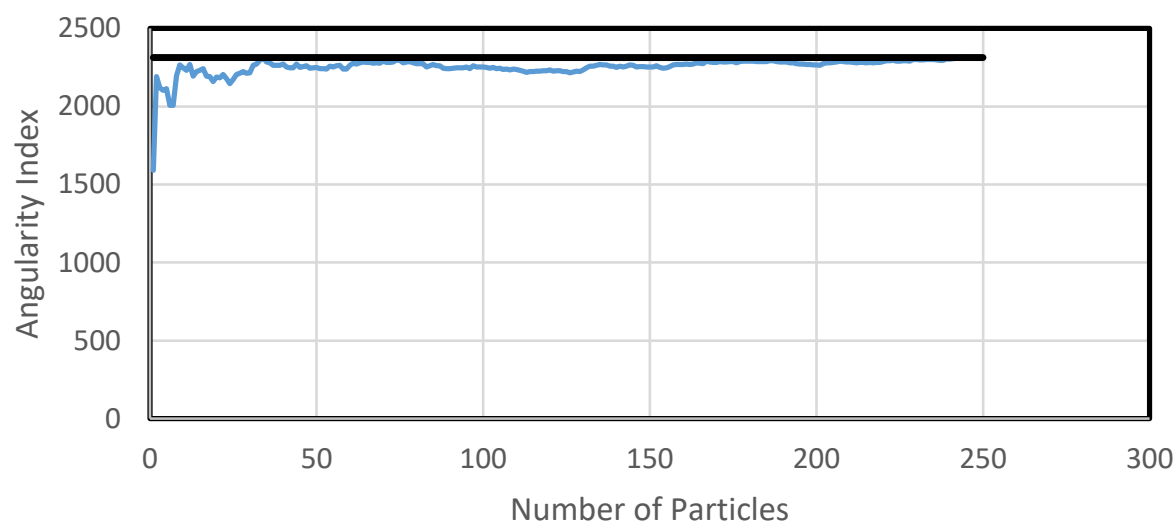


Source 2 - Size \#4 After 7500 Revolutions
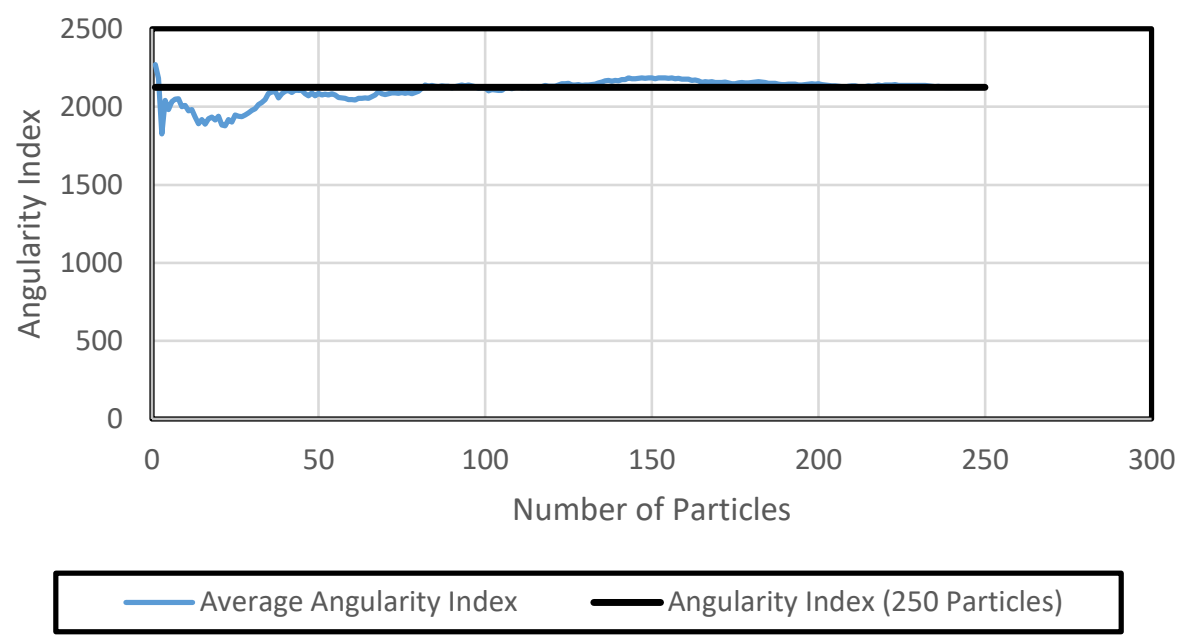

Source 2 - Size \#4 After 9000 Revolutions

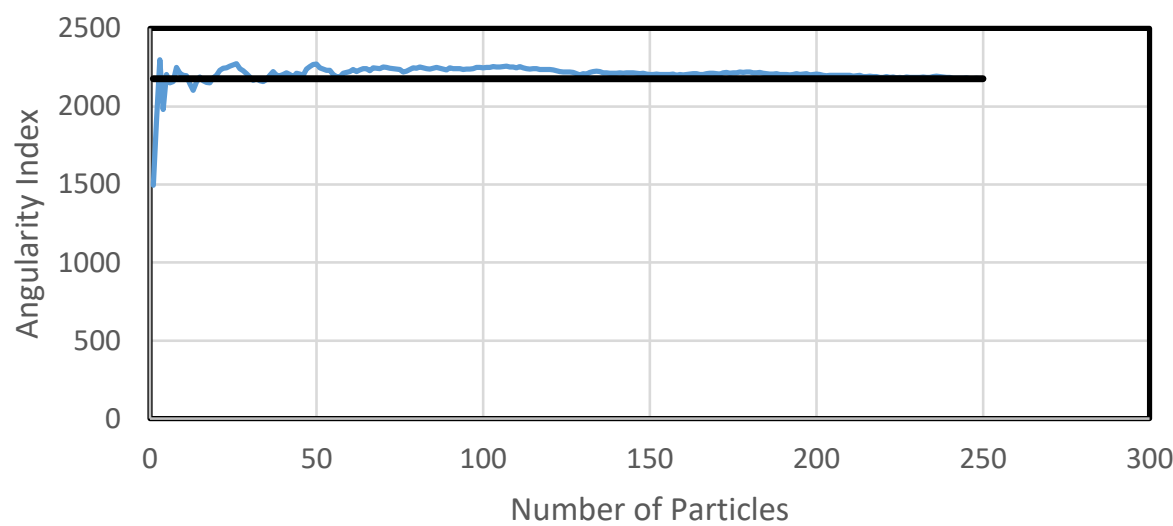

Average Angularity Index _ _ Angularity Index (250 Particles) 
Source 2 - Size \#4 After 10500 Revolutions
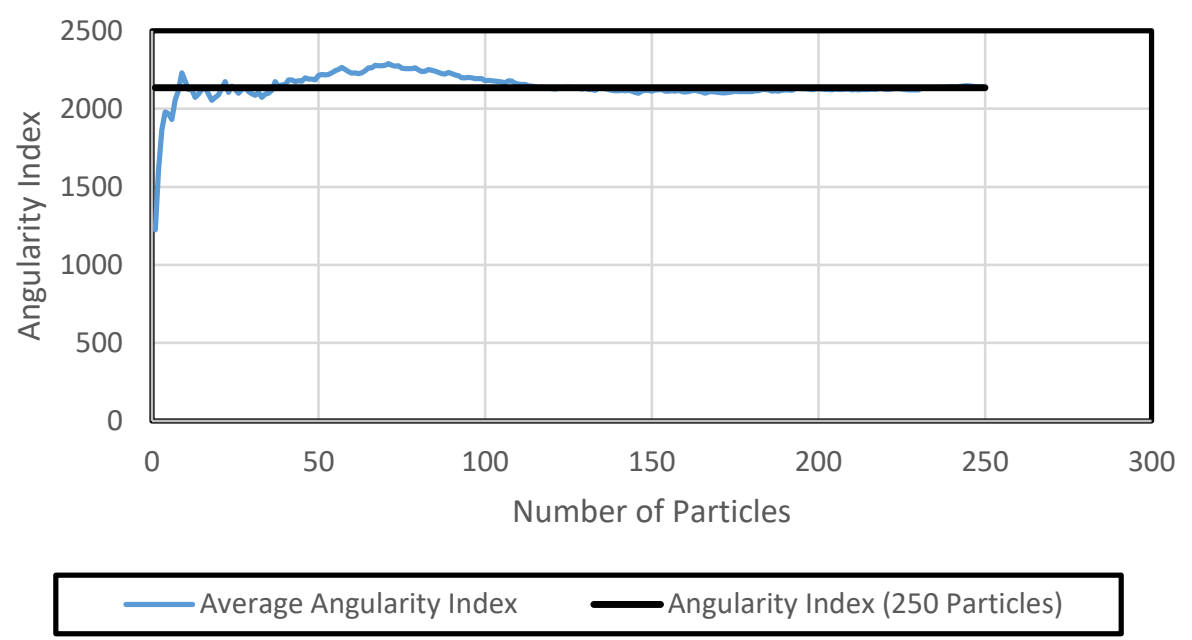

Source 2 - Size \#4 After 12000 Revolutions

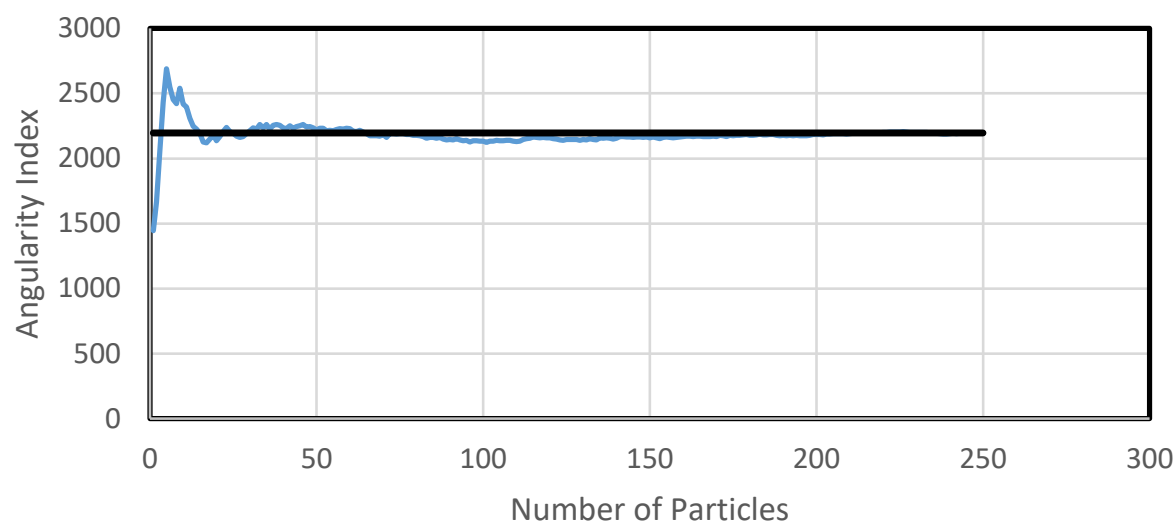


Source 2 - Size \#4 After 13500 Revolutions

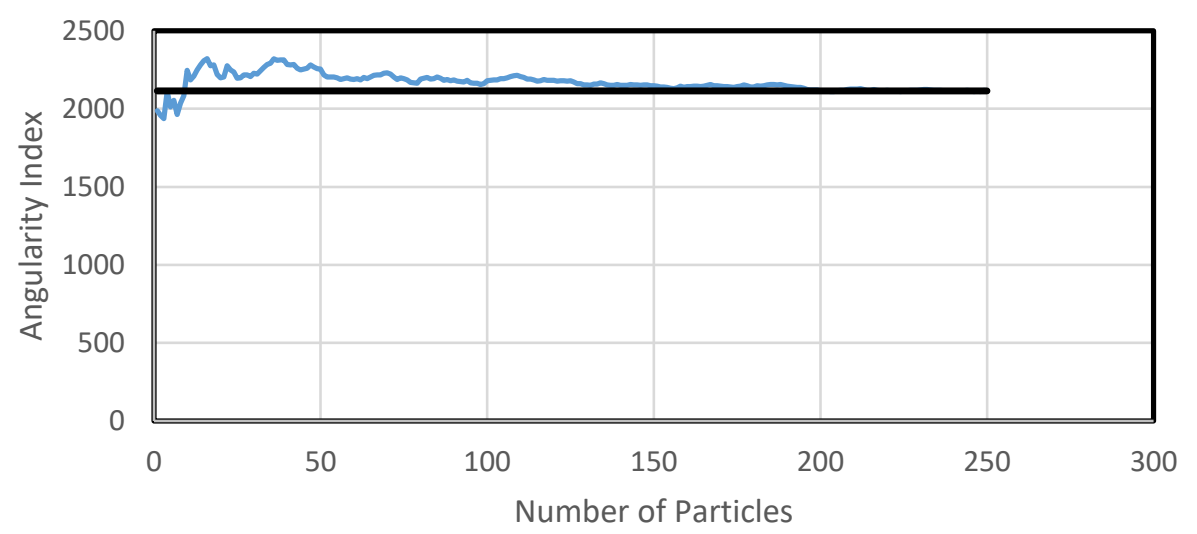

- Average Angularity Index $\quad$ Angularity Index (250 Particles) 


\section{Source 2 - Size \#8 (Angularity)}

Source 2 - Size \#8 Before Polishing
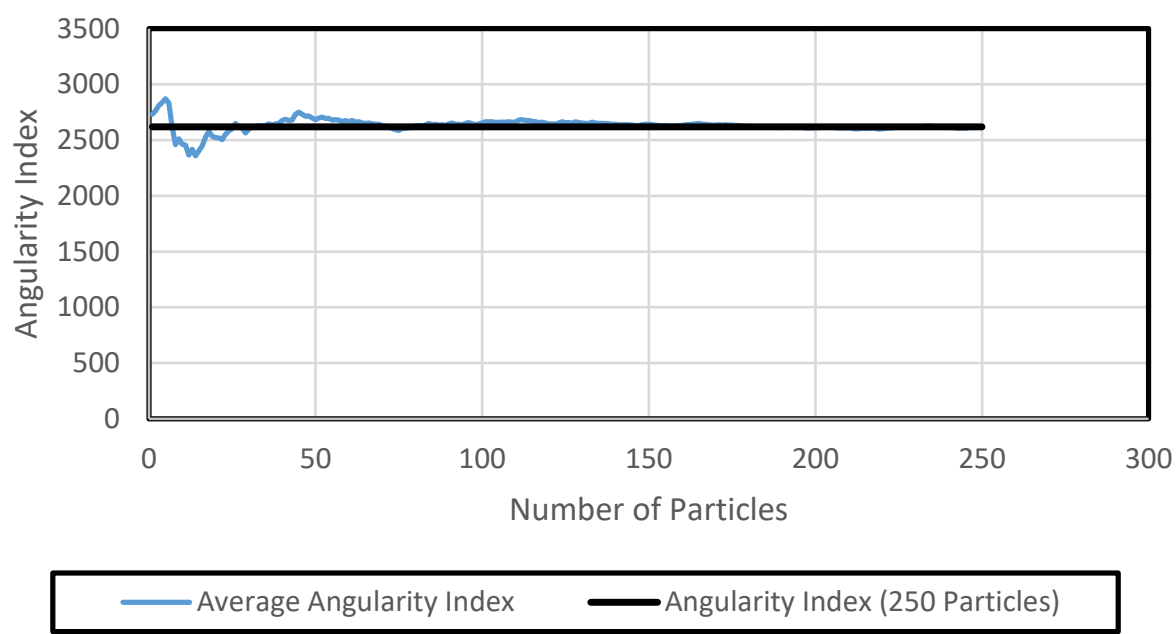

Source 2 - Size \#8 After 3000 Revolutions

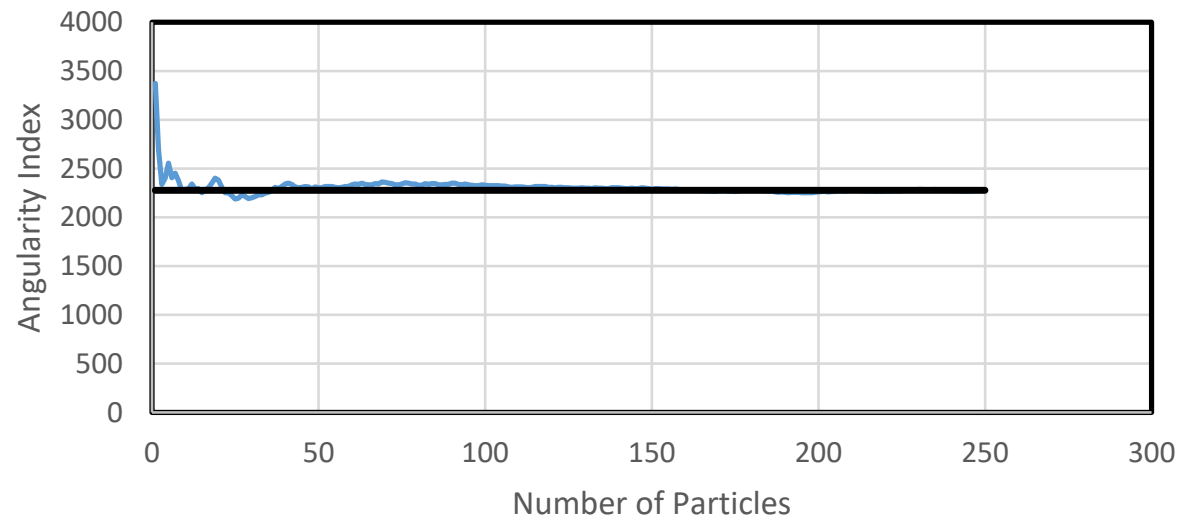

Average Angularity Index Angularity Index (250 Particles) 
Source 2 - Size \#8 After 4500 Revolutions
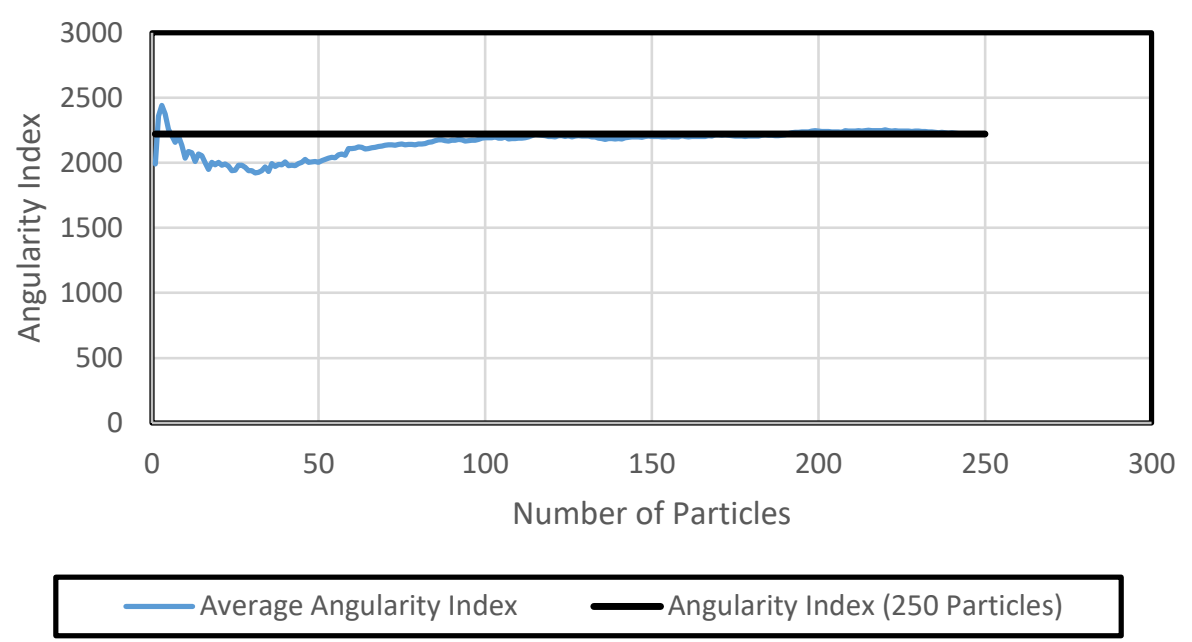

Source 2 - Size \#8 After 6000 Revolutions

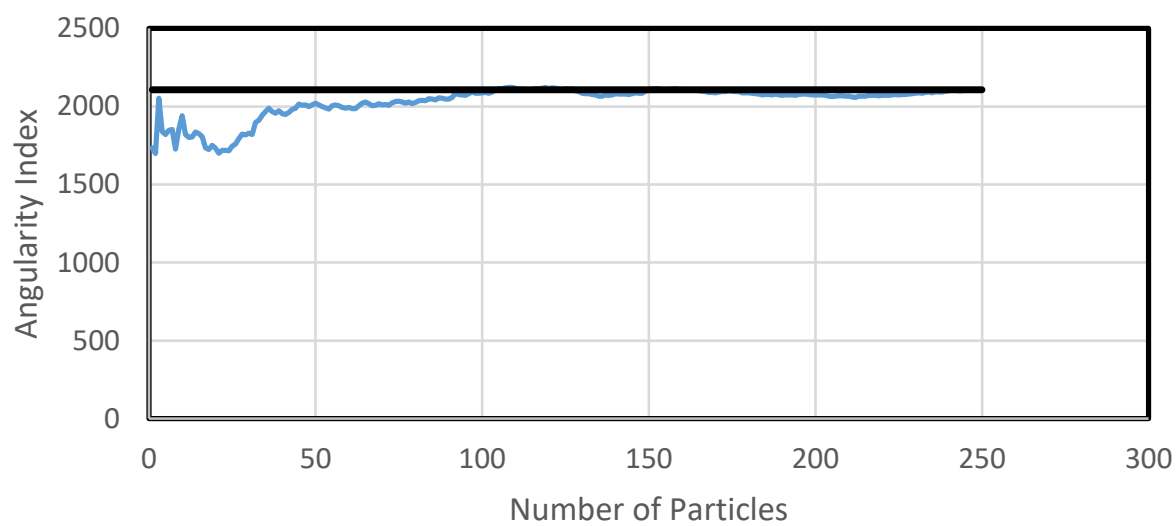


Source 2 - Size \#8 After 7500 Revolutions
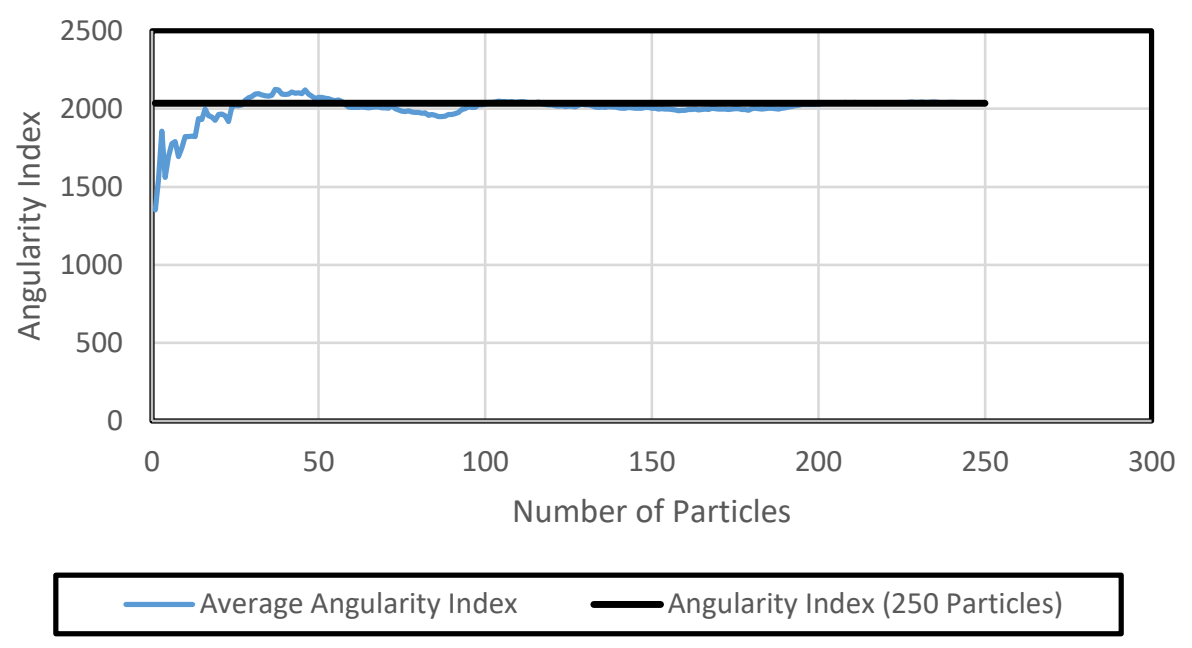

Source 2 - Size \#8 After 9000 Revolutions

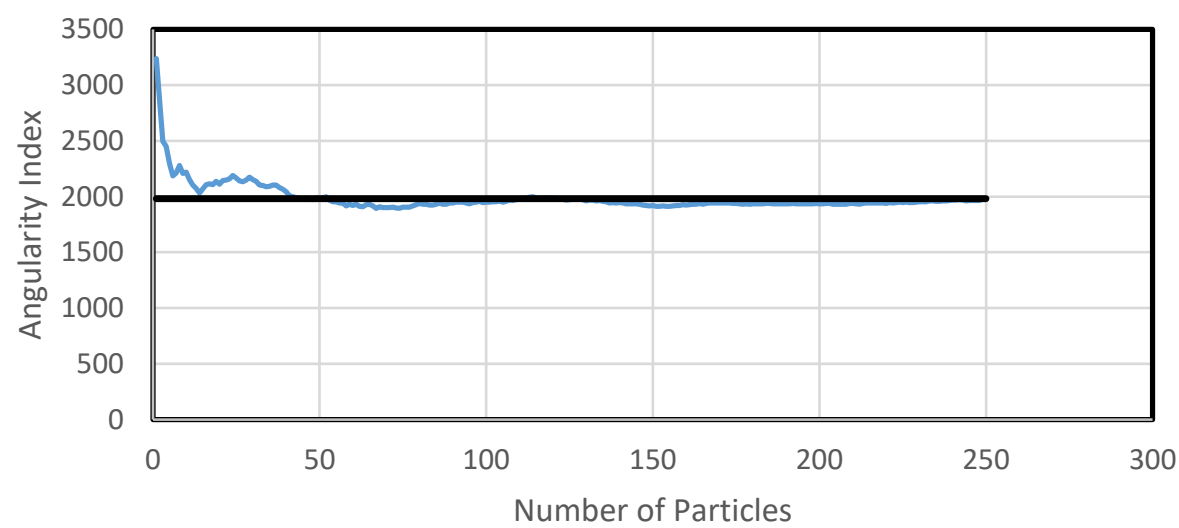

Average Angularity Index _Angularity Index (250 Particles) 
Source 2 - Size \#8 After 10500 Revolutions
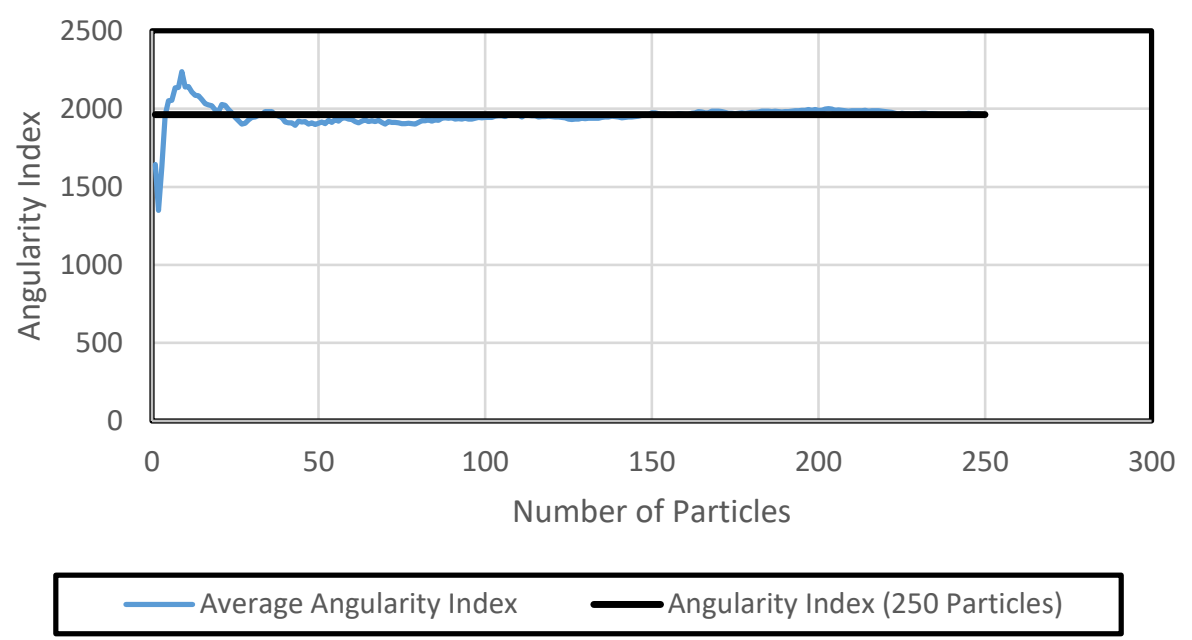

Source 2 - Size \#8 After 12000 Revolutions

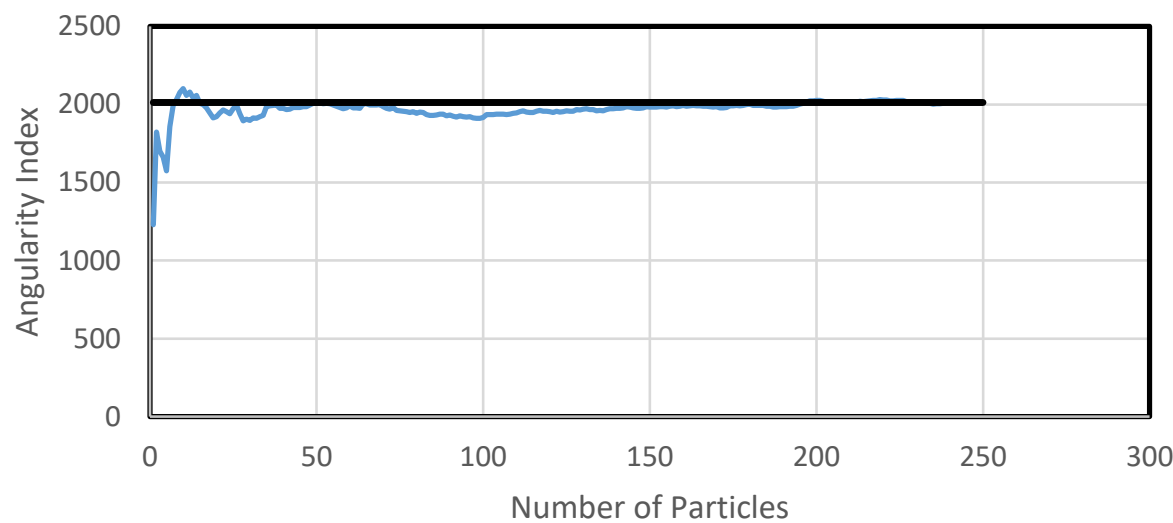

- Average Angularity Index _ Angularity Index (250 Particles) 
Source 2 - Size \#8 After 13500 Revolutions

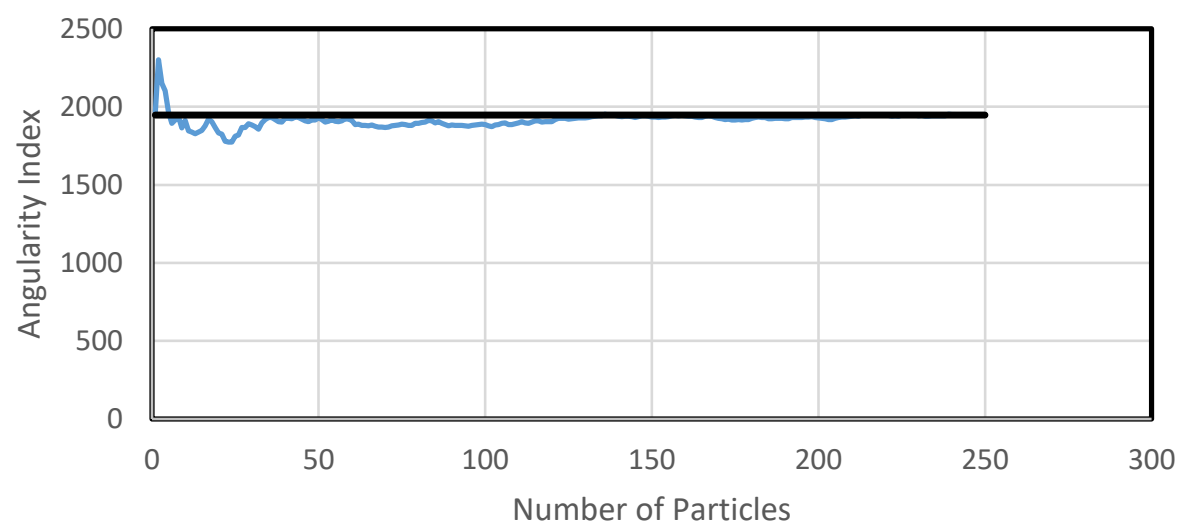

- Average Angularity Index $\quad$ Angularity Index (250 Particles) 


\section{A.2 TEXTURE}

\section{Source 1 - Size \#4}
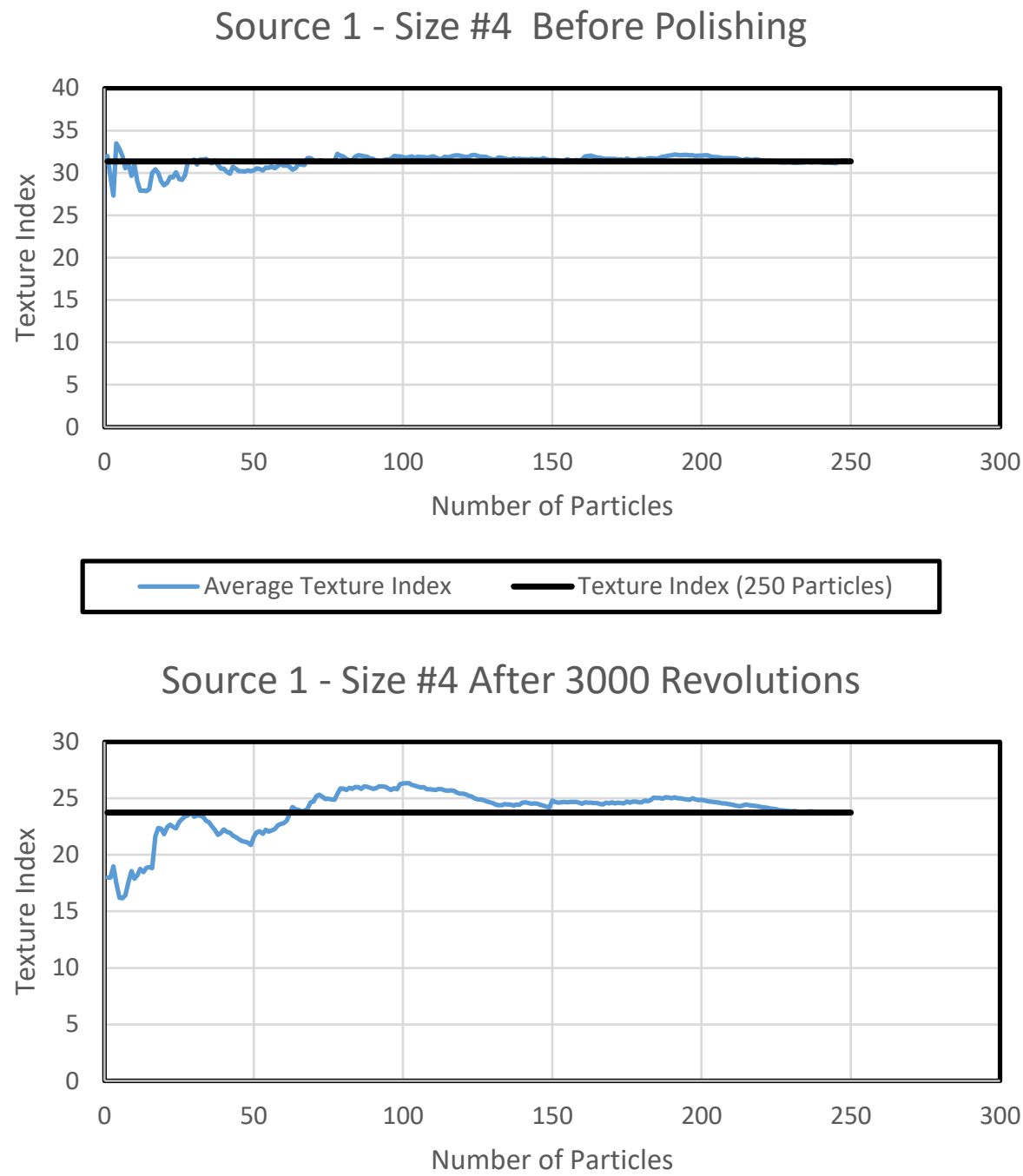

Average Texture Index

Texture Index (250 Particles) 
Source 1 - Size \#4 After 4500 Revolutions
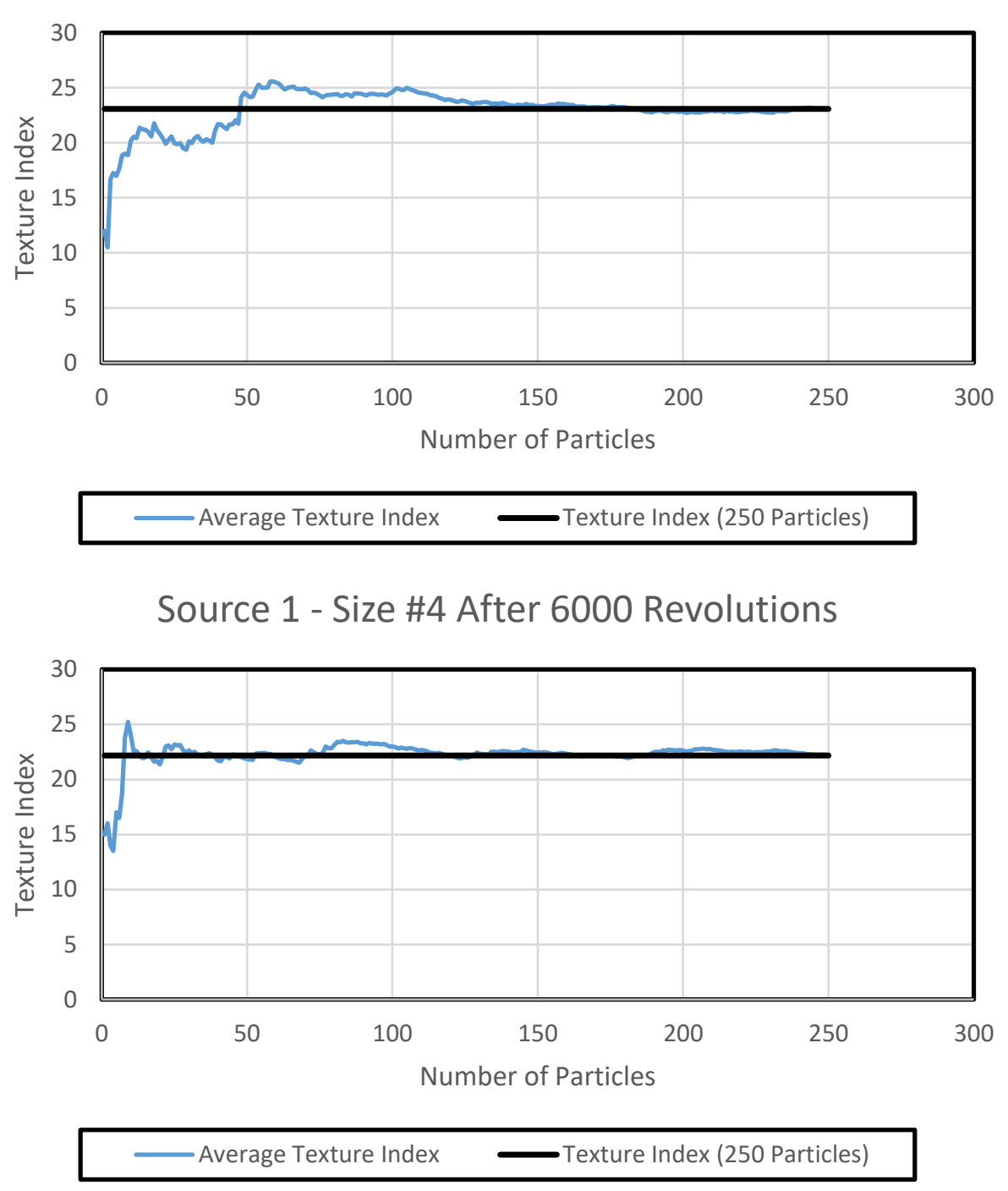
Source 1 - Size \#4 After 7500 Revolutions
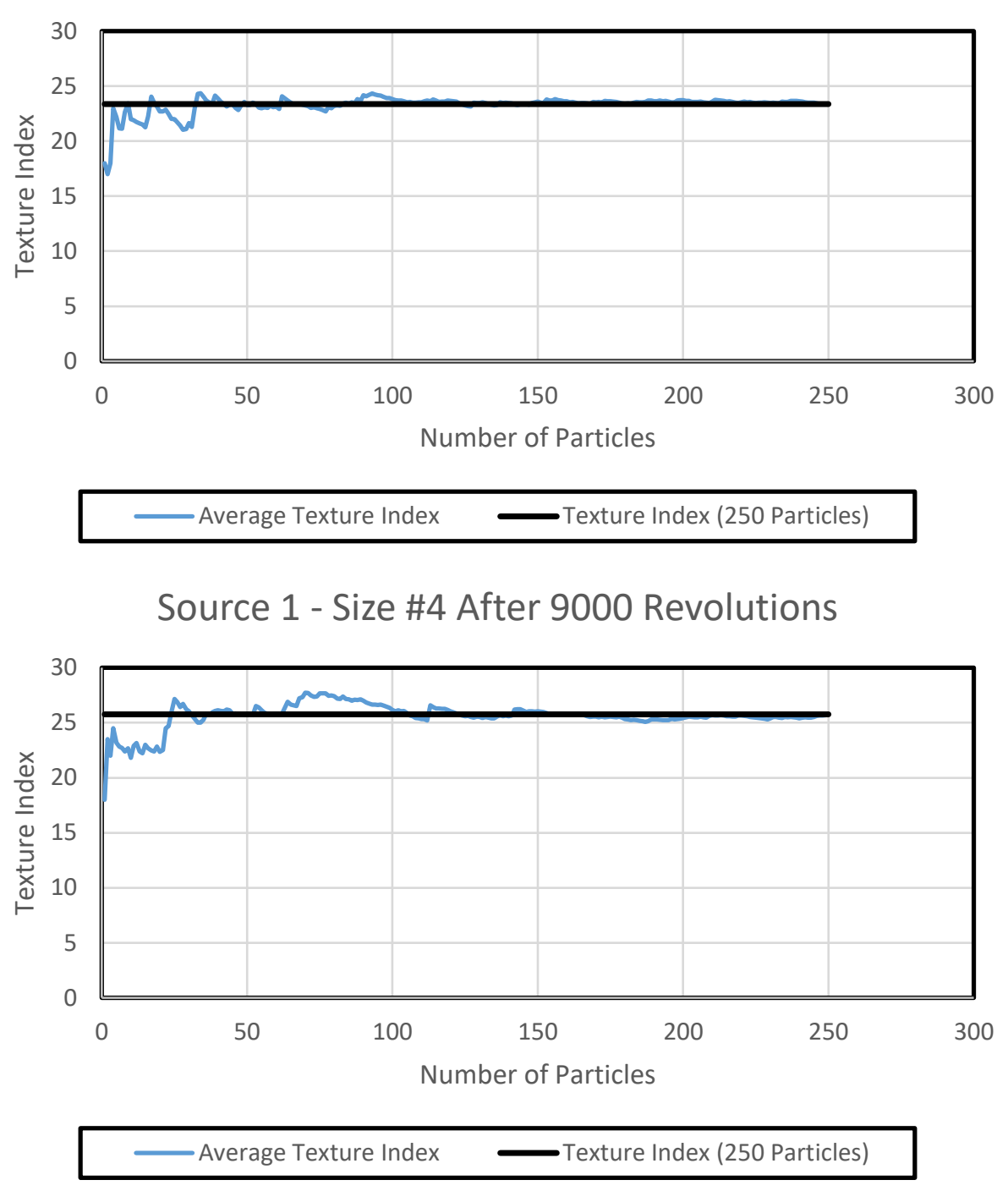
Source 1 - Size \#4 After 10500 Revolutions
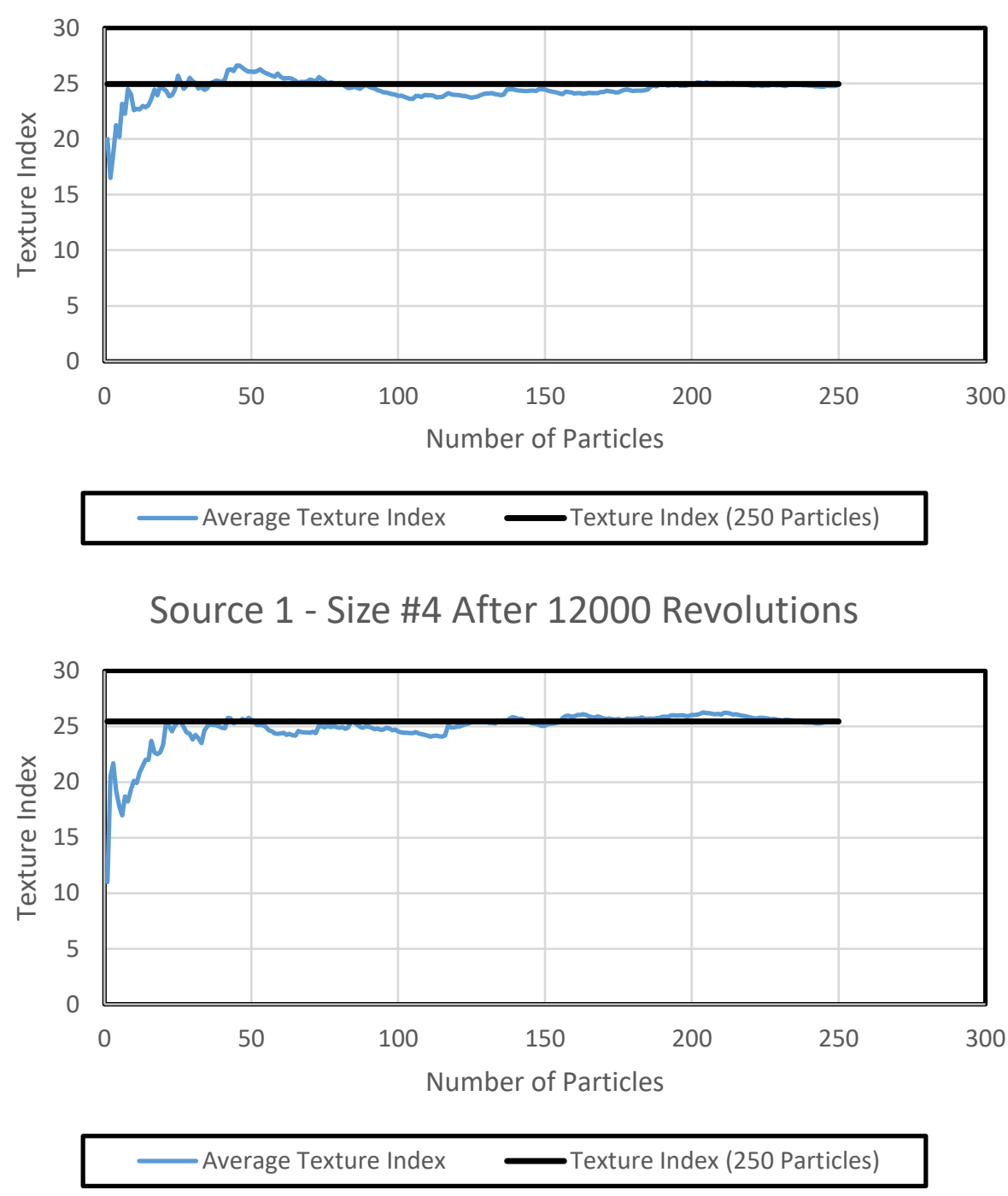
Source 1 - Size \#4 After 13500 Revolutions

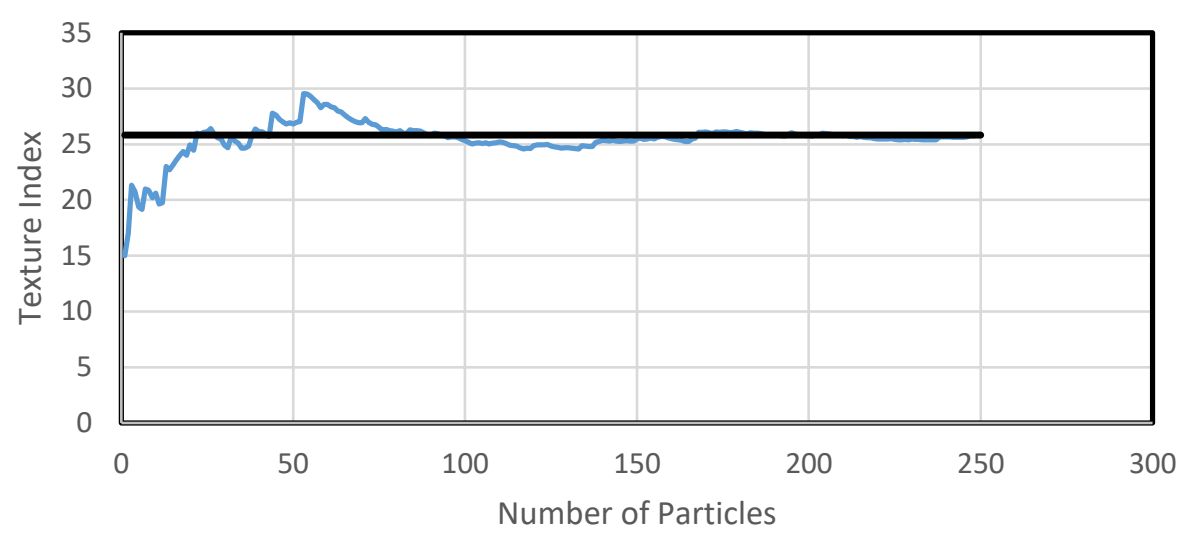

Average Texture Index $\quad$ Texture Index (250 Particles) 


\section{Source 1 - Size \#8 (Texture)}
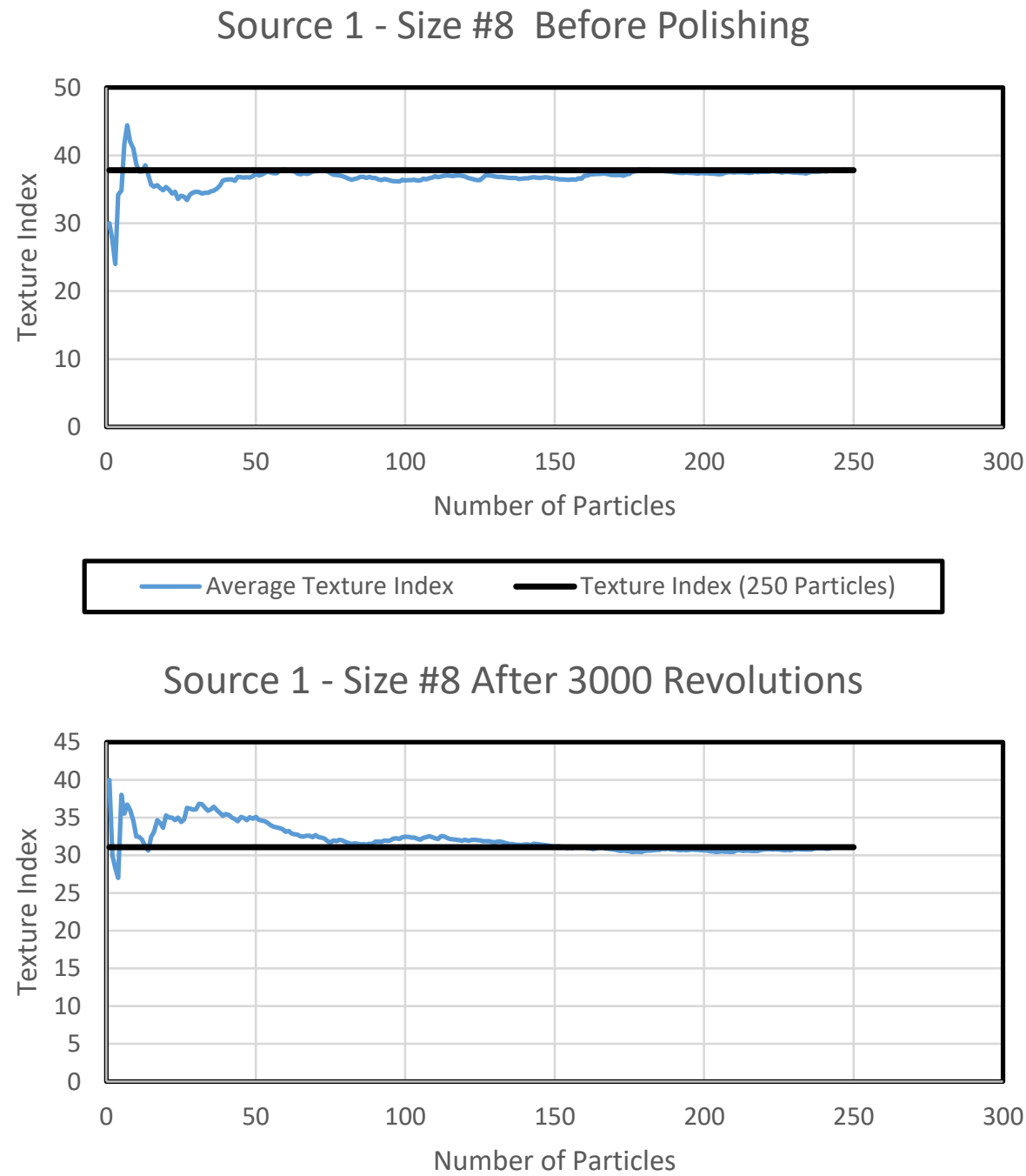

\begin{tabular}{l}
\hline Average Texture Index $\quad$ Texture Index (250 Particles) \\
\hline
\end{tabular}


Source 1 - Size \#8 After 4500 Revolutions

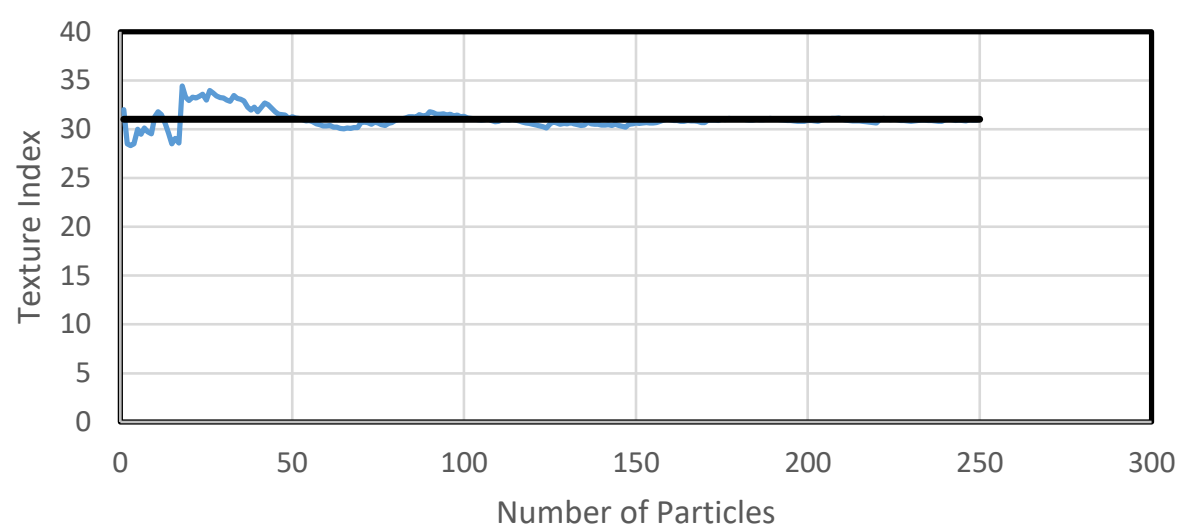

Average Texture Index $\quad \longrightarrow$ Texture Index (250 Particles)

Source 1 - Size \#8 After 6000 Revolutions

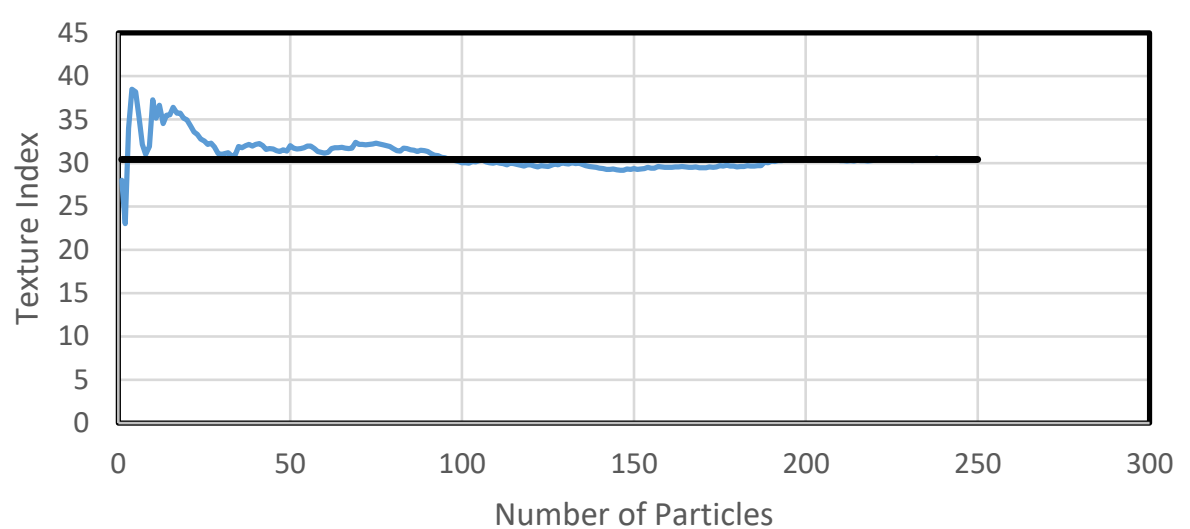

Average Texture Index

Texture Index (250 Particles) 
Source 1 - Size \#8 After 7500 Revolutions

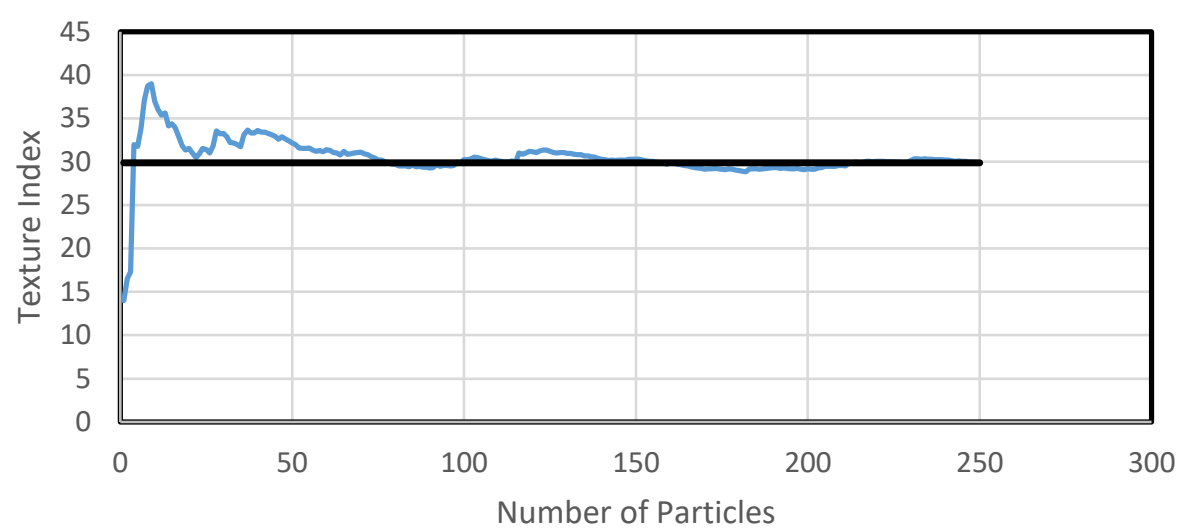

Average Texture Index $\quad$ Texture Index (250 Particles)

Source 1 - Size \#8 After 9000 Revolutions

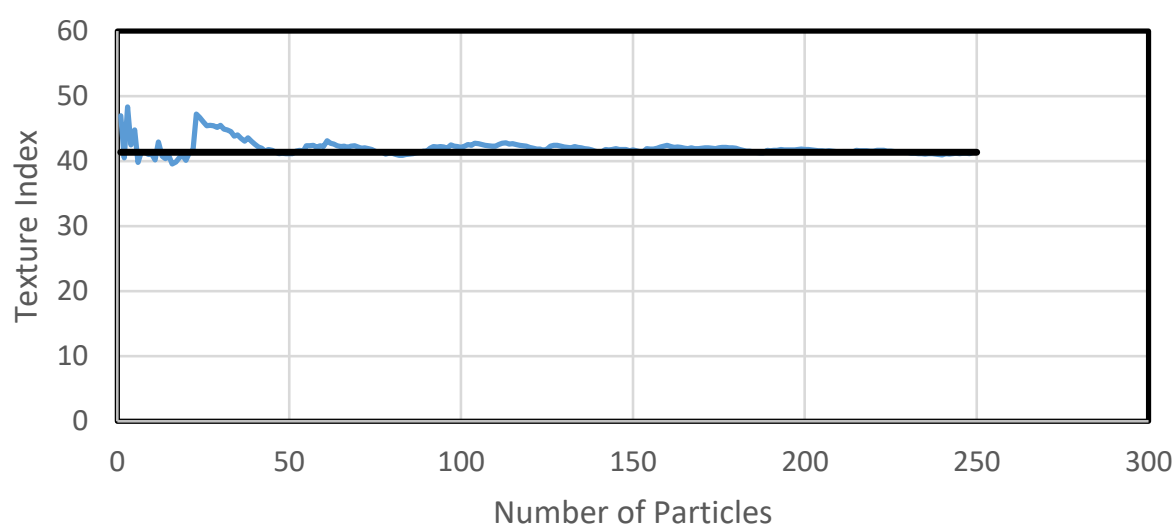

- Average Texture Index Texture Index (250 Particles) 
Source 1 - Size \#8 After 10500 Revolutions

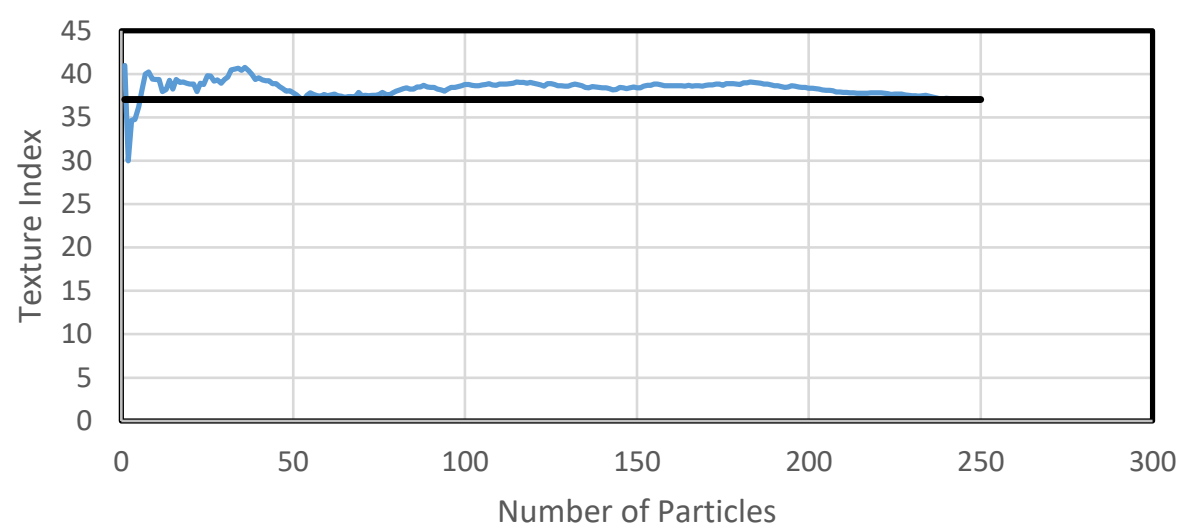

Average Texture Index $\quad$ Texture Index (250 Particles)

Source 1 - Size \#8 After 12000 Revolutions

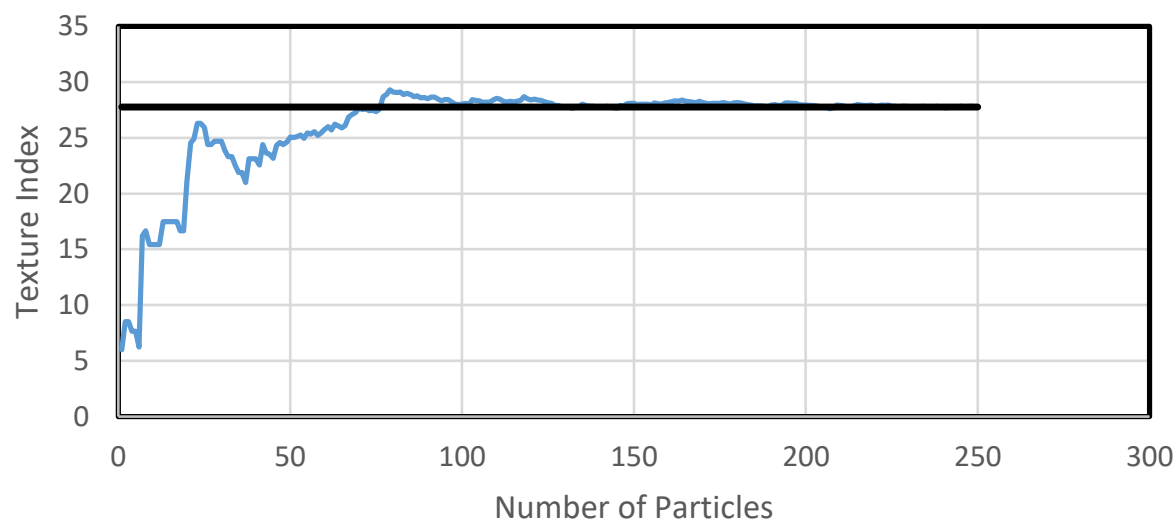

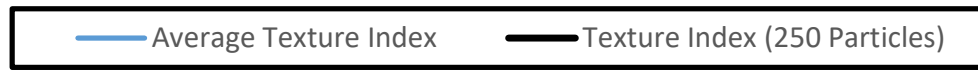


Source 1 - Size \#8 After 13500 Revolutions

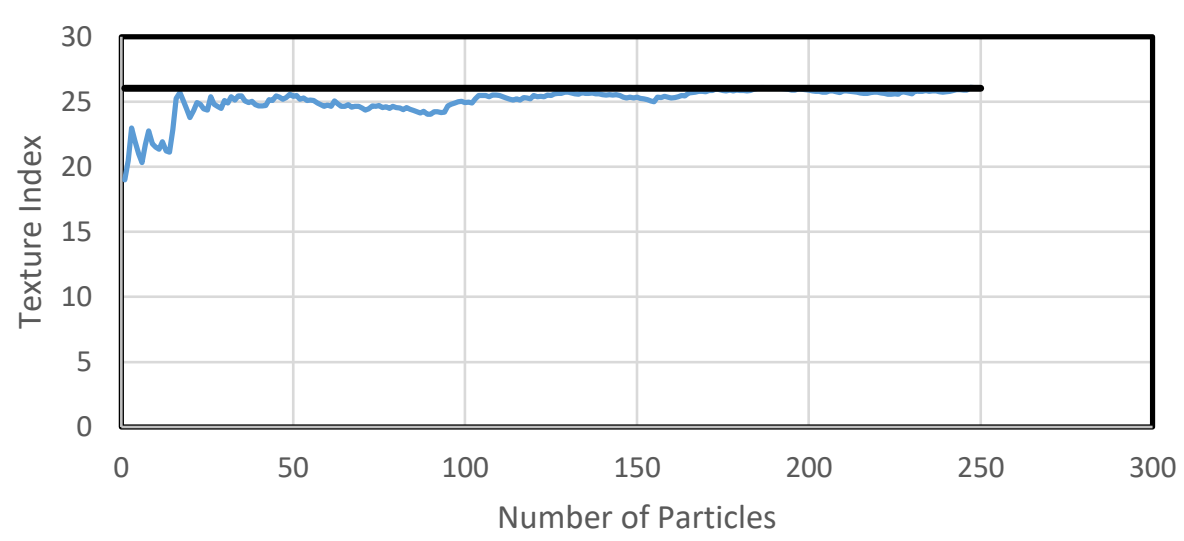

Average Texture Index $\quad$ Texture Index (250 Particles) 


\section{Source 2 - Size \#4 (Texture)}
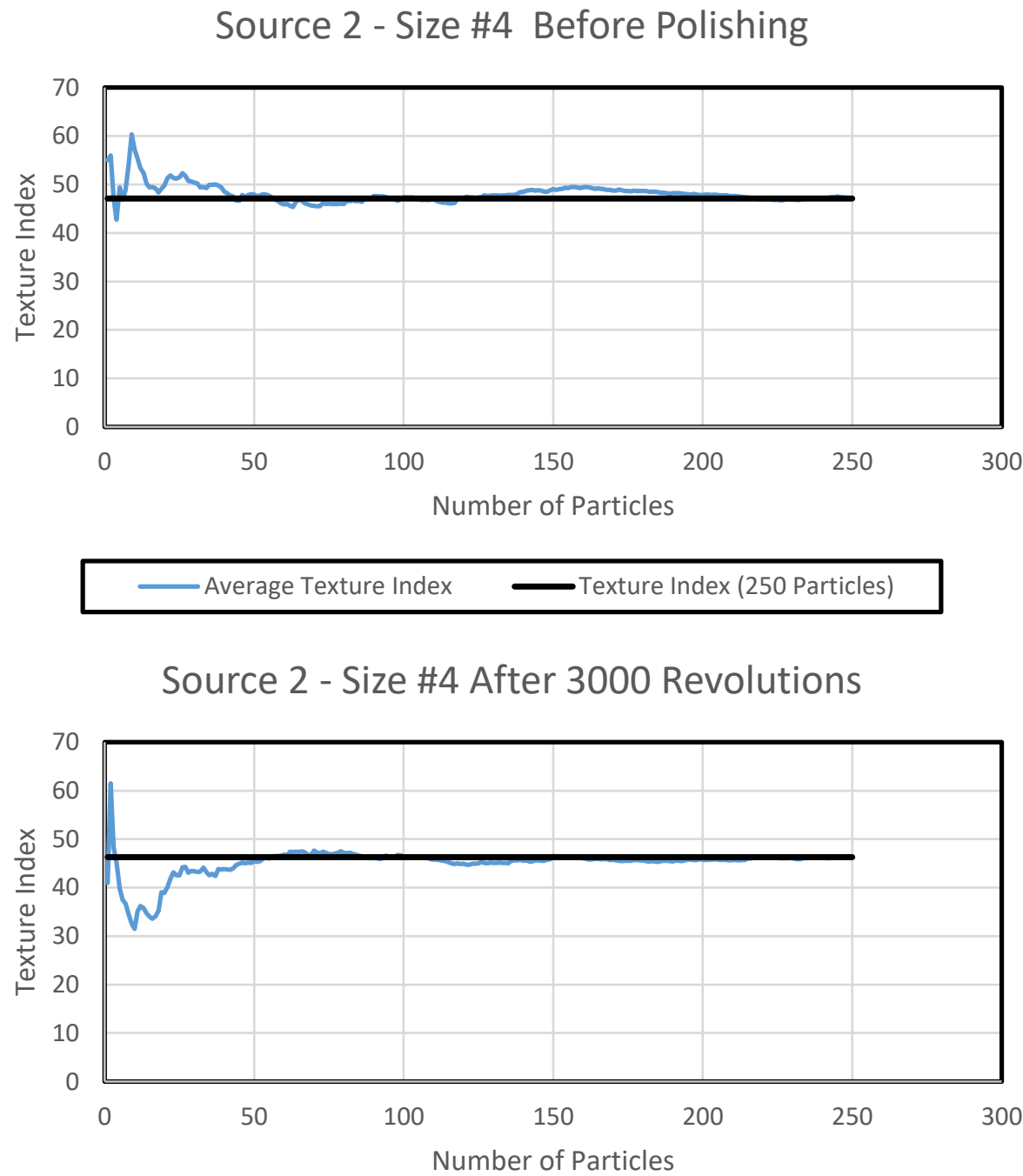

- Average Texture Index

Texture Index (250 Particles) 
Source 2 - Size \#4 After 4500 Revolutions

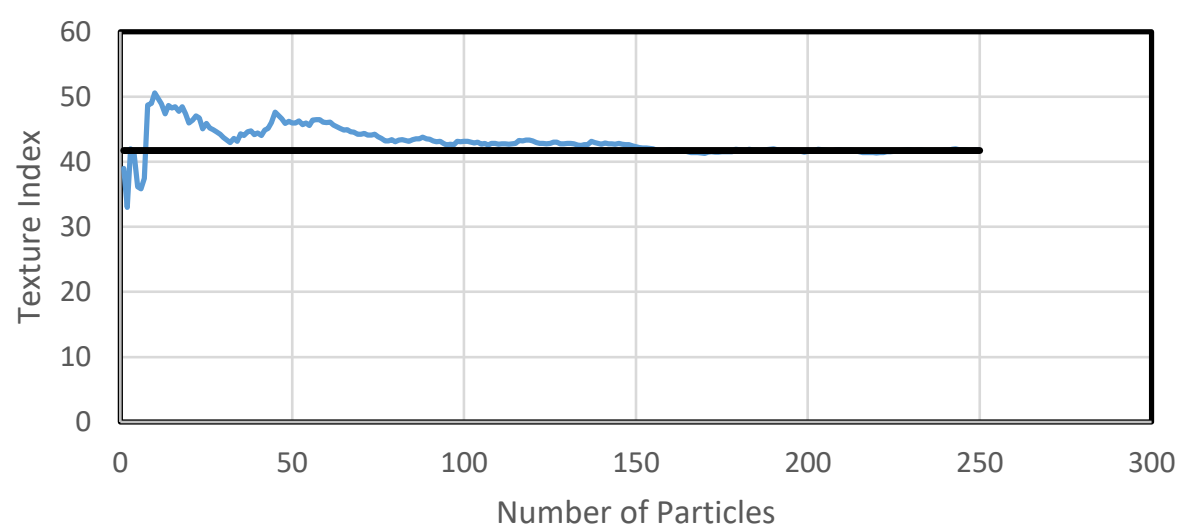

Average Texture Index $\quad$ Texture Index (250 Particles)

Source 2 - Size \#4 After 6000 Revolutions

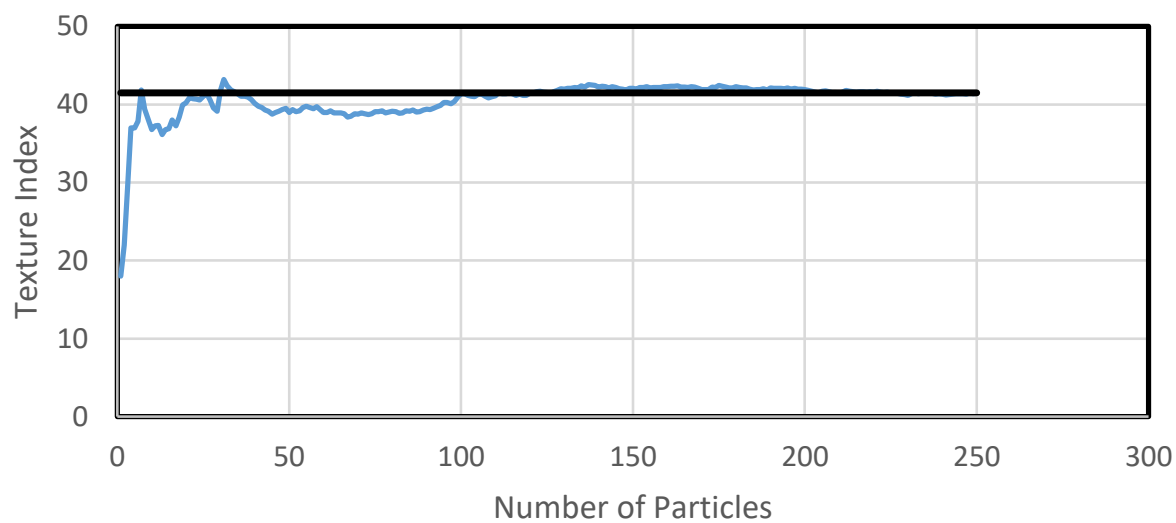

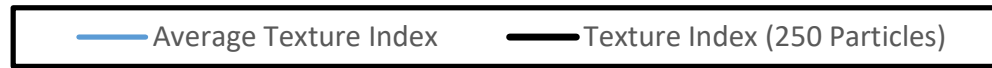


Source 2 - Size \#4 After 7500 Revolutions

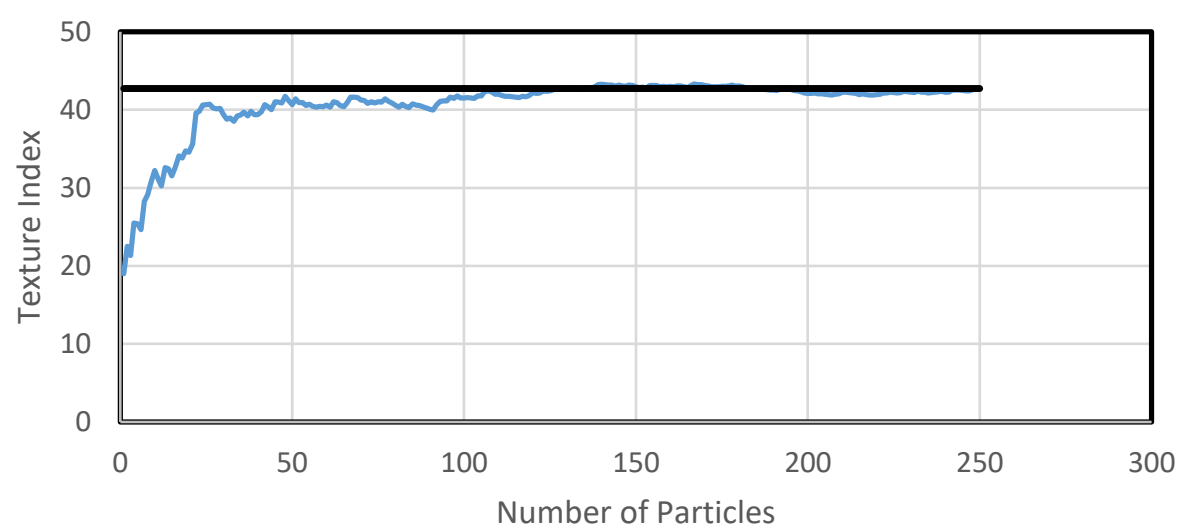

Average Texture Index $\quad \longrightarrow$ Texture Index (250 Particles)

Source 2 - Size \#4 After 9000 Revolutions

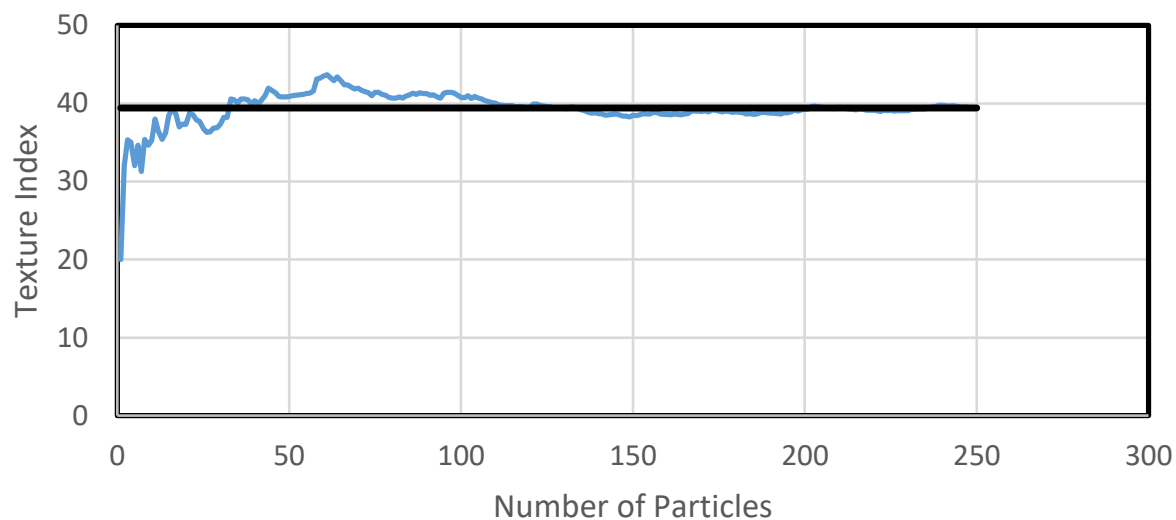

- Average Texture Index Texture Index (250 Particles) 
Source 2 - Size \#4 After 10500 Revolutions

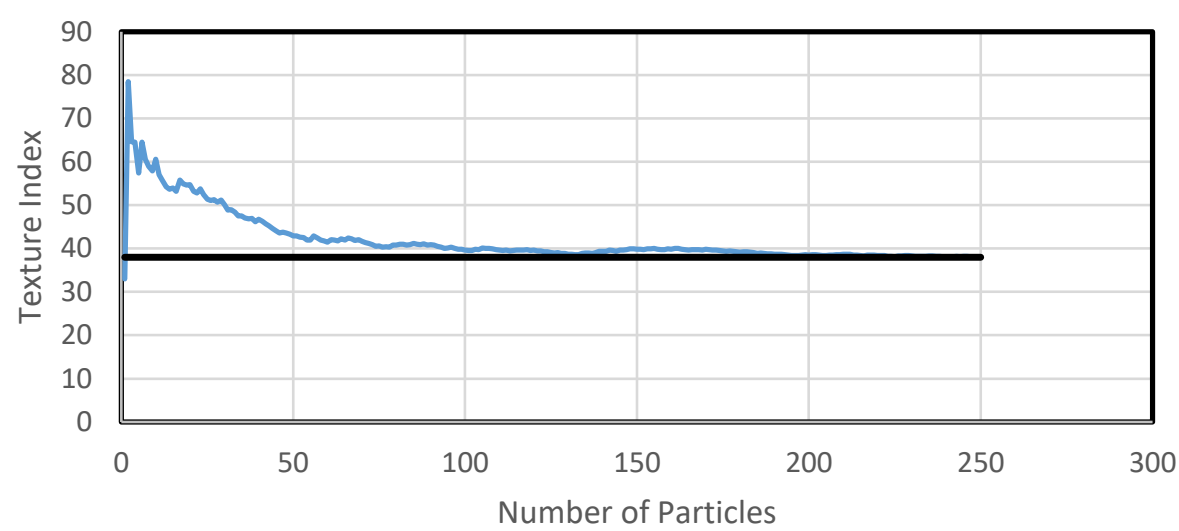

Average Texture Index $\quad$ Texture Index (250 Particles)

Source 2 - Size \#4 After 12000 Revolutions

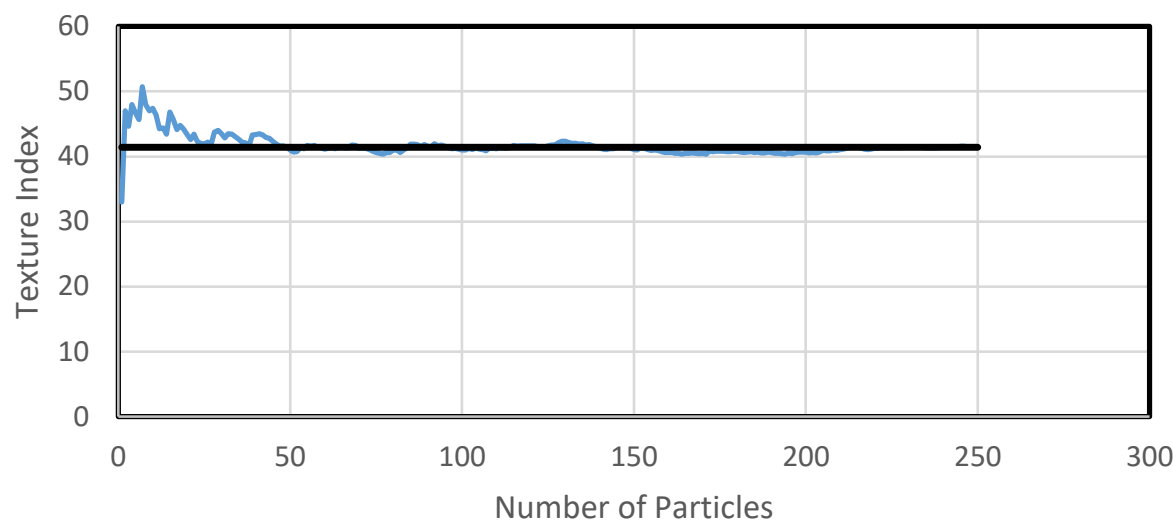

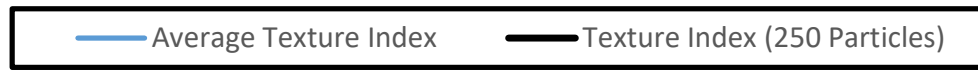


Source 2 - Size \#4 After 13500 Revolutions

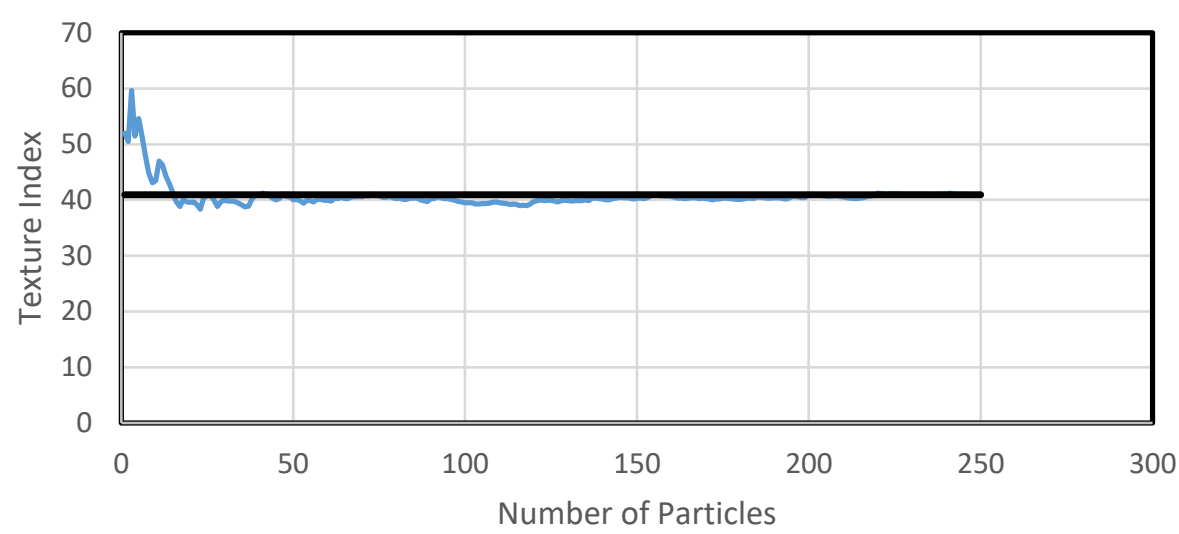

- Average Texture Index Texture Index (250 Particles) 


\section{Source 2 - Size \#8 (Texture)}

Source 2 - Size \#8 Before Polishing

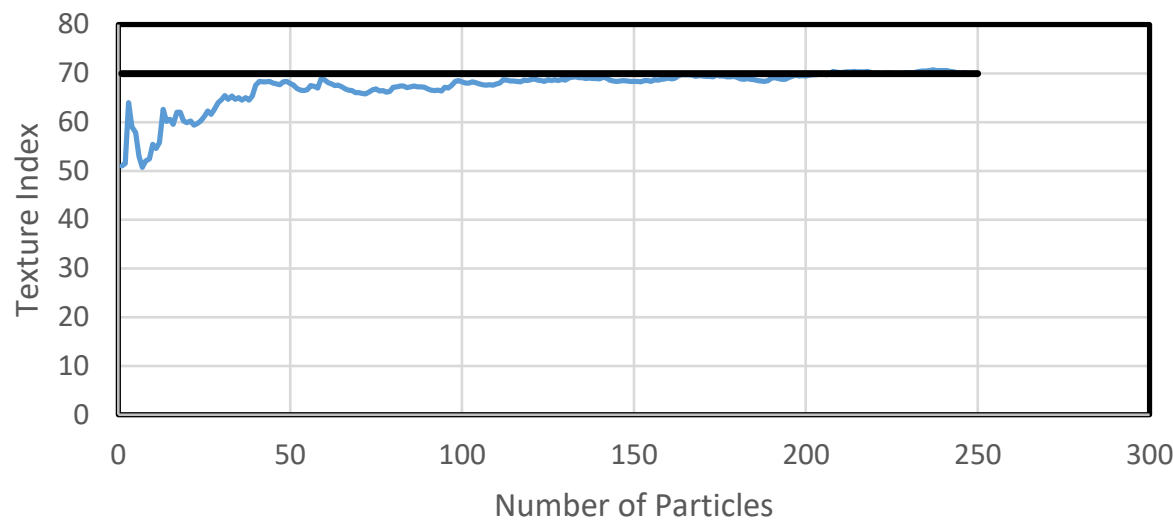

- Average Texture Index $\quad$ Texture Index (250 Particles)

Source 2 - Size \#8 After 3000 Revolutions

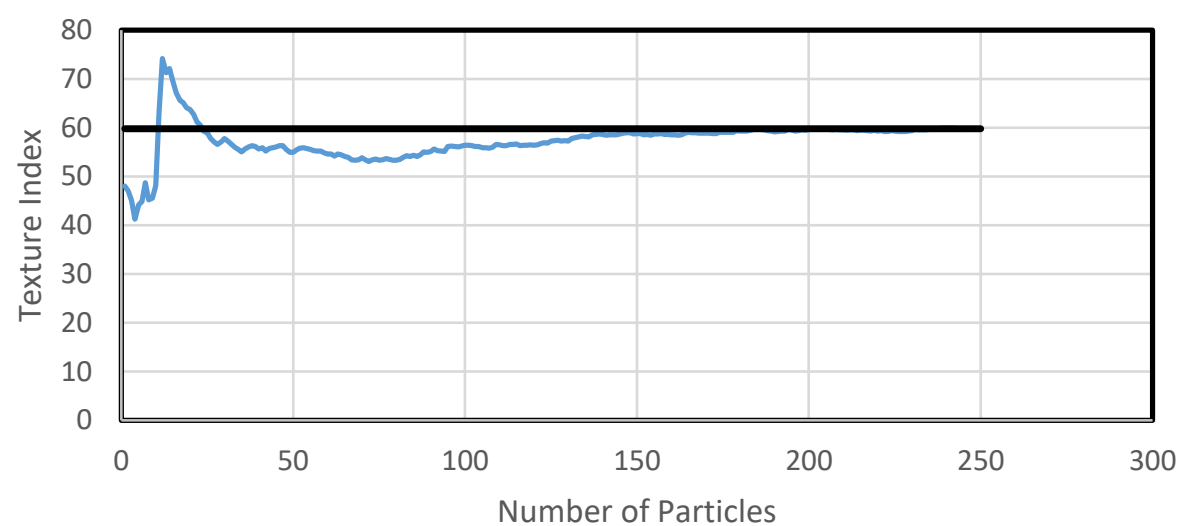

- Average Texture Index $\quad$ Texture Index (250 Particles) 
Source 2 - Size \#8 After 4500 Revolutions
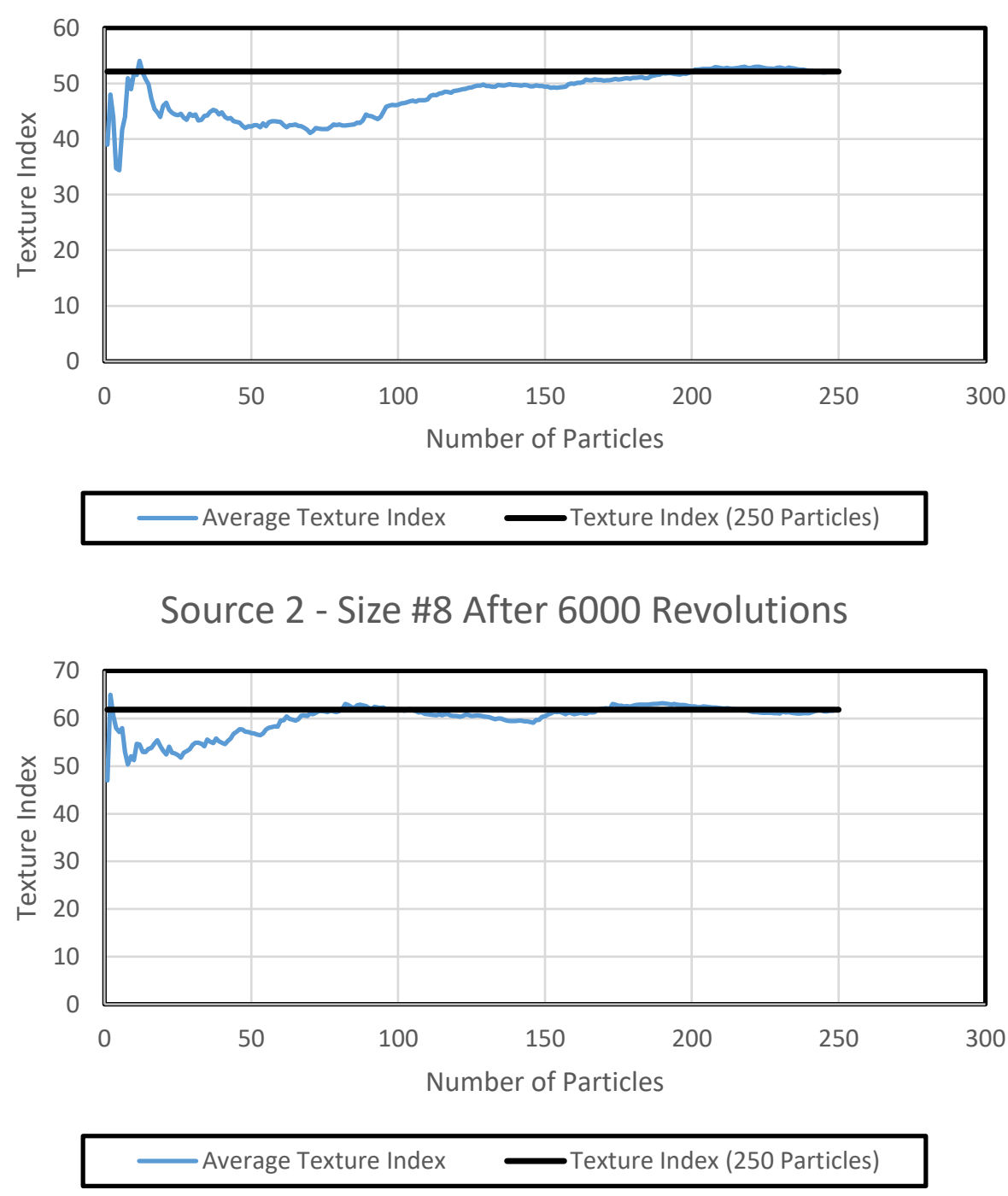
Source 2 - Size \#8 After 7500 Revolutions
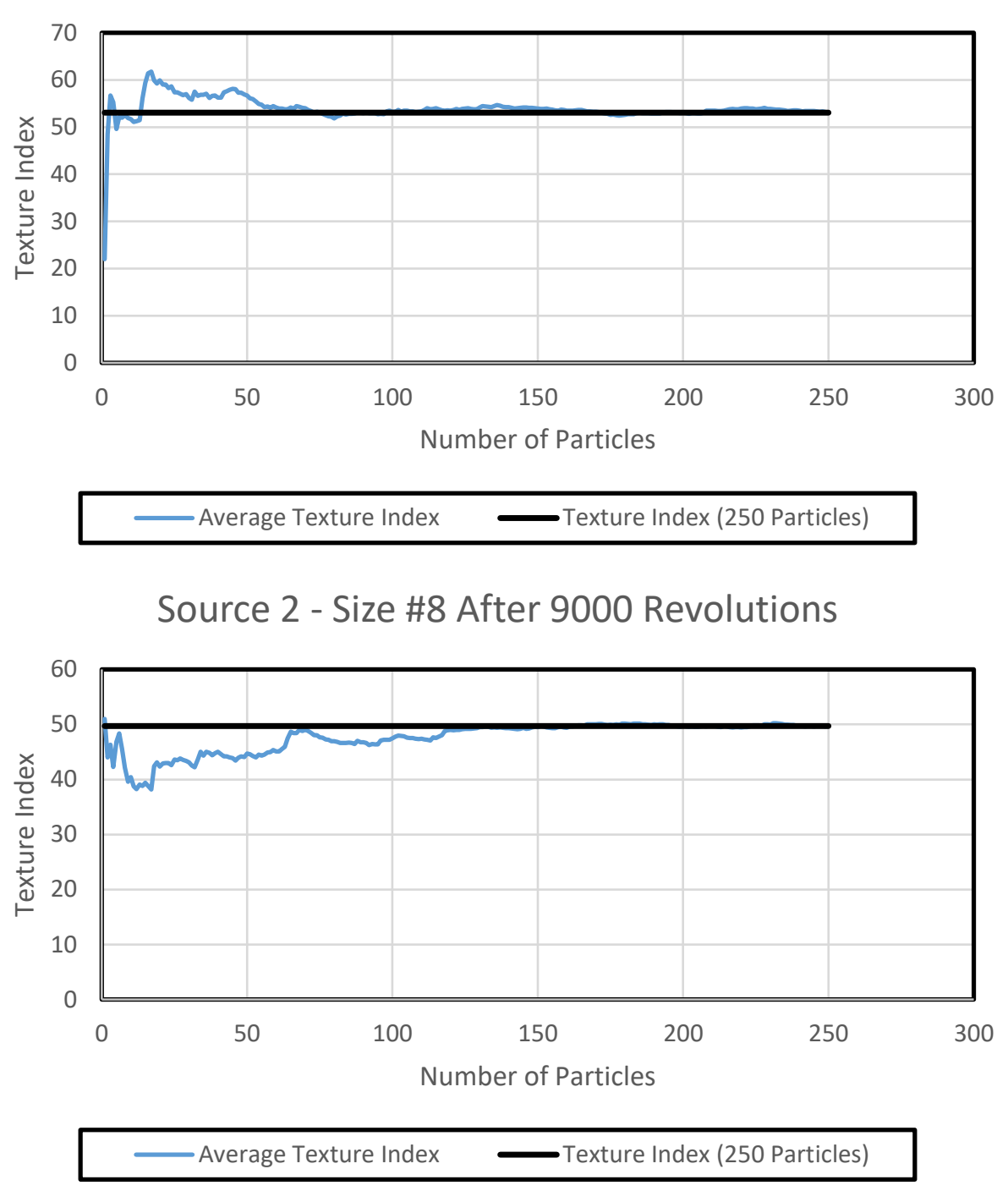
Source 2 - Size \#8 After 10500 Revolutions

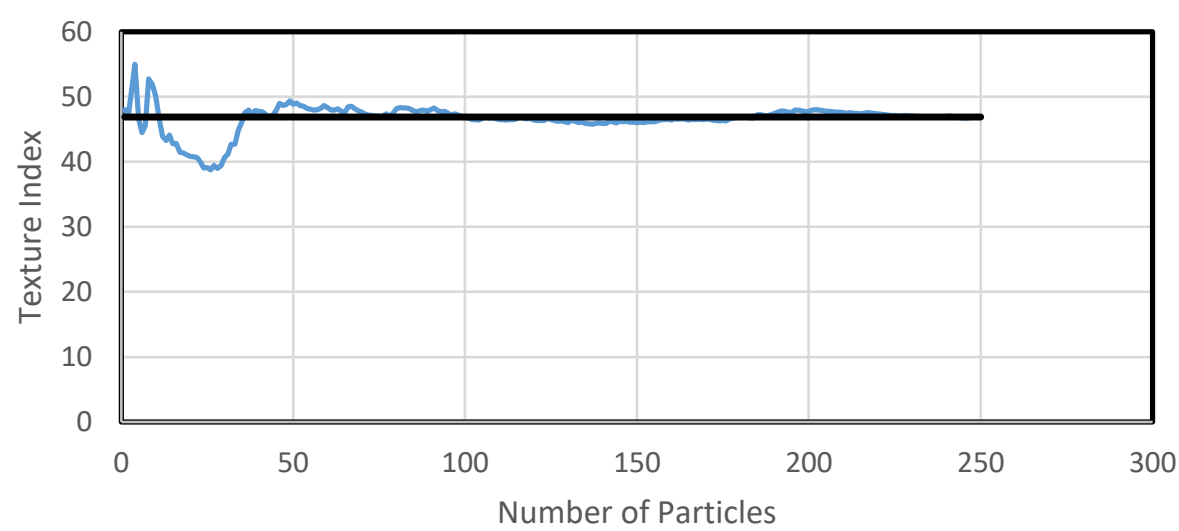

- Average Texture Index $\quad$ Texture Index (250 Particles)

Source 2 - Size \#8 After 12000 Revolutions

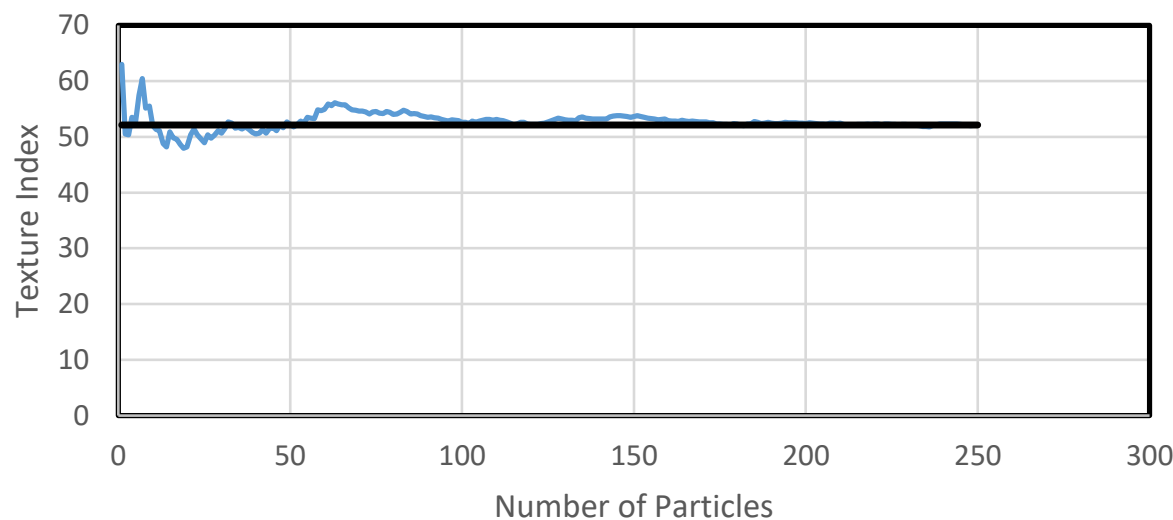

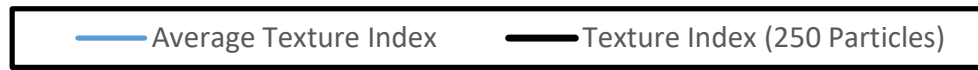


Source 2 - Size \#8 After 13500 Revolutions

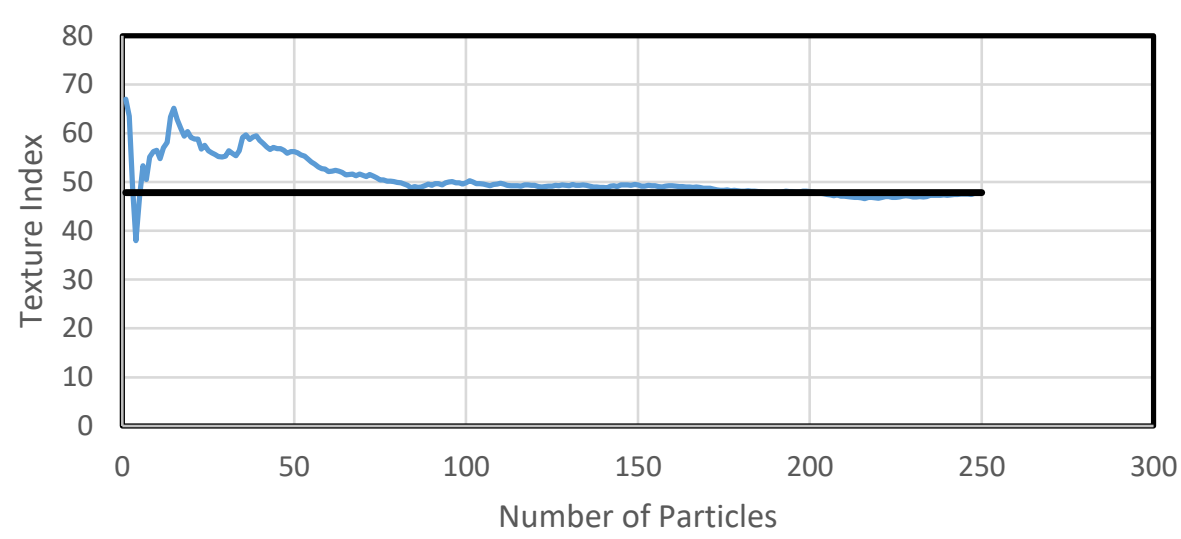

Average Texture Index $\quad$ Texture Index (250 Particles) 


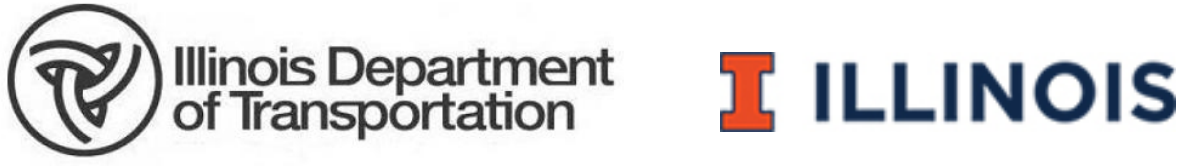

